
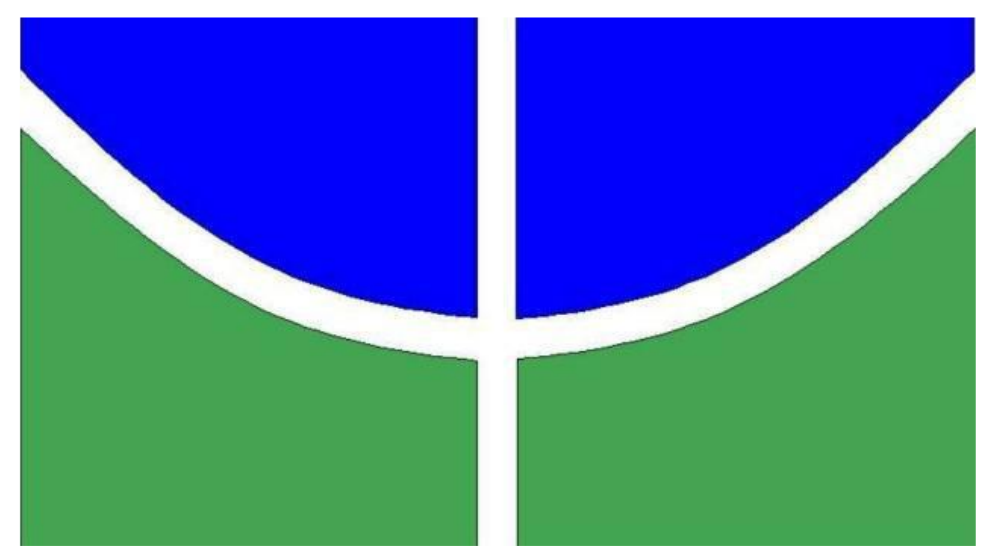

UNIVERSIDADE DE BRASÍLIA

INSTITUTO DE QUÍMICA

PROGRAMA DE PÓS GRADUAÇÃO EM QUÍMICA

Dissertação de Mestrado

\title{
MARCAÇÃO DE EXPLOSIVOS BASEADO EM FOTOLUMINESCÊNCIA PARA CODIFICAR E IDENTIFICAR RESÍDUOS DE PÓS-EXPLOSÃO
}

Filipe Gabriel Barbosa Mauricio

Orientador: Prof. Dra. Ingrid Távora Weber

Coorientador: Prof. Dr. Marcelo Rodrigues de Oliveira 


\section{UNIVERSIDADE DE BRASÍLIA}

INSTITUTO DE QUÍMICA

PROGRAMA DE PÓS GRADUAÇÃO

LABORATÓRIO DE QUIIMICA INORGÂNICA E MATERIAIS

\section{MARCAÇÃO DE EXPLOSIVOS BASEADO EM FOTOLUMINESCÊNCIA PARA CODIFICAR E IDENTIFICAR RESÍDUOS DE PÓS-EXPLOSÃO}

Dissertação apresentada ao Instituto de Química da Universidade de Brasília, como requerimento parcial à obtenção do título de Mestre em Química.

Filipe Gabriel Barbosa Mauricio

Orientador: Prof. Dra. Ingrid Távora Weber

Coorientador: Prof. Dr. Marcelo Rodrigues de Oliveira 
Dedico essa dissertação a todas as pessoas que acreditam no meu potencial e me apoiam em minhas batalhas. Meus pais, Leide e Carlos. Minhas Irmãs, Lydia e Laira. Minha companheira, Camilla Martinez. $E$ meus amigos. Estaremos sempre juntos e vocês sempre podem contar comigo. Vida longa e próspera. 


\section{AGRADECIMENTOS}

Agradeço primeiramente a minha família, Carlos, Leide, Lydia e Laira, que me apoiam em todas as minhas escolhas, sempre me amparando quando preciso. Destaco que amo todos vocês, mesmo não demonstrando o tempo todo.

A minha namorada e futura, Camilla Martinez, que está comigo desde o início deste trabalho me apoiando. Desejo mais que anos ao seu lado.

A todos os meus amigos inseparáveis Herbert, Bruno, Thaiane, Cris e Marcio, me dando alegrias que jamais imaginei e me oferecendo suporte para as conquistas.

A minha Orientadora Prof. Dra. Ingrid Távora Weber, por acreditar no meu trabalho e me acolher como seu aluno. Serão contribuições que levarei por toda a vida profissional e acadêmica.

Ao meu Coorientador Prof. Dr. Marcelo Oliveira, por dar suporte e apoio quando solicitado. Dedicado a ajudar e a ensinar seus alunos.

A toda a equipe do Lima por me direcionar nas escolhas acadêmicas e por compartilhar seus conhecimentos. Obrigado Marcos, Gabriel, Daniel, Kaline, Sarita, Marcella, Karine e Pamela.

Ao Marcio Talhavini e ao Adauto Zago por todo o auxílio e disponibilidade em ajudar a realização desse trabalho.

Ao INC e a Central Analítica - IQ pela disponibilidade dos equipamentos utilizados, que são de suma importância para a conclusão desta pesquisa.

A CAPES pelo financiamento dessa pesquisa e a bolsa e estudos disponibilizada.

E, por fim, a todos que contribuíram direta ou indiretamente para a conclusão deste trabalho. 


\section{RESUMO}

O roubo a caixas eletrônicos a bancos utilizando explosivos tem se tornado uma prática comum e as autoridades encontram dificuldades para rastrear os suspeitos. Até hoje não há formas efetivas para identificar a origem dos explosivos. Paralelamente, o ano de 2013 apresentou o maior índice de mortes de vítimas em ataques terroristas no mundo, obrigando as autoridades a investir em novas tecnologias de detecção e identificação de explosivos. Este trabalho descreve a avaliação da eficácia do uso de marcadores luminescentes para a codificação de explosivos e identificação de seus resíduos pós-explosão. A codificação visa fornecer às autoridades pertinentes informações relativas a origem do explosivo e a suspeitos de os terem utilizado. Os marcadores testados são materiais que contém íons Terra Raras (TR) que apresentam emissão no visível. Foram testados dois marcadores baseados em redes metalorgânicas de coordenação (MOFs) ([(La0.8Tb0.2 $\left.)_{2}(\mathrm{DPA})_{3}\left(\mathrm{H}_{2} \mathrm{O}\right)_{3}\right]$ e $\left.\left[\left(\mathrm{La}_{0.95} \mathrm{Eu}_{0.3} \mathrm{~Tb}_{0.2}\right)_{2}(\mathrm{DPA})_{3}\left(\mathrm{H}_{2} \mathrm{O}\right)_{3}\right]\right)$ e um terceiro cerâmico $\left(\mathrm{ZnAl}_{1,95} \mathrm{~Tb}_{0,05} \mathrm{O}_{4}\right)$. Os marcadores foram introduzidos em cargas explosivas de ANFO (nitrato de amônio - óleo combustível) em proporções de 1, 3 e $5 \%$ em massa e detonados com o objetivo de constatar, visualmente e por análises químicas, a presença dos marcadores em resíduos de pós explosão. Os marcadores $\quad\left[\left(\mathrm{La}_{0.8} \mathrm{~Tb}_{0.2}\right)_{2}(\mathrm{DPA})_{3}\left(\mathrm{H}_{2} \mathrm{O}\right)_{3}\right] \quad$ e $\quad\left[\left(\mathrm{La}_{0.95} \mathrm{Eu}_{0.3} \mathrm{~Tb}_{0.2}\right)_{2}(\mathrm{DPA})_{3}\left(\mathrm{H}_{2} \mathrm{O}\right)_{3}\right] \quad$ foram observados, tanto visualmente no lugar da detonação quanto nas análises químicas, se mostrando fortes candidatos a marcadores de resíduos de explosão. O marcador $\mathrm{ZnAl}_{1,95} \mathrm{~Tb}_{0,05} \mathrm{O}_{4}$ não apresentou luminescência visível após a detonação, apesar de ser detectado por análises laboratoriais. O método de marcação utilizando compostos baseados em MOF mostrou grande potencial para criação de uma tecnologia de codificação/identificação de resíduos de explosivo, entretanto, se faz necessário mais estudos relativos a sensibilidade dos explosivos contendo os marcadores propostos.

Palavras-chave: marcador, luminescência, explosivo, pós-explosão, MOF, cerâmicas; 


\section{ABSTRACT}

The criminal use of explosives has preoccupied the authorities due the difficulty in trace or identify possible suspects after of explosion. At the same time, 2013 had recorded the largest index of death involving terrorism, compelling the authorities to seek a technology to detect and identify the suspects. This work concern in an evaluation of the use of luminescent markers in the detection of explosive residues aiming to provide a new methodology able to label, encode explosives and help in suspect identification based on the luminescent properties inherent to the taggants. The markers are based on Rare Earth visible emission. Two markers based in Metal Organic-Frameworks (MOF) $\left(\left[\left(\mathrm{La}_{0.8} \mathrm{~Tb}_{0.2}\right)_{2}(\mathrm{DPA})_{3}\left(\mathrm{H}_{2} \mathrm{O}\right)_{3}\right] \mathrm{e}\right.$ $\left.\left[\left(\mathrm{La}_{0.95} \mathrm{Eu}_{0.3} \mathrm{~Tb}_{0.2}\right)_{2}(\mathrm{DPA})_{3}\left(\mathrm{H}_{2} \mathrm{O}\right)_{3}\right]\right)$ and a third one based on ceramic $\left(\mathrm{ZnAl}_{1,95} \mathrm{~Tb}_{0,05} \mathrm{O}_{4}\right)$ were tested. The markers were added to explosive charges of ANFO in 1, 3 and $5 \mathrm{wt} \%$ and detonated. Post-explosion residues were in situ visually observed, collected and chemically analyzed. The markers $\left[\left(\mathrm{La}_{0.8} \mathrm{~Tb}_{0.2}\right)_{2}(\mathrm{DPA})_{3}\left(\mathrm{H}_{2} \mathrm{O}\right)_{3}\right]$ and $\left[\left(\mathrm{La} a .95 \mathrm{Eu}_{0.3} \mathrm{~Tb}_{0.2}\right)_{2}(\mathrm{DPA})_{3}\left(\mathrm{H}_{2} \mathrm{O}\right)_{3}\right]$ was easily observed at the explosion range, as well as chemistry analysis proved their identity. Thus MOF based materials can be considered strong candidates to be used as explosive luminescent markers. The ceramic $\mathrm{ZnAl}_{1,95} \mathrm{~Tb}_{0,05} \mathrm{O}_{4}$ does not show visible luminescence to be observed at explosion range. Nevertheless, its identity was confirmed by chemical analysis. The method of tagging explosives based in luminescent MOFs shown great potential to a identifying explosive residues and opens the possibility to explosive encoding and tracing. Nevertheless, it is necessary to perform more detailed studies about explosive sensibility in presence of the propose markers

Keywords: markers, taggants, explosive, post blast, detection, trace, Metal Organic-frameworks, ceramics; 


\section{LISTA DE ABREVIACÕES}

AN - Nitrato de Amônio

ANFO - Nitrato de Amônio - óleo combustível

$A_{x}$ - Fator de Frequência

DMNB - 2,3-dimetil-2,3-dinitrobutano

DNT - Dinitrotolueno

DPF - Departamento de Polícia Federal

DRX - Difração de Raios-X

$E_{a}-$ Energia de Ativação

$E_{d}-$ Tempo de Indução

EDS - Espectroscopia por Dispersão de Energia

EGDN - Dinitrato de etilenoglicol

$E_{t}-$ Temperatura de Explosão

Eu - Európio

$\mathrm{Eu}_{2} \mathrm{O}_{3}$ - Óxido de Európio

EUA - Estados Unidos

$\mathrm{FBI}$ - Federal Bureau of Investigation

FTIR - Infravermelho por Transformada de Fourier

GSR - Gun Shoot Residues

GTD - Global Terrorism Database

$\mathrm{H}_{2} \mathrm{DPA}$ - 2,6-ácido piridinodicarboxílico

IMS - Ion Mobility Spectrometer

INC - Instituto Nacional de Criminalística

Ln - Lantanídeo

MEV - Microscopia Eletrônica de Varredura

MOF - Metal Organic-Framework

$\mathrm{R}$ - Constante Real dos Gases

TATP - Triperóxido de Triacetona

TLC - Thin-Layer Chromatography (Cromatografia Em Camada Delgada)

TR - Terra Rara

UV - Ultravioleta

VSC - Video Scanning Comparator (comparador vídeo espectral)

Zn - Zinco

$\eta$ - Eficiência Quântica 


\section{LISTA DE FIGURAS}

Figura 1. Exemplo de explosão a caixas eletrônicos 1

Figura 2. Número de mortes por ataques terroristas em função dos anos; 2

Figura 3. Principais armas utilizadas em ataques terroristas no período de 1970 e 2007;

Figura 4. Reação de decomposição do trinitrobenzeno após um estímulo (onda de choque, atrito, calor, etc). Quando as ligações entre os átomos dos grupos nitro são quebradas, uma grande quantidade de energia é liberada causando uma explosão;

Figura 5. Exemplos de detonadores elétricos comumente utilizados comercialmente;

Figura 6. Classificação dos explosivos segundo o principal uso comercial;

Figura 7. Aparelho para determinação da Temperatura de Explosão (Et) e Tempo de Indução (Ed);

Figura 8. Aparelho do tipo Fallhammer para determinação de sensibilidade a impacto; 13

Figura 9. Aparelho para determinação da sensibilidade a fricção de acordo com o método de Julius Peters; 14

Figura 10. Fórmulas estruturais do a) DMNB e do b) EGDN; 16

Figura 11. Desenho esquemático simplificado do tubo de deslocamento em um IMS;.

Figura 12. Quenching das bandas do espectro de fluorescência devido a ligação do polímero a uma marcador de explosivos;

Figura 13. Análises utilizadas para identificação de resíduos de explosão, dependendo de sua composição química. Legenda: $\mathrm{MEV} \mathrm{=} \mathrm{microscópio} \mathrm{eletrônico}$ de varredura; $E D S=$ espectroscopia por dispesão de energia; $\mathrm{FTIR}=$ Infravermelho por transformada de Fourrier; TEA = Thermal enrgy analyzer; GC = cromatografia gasosa; $\mathrm{LC}=$ cromatografia líquida; $\mathrm{HPLC}=$ Cromatografia liquida de alta performance; Cromatografia de íons; MS = espectrometria de massas; ...19 Figura 14. Exemplo de determinação de resíduo de explosão por cromatografia em camada delgada (imagem ilustrativa); .20

Figura 15. Diagrama de energias para um delocamento Stokes; .22 
Figura 16. Diagrama esquemático de um exemplo de efeito antena. Nesse caso, $S$ representa os estados singlete enquanto $T$ representa o estado triplete; .........25 Figura 17. Desenho esquemático de formação das MOFs; ...............................27

Figura 18. Esquema de reator para sínteses hidrotermais; ................................28

Figura 19. a) Imagem dos marcadores luminescentes sob luz UV; b) Arma após o disparo de munição contendo o marcador; c) resíduos de marcadores na mão do efetuador do disparo;

Figura 20. Diminuição de luminescência (quenching) do marcador [Zn 2 (bpdc) 2 (bpee)] em contato com a) DNT (Dinitrotolueno) e b) DMNB (2,3dimetil-2,3-dinitrobutano) e seus respectivos espectros de fluorescôncia antes e depois;

Figura 21. Perda de luminescência em função do tipo de explosivo em contato com um dos sensores químicos baseados em MOF propostos por Gole et al.; ...33 Figura 22. Gráfico de magnetização em função da temperatura de uma amostra de marcador contento pelo menos quatro ferritas ( $\mathrm{Tc}=$ Temperatura de Curie); .36 Figura 23. Disposição das cargas explosivas utilizadas nos ensaios; .40

Figura 24. Disposição das cargas explosivas nos gabinetes; 41

Figura 25. Exemplos de Stubs utilizados na coleta dos resíduos de explosão; ....41 Figura 26. Coleta de resíduos de explosão com o auxílio de Stubs e lâmpadas UV (254 nm); 42

Figura 27. Fotos obtidas por VSC dos marcadores puros A, B e C, respectivamente os itens a), b) e c), sob luz visível e sob luz UV (254nm): itens d), e) ef);

Figura 28. Espectros de IV dos marcadores A e B puros em comparação com o espectro do $\mathrm{H}_{2}$ DPA, e seus respectivos estiramentos; 44

Figura 29. Espectros de IV da amostra $C$ e seus respectivos estiramentos; 45 Figura 30. Difratograma dos marcadores baseados em MOFs e I) Contração (esquerda) e expansão (direita) do campo cristalino como resultado da substituição de dopantes de tamanho diferentes na matriz; .46

Figura 31. Difratograma da amostra C; .46

Figura 32. Micrografias referentes ao: a) marcador $A, b)$ marcador $B$ e c) ao marcador C;

Figura 33. Espectros de EDS das amostras dos marcadores a) A b) B e c) C; ....48 
Figura 34. Espectros de emissão dos marcadores A (azul) e C (verde); e o diagrama de energias do íon Tb3+ indicando a transição mais intensa;

Figura 35. Espectro de emissão do marcador B e suas respectivas transições; em verde, as transições ao íon $\mathrm{Tb}^{3+}$; em vermelho, as transições referentes ao íon $\mathrm{Eu}^{3+}$

Figura 36. Comparação entre os espectros de emissão dos marcadores A e C utilizando o espectrofluorímetro de modelo K2 e o microespectrômetro do VSC; 50 Figura 37. Espectros de fluorescência do marcador B aferido por VSC (azul) e por Espectrômetro de Fluorescência (vermelho), destacando a ausência da transição ${ }^{5} \mathrm{D}_{0} \rightarrow{ }^{7} \mathrm{~F}_{4}$;

Figura 38. a) gabinete de computador antes da detonação b) Gabinete após a detonação; c) em destaque, resíduo de explosivo encontrando na parede próxima ao local de detonação; d) Gabinete após a detonação e) resíduos de explosivos encontrados no interior da carcaça após a detonação e f) resíduo de explosão e sentido da onda de impacto proveniente do explosivo; .52

Figura 39. Imagens dos gabinetes após as detonações dos a) resíduos de pós explosão na parte interna superior da carcaça sob luz visível; b) resíduos de explosão das cargas A5 sob luz UV na parte interna lateral e c) resíduos de explosão das cargas B5 sob luz UV; 53

Figura 40. Gabinete contendo resíduos do marcador C5 sob luz UV; .54 Figura 41.Amostras de resíduo de explosão fotografadas por VSC referentes aos marcadores a) A1, b) A3 e c) A5; e os marcadores d) B1, e) B3 e f) B5; .54 Figura 42. Amostras de resíduos de explosão analisadas por VSC sob luz UV (254 nm) das cargas a) C1, b) C3 e c) C5; .55 Figura 43. Espectros de EDS e suas respectivas razões de massas dos elementos constituintes dos marcadores: A1, A3, A5 ( $a, b$ e c), B1, B3, B5 (e, f e g), C1, C3 e C5 (g, h e i);

Figura 44. Espectros de fluorescência dos resíduos de explosão contendo os marcadores a) A e b) B; .58

Figura 45. Espectro de fluorescência dos resíduos de explosivos contendo o marcador C; 59

Figura 46. Espectros de Fluorescência obtidos por VSC das amostras A (a) e B (b); .59 
Figura 47. Exemplo de video spectral comparator (VSC6000/HS da

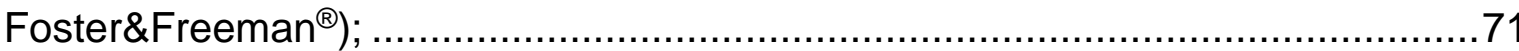




\section{LISTA DE TABELAS}

Tabela 1. Reações de decomposição do Explosivo ANFO em diferentes proporções relacionadas a suas respectivas energias liberadas; 10

Tabela 2. Valores de $R_{f}$ obtidos por TLC de resíduos de explosão frente a diferentes tipos de eluente; .20

Tabela 3. Principais elementos Terras raras e suas configurações eletrônicas; $\ldots 23$ Tabela 4. Exemplos de códigos para tipos de explosivos possíveis para os marcadores luminescentes proposto por Ryan et al.; .35

Tabela 5. Exemplos de códigos para tipos de explosivos para os marcadores luminescentes propostos por Ryan et al; .35

Tabela 6. Relação de massas utilizadas na síntese dos marcadores baseados em MOFs;

Tabela 7. Codificação dos marcadores luminescentes e suas respectivas proporções; 39

Tabela 8. Relação entre os resíduos de explosão e sua visualização a olho nu sob luz UV; .53

Tabela 9. Variação de proporção nominal entre os valores teóricos e os valores encontrados por EDS das amostras de resíduos de explosão, e seus respectivos desvio padrão; 


\section{SUMÁRIO}

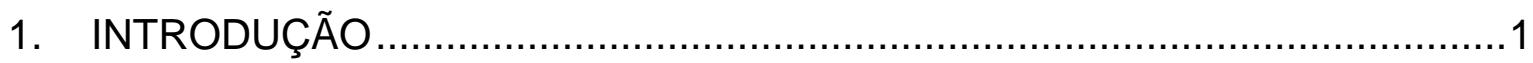

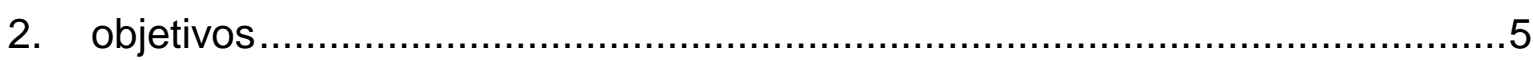

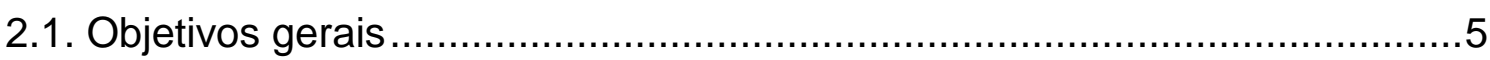

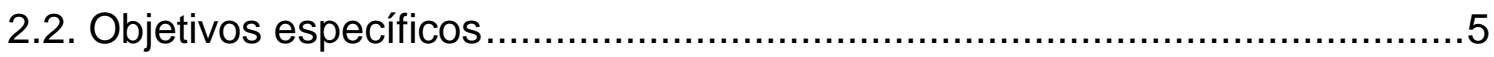

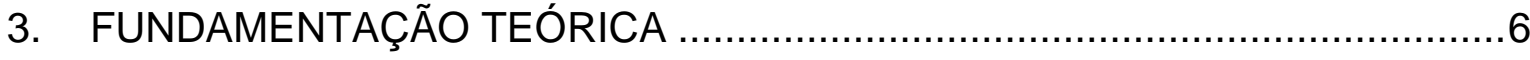

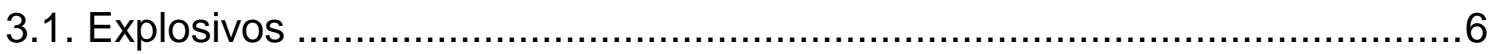

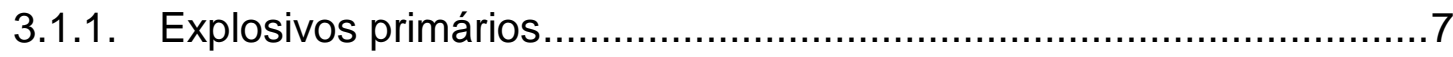

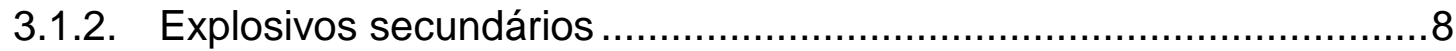

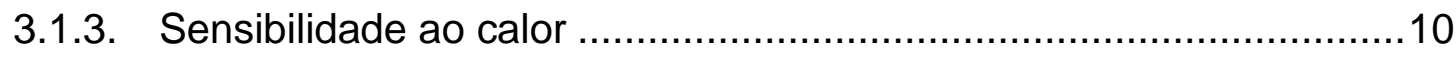

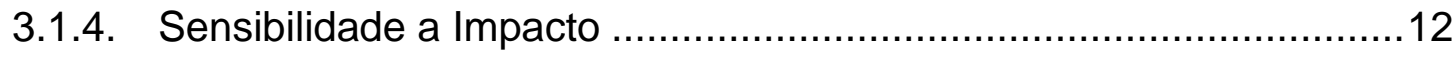

3.1.5. Sensibilidade a friç̧ão..................................................... 13

3.1.6. Cenários de Pré e Pós-explosão .............................................14

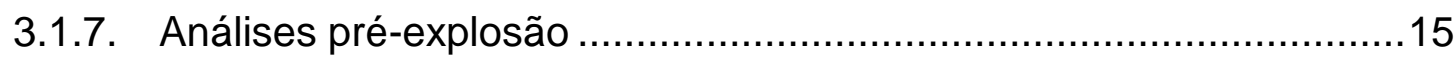

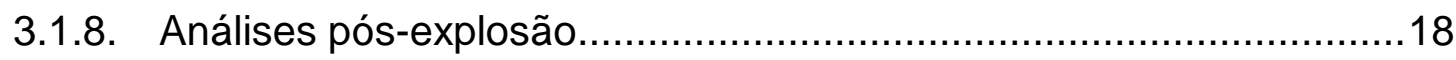

3.2. Luminescência e Processos de excitação/emissão ............................21

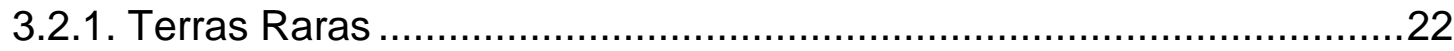

3.2.2. Cerâmicas e MOFs: candidatos a marcadores luminescentes ...........26

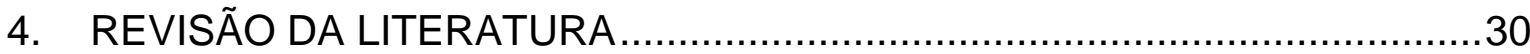

4.1. Marcadores Luminescentes para Munições ..................................30

4.2. Marcadores Luminescentes para Explosivos .............................32

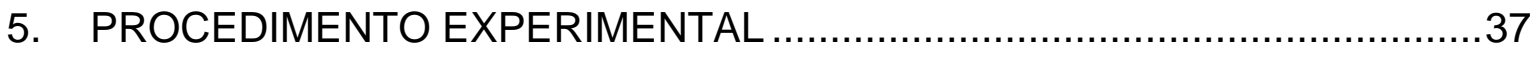

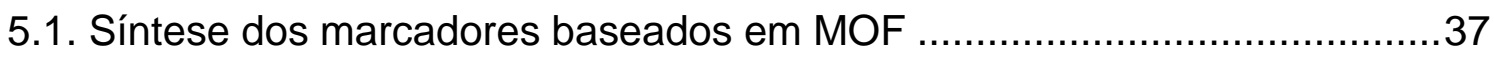

5.2. Síntese do marcador baseado em cerâmica ...................................38

5.3. Incorporação dos marcadores aos explosivos e coleta dos dados..............39

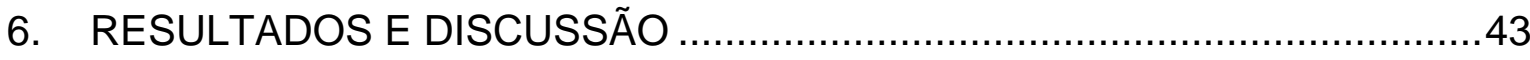

6.1. Caracterização dos marcadores luminescentes .................................43 


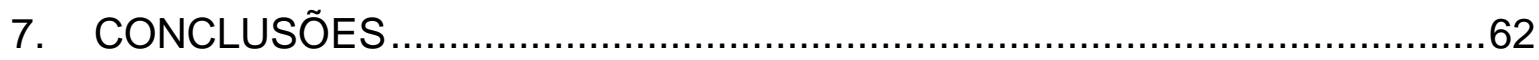

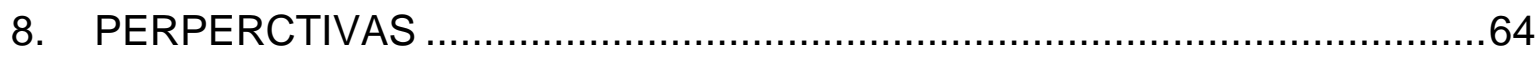

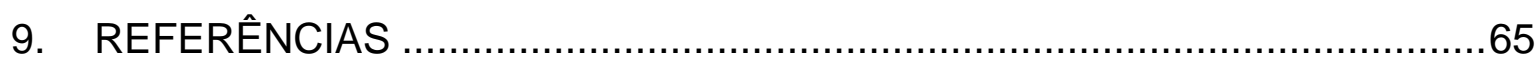

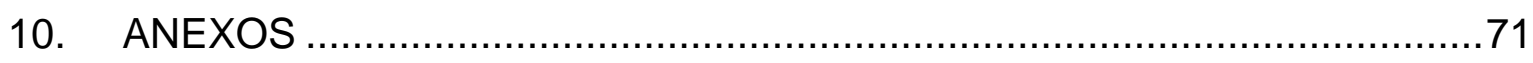

10.1. Equipamentos utilizados na caracterização dos marcadores luminescentes e dos resíduos de explosão ............................................ 71

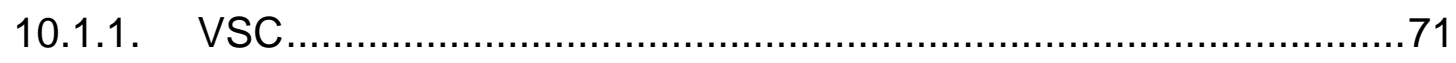

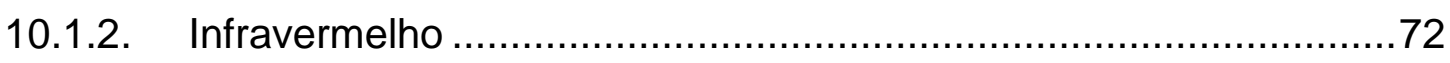

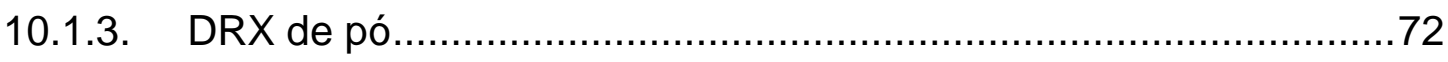

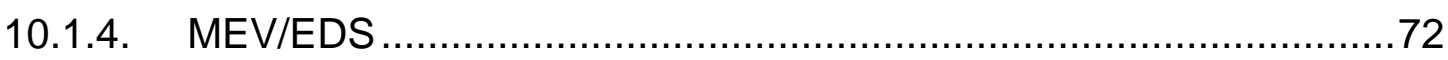

10.1.5. Espectros de Fluorescência ............................................. 72 


\section{INTRODUCÃO}

Nos últimos anos, o uso de explosivos em assaltos a caixas eletrônicos têm aumentado vertiginosamente. Em levantamento estatístico realizado pelo exército brasileiro, apenas no ano de 2010 cerca de 1 tonelada de nitrato de amônio $\left(\mathrm{NH}_{4} \mathrm{NO}_{3}\right)$ e dinamite foram furtadas ou roubadas de pedreiras e obras em sete estados brasileiros, e possivelmente empregados em roubos a caixas eletrônicos em todo o país. ${ }^{1} \mathrm{O}$ número de casos registrados de roubo e furto a explosivos, exclusivamente no estado de São Paulo, sofreu um aumento de $63 \%$ entre os anos de 2012 e 2013. ${ }^{2}$

De acordo com a Confederação Nacional dos Trabalhadores do Ramo Financeiro (Contraf-CUT), entre os anos de 2011 e 2013, houve um aumento de $77 \%$ no número de ataques a bancos e caixas eletrônicos em todo o país. ${ }^{3} \mathrm{~A}$ investigação dos casos envolvendo explosões não é trivial. Os responsáveis pelas investigações encontram dificuldades em estabelecer conexões que auxiliem na elucidação dos casos. Portanto, rastrear a origem dos explosivos, bem como o percurso percorrido até seu uso em assaltos, ou ainda estabelecer correlações entre suspeitos e os explosivos pode ser de grande valia.

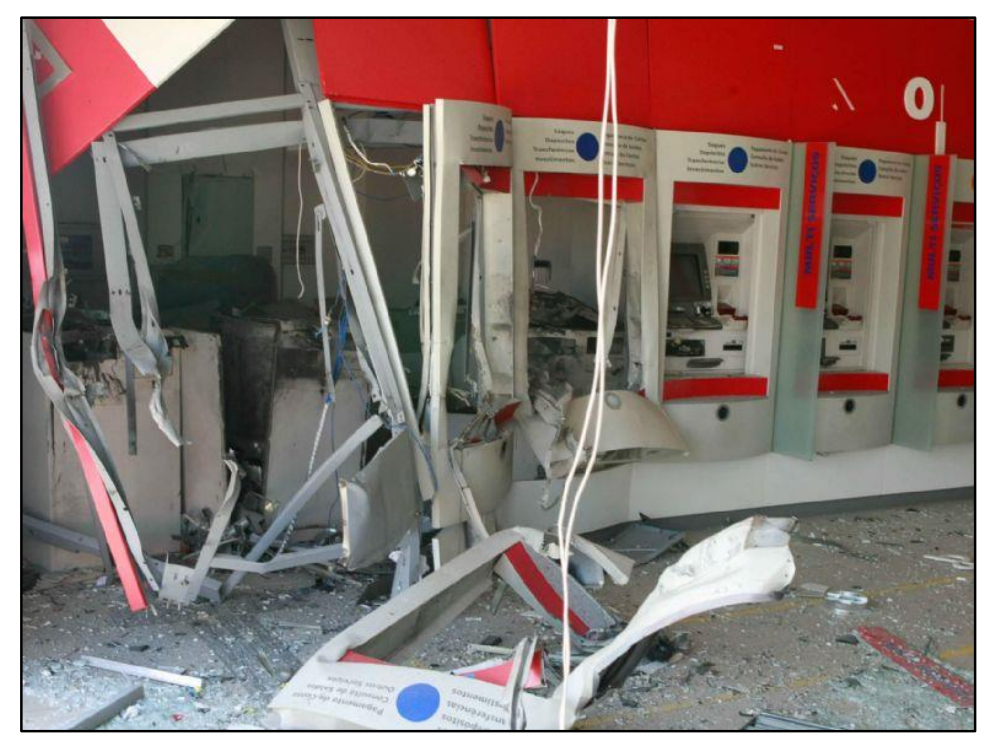

Fonte:- adaptado de Matais et al. ${ }^{4}$.

Figura 1. Exemplo de explosão a caixas eletrônicos 
Além das questões envolvendo furtos à caixa eletrônicos, outro ponto a ser considerado em relação ao uso de explosivos são os ataques terroristas. Os riscos de ameaças terroristas estão presentes em grande parte dos países e a demanda por tecnologias que ajudem a identificar os responsáveis torna-se uma prioridade. Segundo pesquisa realizada por Lafree et al. ${ }^{5}$, com dados obtidos a partir da Global Terrorism Database (GTD), mais de 125.000 casos de ataques terroristas foram registrados no período de 1970 a 2013. Estes ataques se distribuíram em 162 países, sendo que o Iraque, o Afeganistão e o Paquistão concentram a maior incidência de ataques. Os Estados Unidos aparecem na 30 a posição e o Brasil ocupa a $72^{\mathfrak{a}}$ posição. ${ }^{5,6}$

Segundo esse estudo (Figura 2), o número de vítimas fatais de ataques terroristas em 2013 atingiu a marca de 18.000 mortes em todo o globo, valor que representa um aumento de 38\% em relação ao ano anterior (2012). Observa-se que a partir de 2003, o número de mortes subiu tendo como motivo principal o início da guerra ao Iraque. Após uma redução, o número de mortes voltou a crescer após a morte de Osama Bin Laden e o início da guerra da Síria no ano de 2011 , oferecendo um quadro preocupante para as autoridades mundiais. ${ }^{6}$

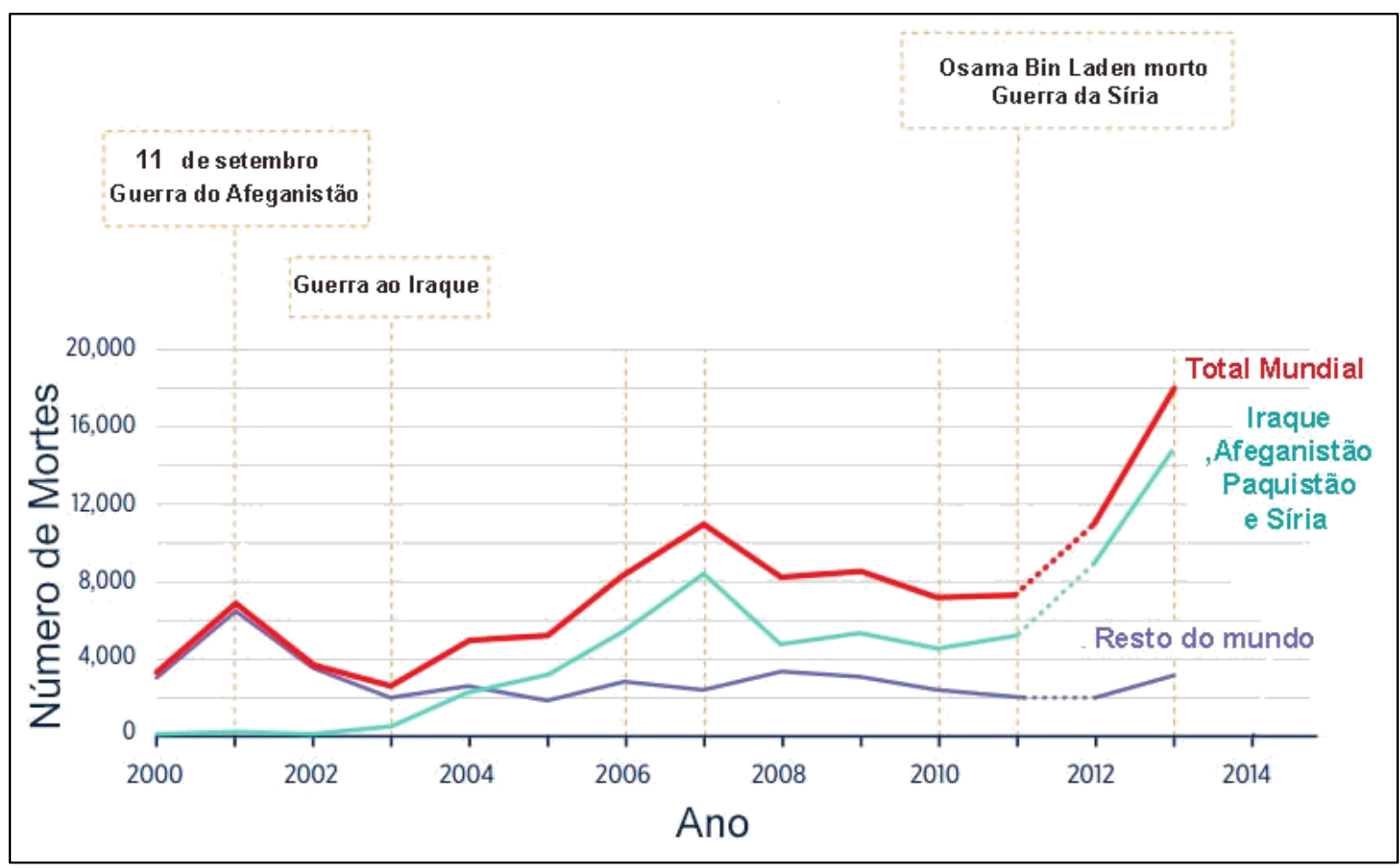

Fonte: adaptado de Lafree et al. ${ }^{5}$

Figura 2. Número de mortes por ataques terroristas em função dos anos; 
A Figura 3 mostra dados obtidos a partir da GTD que apontam que os explosivos estão relacionados com aproximadamente $49 \%$ das mortes ocasionadas por ataques terroristas. Entre os explosivos mais utilizados estão a dinamite, granadas, morteiros, dispositivos improvisados, etc. ${ }^{7}$

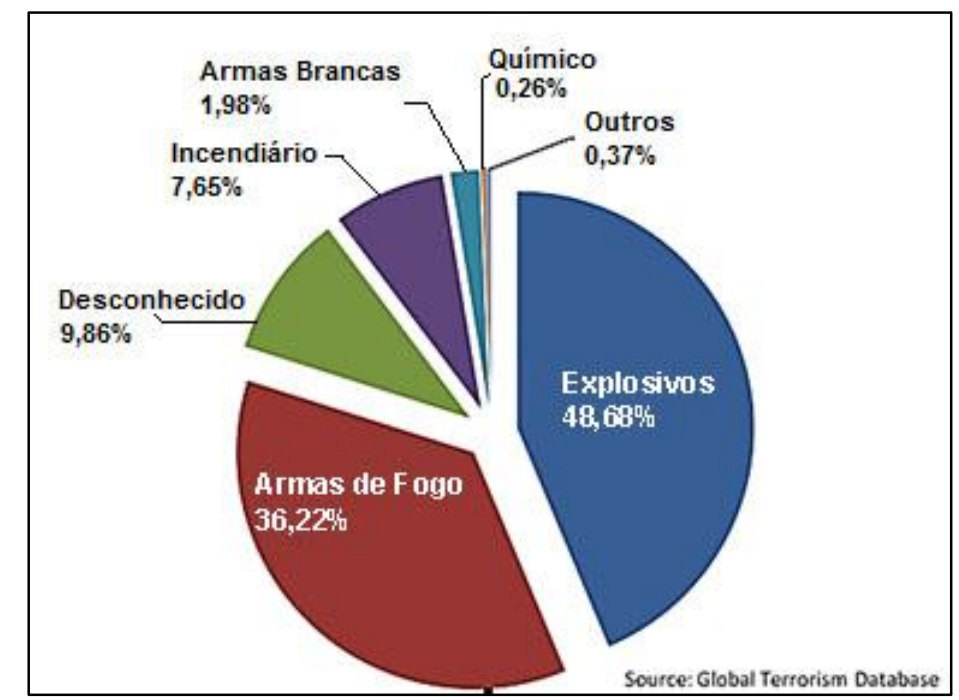

Fonte: adaptado de Lafree $^{7}$

Figura 3. Principais armas utilizadas em ataques terroristas no período de 1970 e 2007;

Uma das maiores dificuldades para rastrear e identificar suspeitos, de furto ou uso criminal de explosivos, vem da ausência de traços químicos específicos das cargas explosivas entre os diferentes locais de manufatura. Dessa forma, após a detonação de um explosivo, fica quase impossível estabelecer a correlação desses artefatos com suas respectivas fábricas, já que não é possível distinguir os resíduos. Informação de origem do explosivo, data de manufatura, lote entre outras, podem ser peças fundamentais para monitorar atividades de suspeitos, e assim, prevenir futuros delitos.

Se faz necessária uma metodologia capaz de codificar individualmente os explosivos para facilitar a identificação e rastreamento de possíveis suspeitos. Além disso, é necessário que essa identificação seja rápida, inequívoca e de baixo custo para viabilizar o tempo de resposta e a apuração de provas. Tendo em vista o panorama citado, o presente trabalho propõe uma tecnologia de codificação e identificação de resíduos de explosão por meio da marcação química de explosivos utilizando marcadores luminescentes dopados com íons 
terras raras baseado nas propriedades luminescentes desses materiais. Após a adição de marcadores específicos para cada explosivo (rotulagem), os resíduos de pós explosão podem ser identificados por análises químicas (fluorescência, Microscópio Eletrônico de Varredura - MEV, Espectroscopia por Dispersão de Energia - EDS, Video Spectral Comparator - VSC) ou com o simples uso de uma lâmpada UV no local do crime, oferecendo informações como local de manufatura, tipo de explosivo, tempo percorrido até a detonação, lote, entre outras com um baixo tempo de resposta e alta confiabilidade. 


\section{OBJETIVOS}

\subsection{OBJETIVOS GERAIS}

Este trabalho propõe uma nova metodologia de codificação e rotulagem de explosivos plásticos/gelatinosos baseada na incorporação de marcadores luminescentes dopados com íons terras raras (TR), com o escopo de facilitar a identificação de resíduos de explosão com base na cor de emissão característica de cada marcador, sua composição química e/ou estrutura. Espera-se que as informação obtidas pela codificação, como tipo de explosivo, local de manufatura, lote, data de fabricação, entre outros, auxiliem as autoridades a rastrear a origem dos explosivos utilizados e gerar evidências necessárias para a imputação de penas a possíveis suspeitos.

\subsection{ETAPAS DO TRABALHO}

- Sintetizar e caracterizar os marcadores dopados com íons terras raras: $\left[\left(\mathrm{La}_{0.8} \mathrm{~Tb}_{0.2}\right)_{2}(\mathrm{DPA})_{3}\left(\mathrm{H}_{2} \mathrm{O}\right)_{3}\right] ; \quad\left[\left(\mathrm{La} 0.95 \mathrm{Eu}_{0.3} \mathrm{~Tb}_{0.2}\right)_{2}(\mathrm{DPA})_{3}\left(\mathrm{H}_{2} \mathrm{O}\right)_{3}\right]$ $\mathrm{ZnAl}_{1,95} \mathrm{~Tb}_{0,05} \mathrm{O}_{4}$;

- Detonar as cargas de forma a simular um caixa eletrônico e verificar a presença de marcadores luminescentes no local de detonação com o auxílio de lâmpadas UV;

- Coletar e caracterizar os resíduos de explosão por espectroscopia de fluorescência na região do UV-vis, microscopia eletrônica de varredura acoplada a espectroscopia de dispersão de energia e video spectral comparator;

- Avaliar os candidatos a marcadores de explosivos priorizando um método de rápido tempo de resposta, baixo custo e fácil detecção. 


\section{FUNDAMENTACÃO TEÓRICA}

\subsection{EXPLOSIVOS}

Uma explosão pode ser defina como uma grande quantidade de energia liberada em um curto período de tempo, acompanhada de um aumento abrupto de volume. Essa energia pode ser proveniente de gases sob alta pressão (explosão física), reações nucleares (fissão, fusão, etc) ou do produto de uma reação envolvendo explosivos químicos. ${ }^{8}$

Em sua grande maioria, os explosivos químicos são constituídos por oxigênio, nitrogênio e elementos oxidáveis. Nesses casos, o oxigênio é normalmente encontrado ligado ao nitrogênio (como nos grupos $\mathrm{NO}-\mathrm{NO}_{2}^{-}$e $\mathrm{NO}_{3}{ }^{-}$ ). Entretanto, existem exceções como as azidas (ex.: $\mathrm{PbN} 6$ ), ozonidas (ex.: $\mathrm{NaO}_{3}$ ) iodeto de nitrogênio $\left(\mathrm{Nl}_{3}\right)$, o $\mathrm{NH}_{3} \mathrm{Nl}_{3}$, etc, que não possuem $\mathrm{O}$ ou $\mathrm{N}$ em sua composição.

A Figura 4 exemplifica uma reação explosiva a partir da molécula de Trinitrobenzeno (TNB). Após o rompimento das ligações entre os átomos grupos nitro, causado por uma onda de choque ou atrito, é obtido uma grande quantidade de calor e energia que desloca a massa de ar próxima, caracterizando uma explosão. $8,9,10$

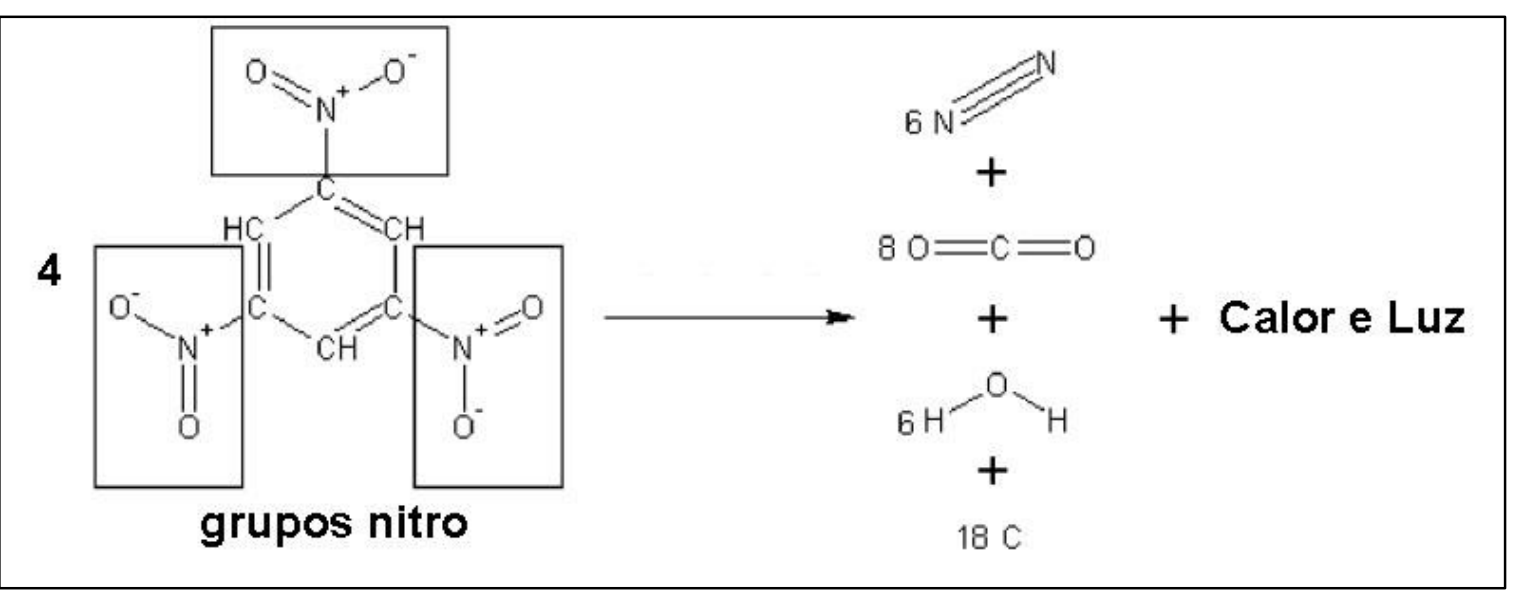

Fonte: adaptado de Ledgard ${ }^{10}$

Figura 4. Reação de decomposição do trinitrobenzeno após um estímulo (onda de choque, atrito, calor, etc). Quando as ligações entre os átomos dos grupos nitro são quebradas, uma grande quantidade de energia é liberada causando uma explosão; 
Segundo Urbanski et al. ${ }^{11}$, os explosivos podem ser classificados de acordo com sua composição química ou por seu uso comercial. A partir do ponto de vista químico, é possível categorizar os explosivos segundo a presença de oito grupos estruturais responsáveis pelas características do explosivo, chamados de grupos explosóforos:

- $-\mathrm{NO}_{2}$ e $-\mathrm{ONO}_{2}$ (Substancias inorgânicos e orgânicos);

- $-\mathrm{N}=\mathrm{N}-\mathrm{e}-\mathrm{N}=\mathrm{N}=\mathrm{N}-$ (Substancias inorgânicos e orgânicos);

- $-\mathrm{NX}_{2}$ (aonde $\mathrm{X}$ é um halogênio);

- $-\mathrm{N}=\mathrm{C}$ (fulminatos);

- -O-O- e-O-O-O- (peróxidos e ozonidas, respectivamente);

- $-\mathrm{C} \equiv \mathrm{C}$ - (acetilenos)

- M-C (metais ligados a organometálicos).

Entretanto, a classificação mais comum para os explosivos leva em consideração os principais usos comerciais. Esta classificação será detalhada a seguir.

\subsubsection{Explosivos primários}

Esses materiais possuem maior sensibilidade a estímulos físicos e elétricos que os explosivos secundários e podem ser detonados com o auxílio de calor, atrito, descargas elétricas, ondas de choque, entre outros. Junto a isso, liberam uma maior quantidade de energia quando detonados se comparados aos outros tipos de explosivos..$^{8,10,11}$

Em função de sua sensibilidade, esses materiais não podem ser utilizados como explosivo principal para detonação, devido ao risco de detonações acidentais. Entretanto, são largamente utilizados como iniciadores de explosivos secundários. Neste caso são usados em detonadores, ou primer, os quais podem ser um cartucho metálico contendo uma carga de explosivo primário que, quando detonado, inicia um explosivo secundário remotamente. ${ }^{8}$ Os primers podem ser classificados como elétricos ou não elétricos, dependendo do sistema de iniciação. Todavia, os dispositivos elétricos oferecem mais controle e segurança no manuseio de explosivos, sendo largamente empregado pela indústria nas 
últimas décadas. ${ }^{12} \mathrm{~A}$ imagem abaixo demonstra alguns exemplos de detonadores elétricos de explosivos utilizados comercialmente.

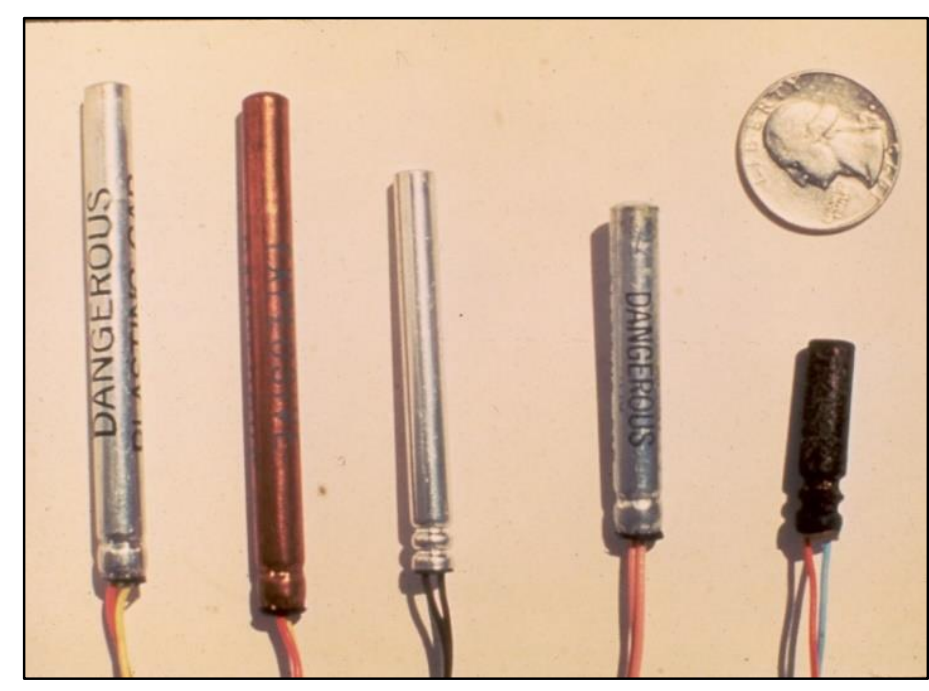

Fonte: Richmond et al. ${ }^{13}$

Figura 5. Exemplos de detonadores elétricos comumente utilizados comercialmente;

\subsubsection{Explosivos secundários}

É possível destacar três características fundamentais para definir os explosivos secundários. Primeiramente, esses materiais dependem de muito mais energia para dar início ao processo de detonação se comparados com os explosivos primários. Em segundo lugar, esse tipo de explosivo praticamente não apresenta sensibilidade a estímulos elétricos. Em terceiro, esse tipo de explosivo geralmente é iniciado por um explosivo primário. ${ }^{14}$ Devido ao alto número de aplicações para explosivos secundários, duas subcategorias são necessários: explosivos de uso militar (com alta densidade) e explosivos comerciais (menor densidade). ${ }^{8,14}$

De maneira sucinta, a classificação dos explosivos está disposto na Figura 6. 


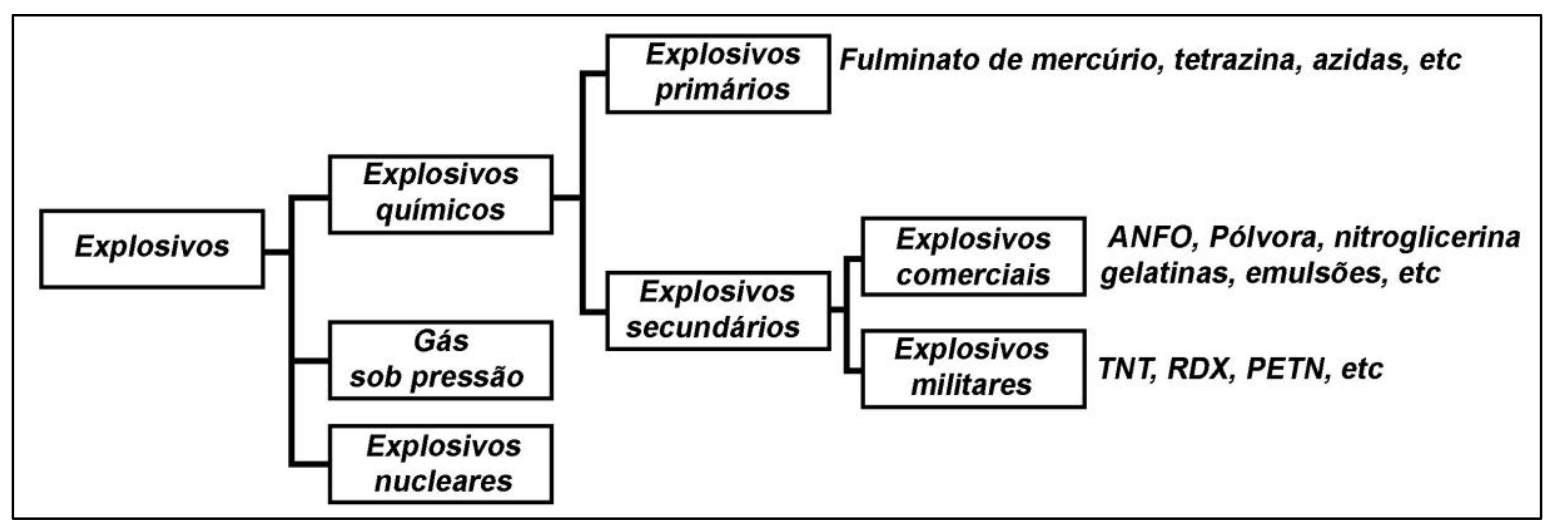

Fonte: adaptado de Akhavan ${ }^{8}$

Figura 6. Classificação dos explosivos segundo o principal uso comercial;

O nitrato de amônia $\left(\mathrm{NH}_{4} \mathrm{NO}_{3}\right)$ possui uma grande importância para os explosivos secundários. Com exceção dos explosivos militares, o AN (ammonium nitrate) é a base de quase todos os explosivos comerciais. Apenas os EUA são responsáveis por uma produção anual de 2 milhões de toneladas de $A N$, e a demanda cresce a cada ano. O AN pode ser obtido facilmente a partir da neutralização de ácido nítrico $\left(\mathrm{HNO}_{3}\right)$ com amônia $\left(\mathrm{NH}_{4}{ }^{+}\right)$. O produto resultante é evaporado, originando granulados sólidos. ${ }^{15}$

O AN foi utilizado em explosivos pela primeira vez em 1867, pelos químicos suíços Ohlsson e Norrbein. Entretanto, apenas na década de 50, passou-se a usar AN em combinação com combustível, dando origem a uma emulsão líquida resistente a humidade. A mistura de AN e combustível é denominada ANFO (ammonium nitrate - fuel oil) e é classificada como um explosivo secundário. $O$ principal uso do ANFO está ligado a área de mineração e extração de rochas entretanto, também é utilizado na área de demolição de estruturas e confecção de túneis/metros. O baixo custo e a segurança no manuseio fizeram desse material o explosivo mais utilizado em todo o mundo. ${ }^{15}$

A composição mais comum de ANFO apresenta cerca de $94 \%$ de AN e $6 \%$ de diesel, além da possibilidade de sensitizadores como pó de alumínio $\left(A I^{0}\right)$. Sickler ${ }^{14}$ relaciona a energia liberada pela reações de decomposição do ANFO em diferentes proporções de combustível e sensitizador, como mostrado na Tabela 1. Observa-se um aumento considerável na energia libera quando utilizado o Al na composição, justificando o uso de sensitizadores para melhorar a performance do explosivo. 
Tabela 1. Reações de decomposição do Explosivo ANFO em diferentes proporções relacionadas a suas respectivas energias liberadas;

\begin{tabular}{c|c|c}
$\begin{array}{c}\text { Proporção entre Nitrato de amônio } \\
\text { e combustível (diesel) }\end{array}$ & \multicolumn{1}{|c}{ Reação } & $\begin{array}{c}\text { Energia liberada/ } \\
\text { grama (J/g) }\end{array}$ \\
\hline 94,5\% de $A N ; 5,5 \%$ de combustível & $3 \mathrm{NH}_{4} \mathrm{NO}_{3}+\mathrm{CH}_{2} \rightarrow 7 \mathrm{H}_{2} \mathrm{O}+\mathrm{CO}_{2}+3 \mathrm{~N}_{2}$ & 3,891 \\
$92,0 \%$ de $A N ; 8,0 \%$ de combustível & $2 \mathrm{NH}_{4} \mathrm{NO}_{3}+\mathrm{CH}_{2} \rightarrow 5 \mathrm{H}_{2} \mathrm{O}+\mathrm{CO}+2 \mathrm{~N}_{2}$ & 3,389 \\
$96,6 \%$ de $A N ; 3,4 \%$ de combustível & $5 \mathrm{NH}_{4} \mathrm{NO}_{3}+\mathrm{CH}_{2} \rightarrow 11 \mathrm{H}_{2} \mathrm{O}+\mathrm{CO}_{2}+4 \mathrm{~N}_{2}+2 \mathrm{NO}$ & 2,510 \\
$81,6 \%$ de $A N ; 18,4 \%$ de $A l$ & $2 \mathrm{NH}_{4} \mathrm{NO}_{3}+2 \mathrm{Al} \rightarrow 6 \mathrm{H}_{2} \mathrm{O}+\mathrm{Al}_{2} \mathrm{O}_{3}+3 \mathrm{~N}_{2}$ & 6,778
\end{tabular}

A proporção dos componentes do explosivo e a adição de sensitizadores, geralmente alteram as características do material e, por consequência, sua forma de reagir ao ambiente. Durante o processo de manufatura ou manuseio, os explosivos são expostos a vários estímulos físicos e mecânicos, como calor, fricção e impacto. A habilidade de um explosivo reagir a um estímulo, acarretando em uma detonação ou combustão, é denominada sensibilidade. Testes de sensibilidade são extremamente necessários para a determinação dos parâmetros de segurança em explosivos, seja para transporte, manuseio ou armazenamento. ${ }^{16}$

Um ponto importante nas análises de sensibilidade envolve os mecanismos de detonação do explosivo. Diversos mecanismos de iniciação podem ser aplicados em cargas explosivas com objetivo detonar 0 material, como aquecimento, impacto ou fricção. ${ }^{17,18}$ Suceska $^{17}$ relaciona algumas metodologias básicas para a determinação da sensibilidade em explosivo a partir de estímulos mecânicos:

\subsubsection{Sensibilidade ao calor}

A partir dos ensaios de sensibilidade ao calor é possível obter alguns parâmetros como: Tempo de indução $\left(E_{d}\right)$, Temperatura de explosão $\left(E_{t}\right)$ e Energia de ativação $\left(E_{a}\right)$. Todos esses parâmetros combinados podem ser comparados com demais explosivos a fim de determinar a melhor forma de otimizar, manusear ou armazenar o material, baseado em sua forma de reagir as mudanças de temperatura. O principal método de determinação desses valores é 
pelo aquecimento homogêneo de uma pequena amostra do explosivo analisado. Dessa maneira, pode-se utilizar as leis de Arrhenius para descrever o comportamento do material. ${ }^{16,17,19}$

Para todo explosivo, pode ser definido uma temperatura mínima na qual ocorre a explosão. Entretanto, ao se atingir essa temperatura, o tempo até a detonação pode variar de horas até microssegundos, dependendo do material analisado. O tempo percorrido quando se coloca uma amostra em determinada temperatura até a detonação do explosivo é definido como Tempo de Indução $\left(E_{d}\right) .17,19$

De maneira análoga, a determinação da Temperatura de Explosão $\left(E_{t}\right)$ depende das propriedades inerentes do explosivo. Segundo Agrawal, ${ }^{16} \circ E_{t}$ é defino como a temperatura necessária para a detonação de $20 \mathrm{mg}$ de explosivo em exatamente 10 ou 5 segundos. ${ }^{17,19}$

A Figura 7 mostra um desenho esquemático de um equipamento de aquecimento padrão, para a determinação do $E_{d}$ e $E_{t}$. Segundo a metodologia proposta por Copp et al. ${ }^{19}$, uma amostra de $20 \mathrm{mg}$ de explosivo é colocado em estojo metálico aberto. Em seguida, o estojo é imerso em um banho contendo metal fundido a $300 \stackrel{\circ}{\circ}( \pm 5 \stackrel{\circ}{\circ})$. Um cronometro é utilizado para medir o tempo em que o estojo é inserido no banho até a detonação/combustão do explosivo, obtendo assim o tempo de indução $\left(E_{d}\right)$. De forma semelhante, a Temperatura de Explosão pode ser obtida. Ao se medir o tempo de indução o intervalo de tempo pode ser diferente do valor desejado (10/5 segundos). Caso o tempo não esteja correspondendo, a temperatura do banho é aumentada ou diminuída em $10 \stackrel{\circ}{\mathrm{C}}$ e o uma nova amostra é colocada no banho. Após sucessivas tentativas, a temperatura pode ser ajustado para que o explosivo detone aos exatos 10/5 segundo, obtendo o parâmetro $E_{t .}{ }^{19}$ 


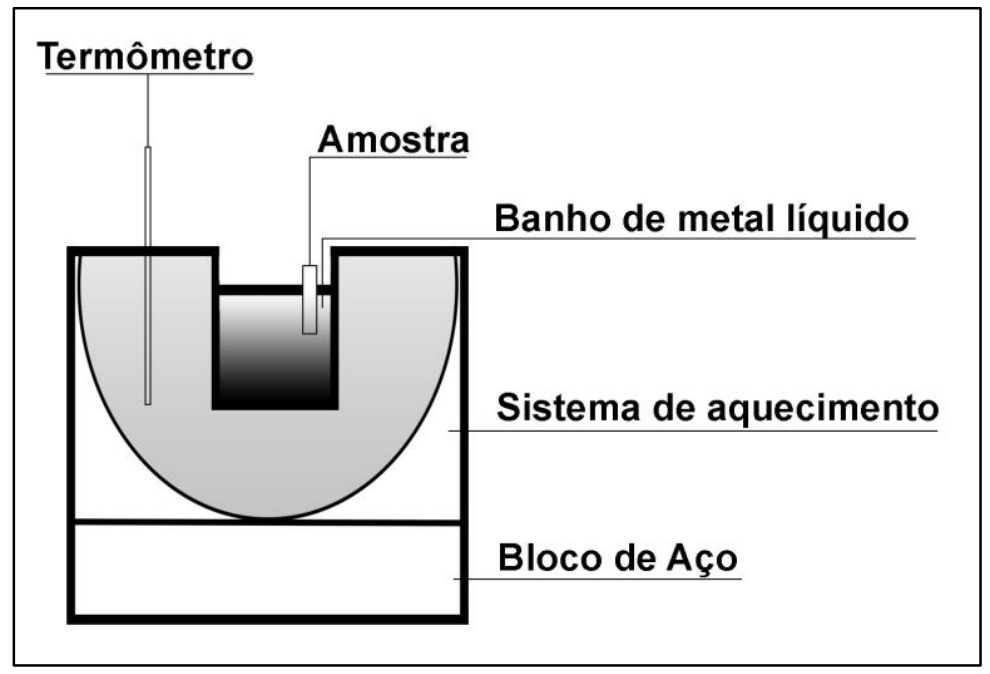

Fonte: Adaptado de Agrawal ${ }^{16}$

Figura 7. Aparelho para determinação da Temperatura de Explosão (Et) e Tempo de Indução (Ed);

A energia de ativação $\left(E_{a}\right)$ é obtida por meio da equação de Arrhenius descrita abaixo. Destaca-se que a energia de ativação apresenta informações mais completas sobre a sensibilidade do explosivo que os parâmetros $E_{d}$ e $E_{t .}{ }^{18,19}$

$$
E d=A_{X} \cdot e^{\frac{E a}{R \cdot T}}
$$

Aonde,

$E_{d}=$ tempo de indução

$A_{x}=$ Fator de frequência dependente de cada explosivo

$E_{a}=$ Energia de ativação

$R=$ constante real dos gases

$T=$ temperatura absoluta do banho quando o explosivo foi detonado

\subsubsection{Sensibilidade a Impacto}

Em uma iniciação mecânica, qualquer estímulo provocado gera um aumento da temperatura no local da ação, denominado hotspot. Esse fenômeno pode ser gerado, por calor, atrito, passagem de corrente elétrica ou impacto sobre o explosivo. Utilizando esse conceito, o teste de sensibilidade a impacto tem por objetivo compreender o comportamento do explosivo sob ação forças externas. Para essa análise, um cilindro de massa definida (entre 0,5 até $5 \mathrm{~kg}$ ) a uma altura padrão de $25 \mathrm{~cm}$ é solto sob a ação da gravidade em cima de uma amostra de explosivo, como mostrado pela Figura 8. A sensibilidade ao impacto é mensurada 
através da determinação da massa mínima capaz de iniciar a decomposição, ignição ou detonação do explosivo analisado. Esses valores de massa mínima podem ser comparados com demais explosivos a fim de determinar a segurança do material.

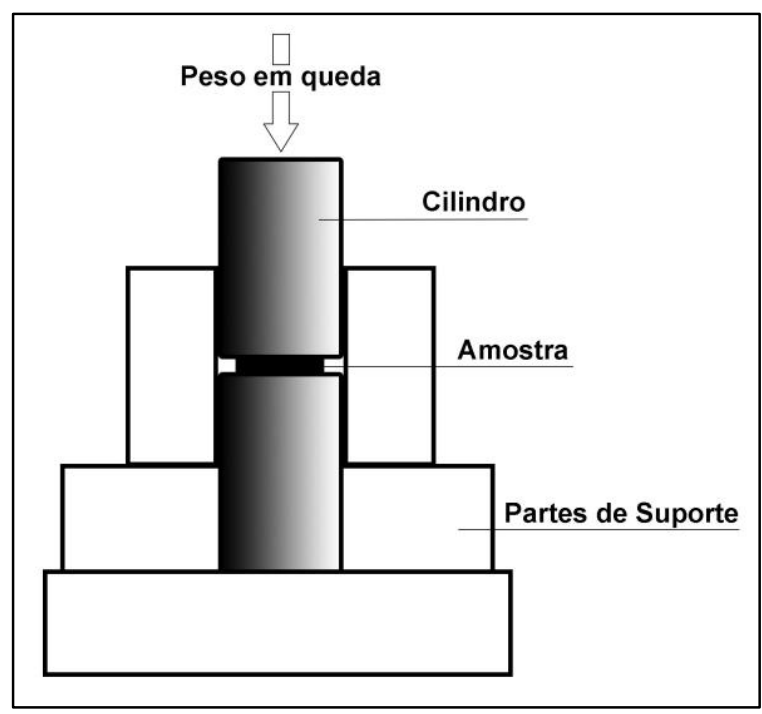

Fonte: Adaptado de Agrawal ${ }^{16}$ Figura 8. Aparelho do tipo Fallhammer para determinação de sensibilidade a impacto;

\subsubsection{Sensibilidade a fricção}

Durante o ciclo de produção dos explosivos, é comum ocorrer atrito com diferentes materiais e superfícies. Essa fricção pode em alguns casos levar a ignição do explosivo, tornando-se um risco aos usuários. Assim como os ensaios de impacto, a fricção pode ser explicada pela criação de um hotspot devido a força de atrito formado na superfície do explosivo. ${ }^{17}$ Entre os trabalhos encontrados na literatura, o aparelho de friç̧ão de Julius Peters é amplamente utilizado pela Europa e apresenta os melhores fatores de reprodutibilidade entre os demais métodos. Esse método consiste em espalhar uniformemente uma amostra de explosivo ( $\approx 10 \mathrm{mg}$ ) em um anteparo de cerâmica, como demonstrado na Figura 9. Em seguida, um pistilo cerâmico é fixado em cima da amostra, pressionando-a. $\mathrm{O}$ anteparo por sua vez, é ligado a um motor que desliza a placa de cerâmica contendo a amostra em movimento circulares, com um arco $10 \mathrm{~mm}$ e uma velocidade $10 \mathrm{~cm} / \mathrm{s}$. A força, medida em Newtons $(\mathrm{N})$, entre o pistilo e o anteparo é aumentada gradativamente até que se observe indícios de ignição, 
combustão ou detonação da amostra. Dessa maneira, o resultado de sensibilidade é expresso pelo mínimo de força, em newtons, capaz de ocasionar a ignição do analito.

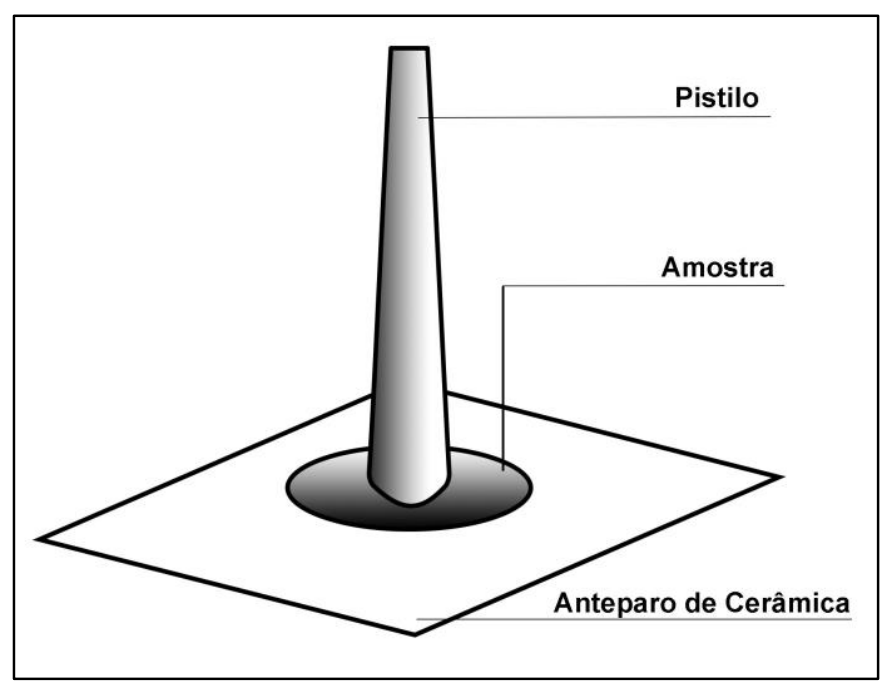

Fonte: adaptado de Agrawal ${ }^{16}$

Figura 9. Aparelho para determinação da sensibilidade a fricção de acordo com o método de Julius Peters;

\subsubsection{Cenários de Pré e Pós-explosão}

Infelizmente, explosivos foram usados em vários atos criminosos durante a história. Como exemplo, pode-se destacar os ataques ao World Trade Center em 1993 e o ataque a sede do FBI na cidade de Oklahoma em 1995, ambos utilizando carros bomba contendo cargas de ANFO. Também é possível enfatizar a tentativa de ataque a Alemanha em 2007, na qual foi encontrado 20 barris de $\mathrm{H}_{2} \mathrm{O}_{2}$ que seriam usados por terroristas. ${ }^{20} \mathrm{Em}$ um problema recente e igualmente preocupante, o Brasil vem sendo vítima de diversos ataques a caixas eletrônicos pondo em risco a segurança da população. Em 1988 um ataque terrorista ao avião Pan American 103, sobre a Escócia, causou 259 mortes. As investigações posteriores mostraram que um explosivo líquido foi o responsável pela queda do avião, que gerou o empenho das autoridades para desenvolver estudos de tecnologias e tentar diminuir os riscos de ataques com o uso de explosivos. ${ }^{15}$

Seguindo os estudos desenvolvidos para entender e inibir novos ataques, o uso de explosivos por criminosos pode ser divido em duas situações: na primeira hipótese, o explosivo utilizado em um ataque não é detonado. Nesse caso, 
denomina-se um cenário de pré-explosão. Na segunda situação, o explosivo já foi detonado, chamando assim de cenário de pós-explosão. ${ }^{21,22,23}$ Cada cenário é analisado de maneiras diferentes, de acordo com seus respectivos objetivos.

\subsubsection{Análises pré-explosão}

Em análises pré-explosão busca-se prioritariamente detectar e encontrar possíveis explosivos que estejam escondidos, antes de sua detonação. A literatura relaciona várias metodologias de reconhecimento de explosivos, todavia, apenas as mais utilizadas serão abordadas. A detecção e explosivos ainda pode ser dividida em duas subcategorias: tecnologias de massa e tecnologias de traços. $^{24}$ As tecnologias de massas buscam por alterações no peso de determinadas amostras que podem dar indícios da existência de explosivos. Como exemplo, o explosivo triperóxido de triacetona (TATP) pode ser introduzido em salsichas, e a partir da densidadelmassa do alimento é possível determinar a presença de explosivos. ${ }^{25}$ Já as análises de traços, em geral se baseiam na identificação de sinais químicos específicos a partir de uma base de dados do composto alvo. Devido a essa seletividade, as análises de traços químicos tem menor probabilidade de oferecer informações falsas ou inequívocas. Porém, a detecção de explosivos por traços químicos depende de uma base de dados e de sinais já conhecidos desses explosivos, impedindo a detecção de explosivos não conhecidos pelo método. 24,25

Uma das tecnologias desenvolvidas e aplicadas mundialmente é o treinamento de cachorros rastreadores na detecção de explosivos a partir do olfato sensível desses animais. ${ }^{21}$ Todavia, custo de treinamento por animal chega a US $\$ 6.000$ e o preço de manutenção mensal chega a US $\$ 2.000$ (dados de 2013). ${ }^{26}$ Como contra ponto ao treinamento de cães farejadores, técnicas de radiografia são particularmente efetivas na detecção de cargas explosivas. Entretanto essa técnica não apresenta grande sensibilidade e depende que o explosivo possua um tamanho mínimo para a sua detecção. Sendo assim, o método permite que os criminosos escondam ou despistem o explosivo afetando a capacidade de detecção equipamento. ${ }^{24}$ 
Um dos principais problemas no transporte de explosivos plásticos é a alta volatilidade dos componentes da mistura, deixando resíduos na atmosfera no qual são armazenados. Fundamentado nessa característica, várias tecnologias de detecção de explosivos se baseiam nas propriedades voláteis de alguns compostos. Os principais compostos voláteis encontrados em explosivos plásticos são: 2,3-dimetil-2,3-dinitrobutano (DMNB) e o dinitrato de etilenoglicol (EGDN), representados na Figura 10. Em concordância com isso, a detecção de explosivos escondidos usando instrumentação analítica se baseia na presença de vapores de DMNB e EGDN no ar ambiente. ${ }^{27}$ Como nem todos os explosivos apresentam tais moléculas em sua composição, as duas substâncias passaram a ser incorporadas nos demais explosivos fabricados como marcadores de detecção, seguindo o modelo estipulado pela convenção de Montreal de 1999 para contensão de ameaças terroristas em aeroportos, com a intenção de gerar uma metodologia de detecção generalizada. ${ }^{27,} 28$

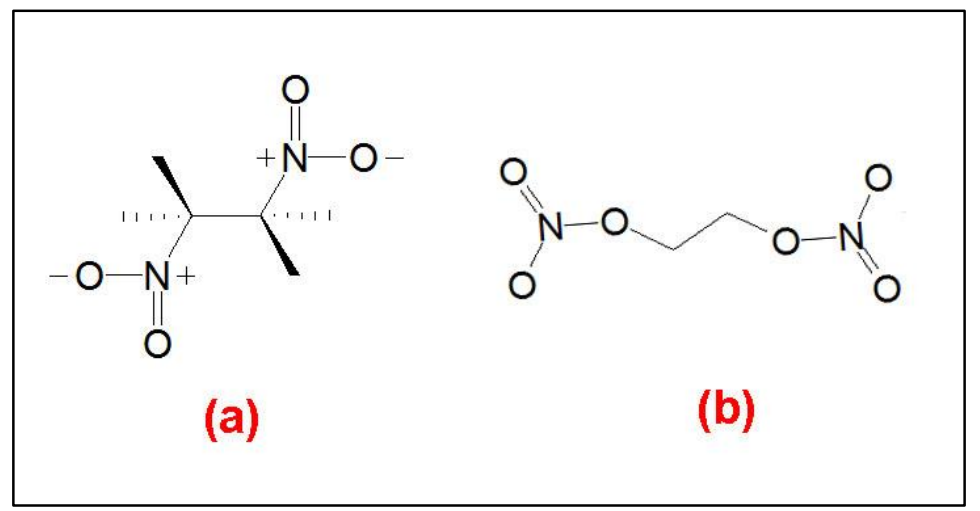

Figura 10. Fórmulas estruturais do a) DMNB e do b) EGDN;

A espectrometria de mobilidade de íons (ion mobility spectrometry - IMS) se tornou uma das principais técnicas na detecção de traços de explosivos. Por ser uma técnica simples e de fácil miniaturização, esses equipamentos são encontrados nos aeroportos da maioria dos países. ${ }^{27,} 29$ O funcionamento do IMS depende da volatilidade de compostos químicos encontrados em explosivos, como os marcadores DMNB e EGDN. ${ }^{30}$ Quando o equipamento é aproximado do explosivo, a amostra do marcador volátil é aspirada para o componente central do IMS, o tubo de deslocamento, esquematizado na Figura 11. Em seguida, a amostra é mistura a um gás iônico que, através de reações químicas, produzem 
íons a partir da amostra. Esses íons são arrastados a um campo eletromagnético ( $\approx 200 \mathrm{~V} / \mathrm{cm})$ através do tubo com uma velocidade característica. A velocidade é calculada pelo tempo requerido para amostra percorrer todo o tubo, desde a entrada no sistema até o seu impacto no detector. O espectro obtido pelo IMS é definido pela intensidade de partículas detectadas em função do tempo de deslocamento, geralmente em milissegundos (ms). Cada componente apresenta espectros característicos que são comparados com a base de dados e soam um alarme sonoro quando compatíveis com os explosivos alvo. ${ }^{30,31}$

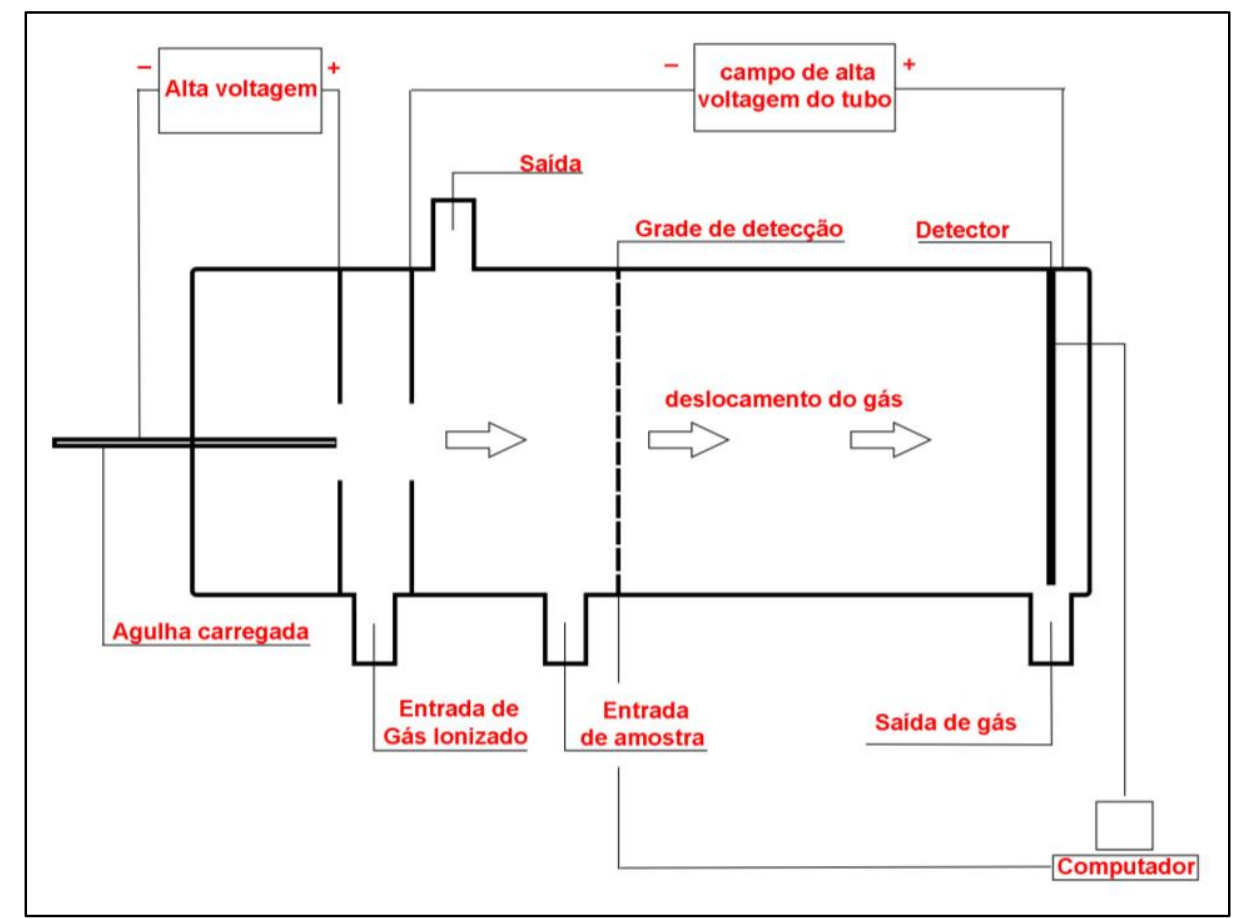

Fonte: Adaptado de Marshall ${ }^{24}$ Figura 11. Desenho esquemático simplificado do tubo de deslocamento em um IMS;

Outra opção desenvolvida nos últimos anos é o uso de polímeros luminescentes sensíveis a presença de marcadores de explosivo. Nesses casos, a detecção é baseada na diminuição da fotoluminescência do polímero em contato com o marcador volátil, oferecendo indícios da presença de explosivos. ${ }^{29}$ A chave para o funcionamento dessa técnica está no grupo cromóforo emissor, que sofre quenching na presença no volátil. Um dos mecanismos de Quenching (diminuição da luminescência) é por reação oxidativa. Nesse caso, a transferência de um elétron do cromóforo para o marcador volátil provoca uma diminuição da 
eficiência das transferências radiativas, diminuindo a emissão do polímero. ${ }^{31,32} \mathrm{~A}$ imagem abaixo demonstra o princípio de funcionamento do método.

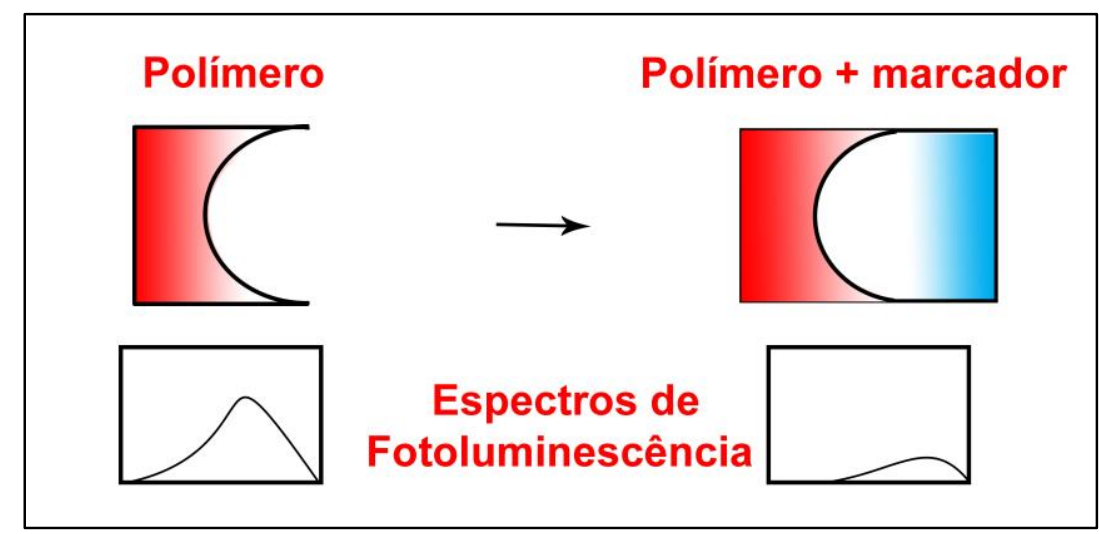

Fonte: Adaptado de Shaw ${ }^{32}$

Figura 12. Quenching das bandas do espectro de fluorescência devido a ligação do polímero a uma marcador de explosivos;

Mesmo apresentando bons resultados, as metodologias de detecção por traços de explosivo apresentam problemas que atrapalham a eficácia do método: (1) a coleta de voláteis de explosivos muitas vezes é ineficaz; (2) se não houver uma grande quantidade de amostras, ela pode não chegar ao detector; (3) é um método previsível e facilmente burlável. Como as análises de traços dependem de sinais conhecidos de explosivos em uma base de dados, basta não utilizar tais substâncias para que o método perca a eficácia. Sendo assim, é necessário a constante adaptação do método para minimizar os riscos; e (4) após a detonação do explosivo, praticamente não há indícios de voláteis na cena do crime devido as altas temperaturas alcançadas. ${ }^{24}$ Novas pesquisas emergem a cada ano buscando reduzir os problemas de tecnologia, entretanto, os risco de ataques com explosivos ainda são muito presentes.

\subsubsection{Análises pós-explosão}

Diferente dos métodos anteriormente discutidos, as análises pós explosão tem por objetivo principal coletar informações e evidências na cena de explosão que auxiliem as investigações e na busca por suspeitos. ${ }^{22,} 33$ Após a detonação, muitos vezes o local se encontra totalmente destruído não oferecendo indícios visuais, dificultando a identificação do explosivo utilizado. Visto que apenas 
análises laboratoriais podem dar resultados conclusivos acerca do tipo de explosivo detonado, várias análises podem ser utilizadas para caracterizar resíduos de pós explosão. ${ }^{33}$ Deve-se observar, que explosivos podem apresentar composições orgânicas ou inorgânicas, necessitando de diferentes métodos de análise para se obter uma informação pertinente. ${ }^{23} \mathrm{~A}$ imagem abaixo resume algumas das análises possíveis para identificar resíduos de explosivos dependo de sua composição.

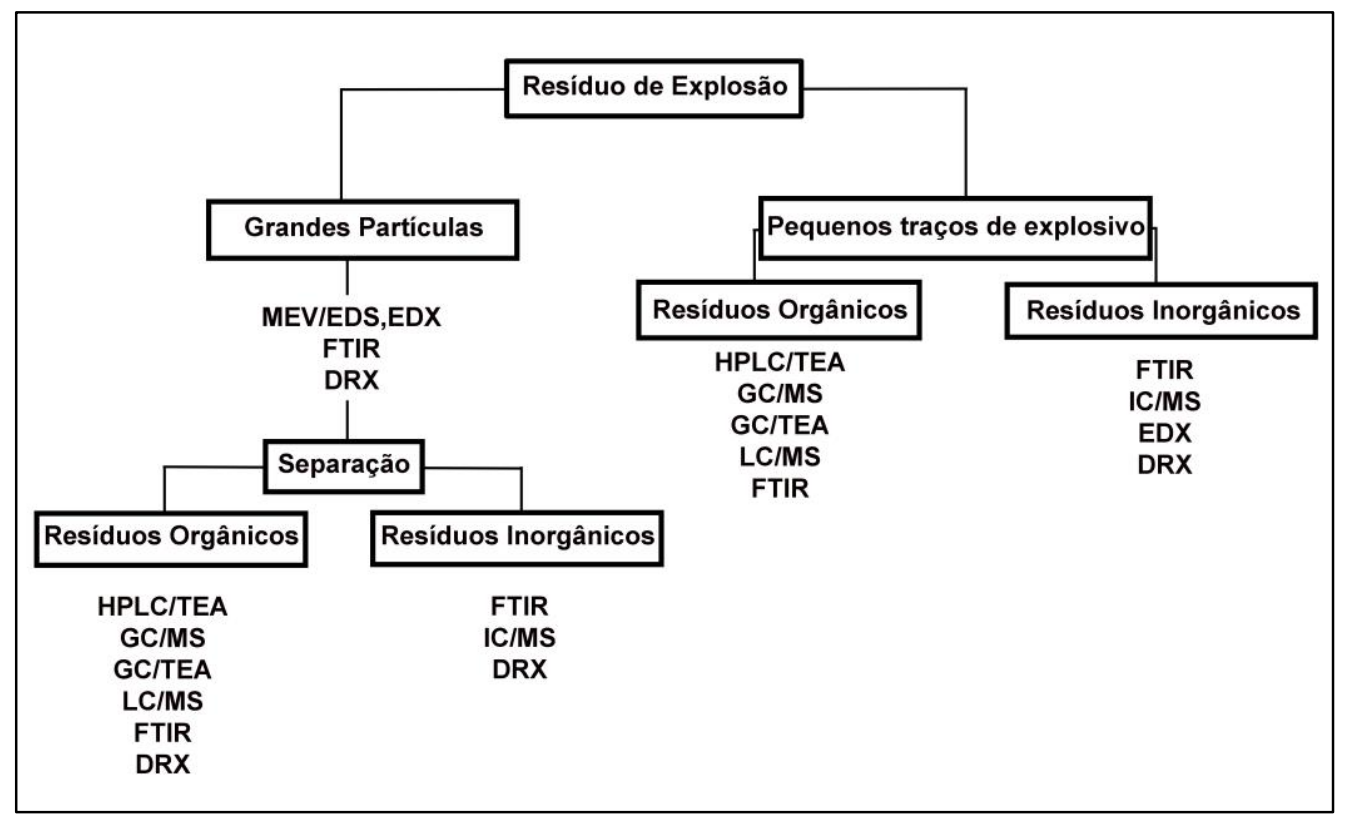

Fonte: adaptado de Beveridge ${ }^{33}$

Figura 13. Análises utilizadas para identificação de resíduos de explosão, dependendo de sua composição química. Legenda: MEV = microscópio eletrônico de varredura; EDS = espectroscopia por dispesão de energia; FTIR = Infravermelho por transformada de Fourrier; TEA = Thermal enrgy analyzer; GC = cromatografia gasosa; LC = cromatografia líquida; HPLC = Cromatografia liquida de alta performance; Cromatografia de íons; MS = espectrometria de massas;

As análises listadas acima, embora mais precisas e seletivas, em geral dependem de etapas preliminares de tratamento dos resíduos de explosão e muitas vezes, podem ser pouco conclusivas dependendo da quantidade de amostra. ${ }^{24}$ Como forma de diminuir o tempo de resposta, o uso de Cromatografia em Camada Delgada (Thin-layer chromatography - TLC) pode ser uma ferramenta que produz resultados facilmente interpretáveis e rápidos para explosivos orgânicos, como exemplifica a Figura 14. Todavia, apenas a combinação entre a distância percorrida pelo composto (expresso pelo $R_{f}$ ) e a 
coloração observada não podem ser consideradas como uma identificação independente e inequívoca. ${ }^{24}, 34 \mathrm{~A}$ tabela 2 mostra alguns resultados de $R_{f}$ obtidos por TLC para explosivos orgânicos.

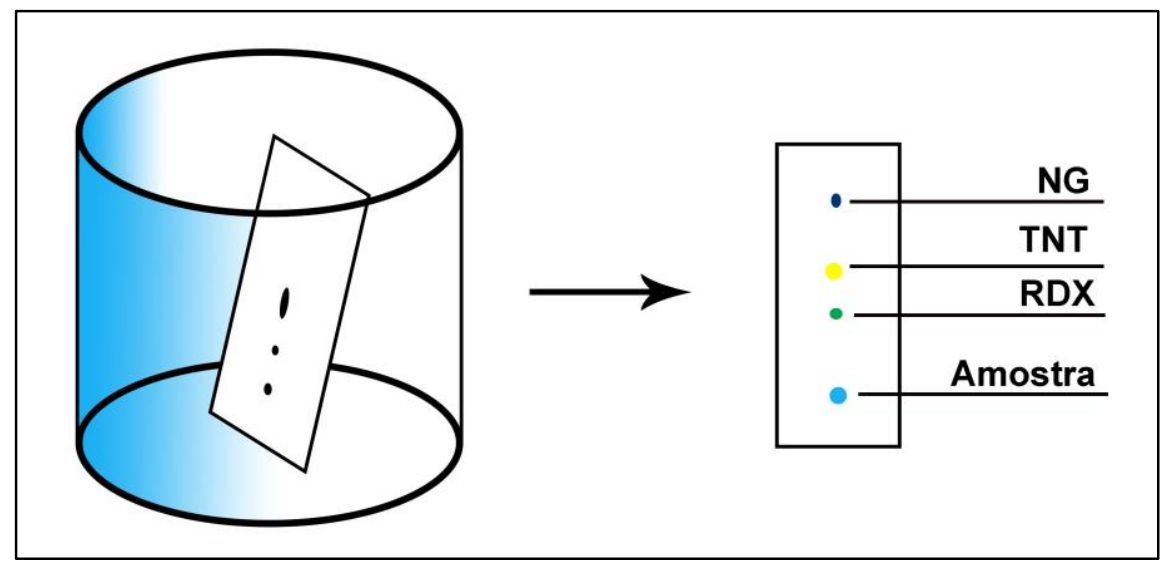

Fonte: Adaptado de Martinez et al. ${ }^{35}$ Figura 14. Exemplo de determinação de resíduo de explosão por cromatografia em camada delgada (imagem ilustrativa);

Tabela 2. Valores de $R_{f}$ obtidos por TLC de resíduos de explosão frente a diferentes tipos de eluente;

\begin{tabular}{l|ccc}
\hline \multirow{2}{*}{ Explosivo } & \multicolumn{3}{|c}{$R_{f}$} \\
\cline { 2 - 4 } & Eluente A & Eluente B & Eluente C \\
\hline$N G$ & 0,61 & 0,32 & 0,84 \\
$H M X$ & 0,01 & 0,02 & 0,25 \\
$R D X$ & 0,07 & 0,03 & 0,53
\end{tabular}

$\mathrm{NG}=$ Nitroglicerina; $\mathrm{HMX}=$ ciclotetrametileno-tetranitramina; $\mathrm{RDX}=$ ciclotrimetilenotrinitramina; Eluente $\mathrm{A}=$ tolueno; Eluente $\mathrm{B}$ = éter; Eluente $\mathrm{C}$ = Acetato de Etila; Fonte: Adaptado de Yinon ${ }^{34}$

Mesmo com o desenvolvimento de novas metodologias, os investigadores encontram diversas dificuldades em análises de pós-explosão. Uma vez detonado, fica muito difícil, se não impossível, obter traços ou resíduos que ofereçam evidencias aos responsáveis pelas investigações. As análises químicas também se restringem a determinação do tipo de explosivo e informações, como - local de manufatura, data de fabricação, lote do material, entre outros, se perdem após a explosão. ${ }^{36,} 37 \mathrm{O}$ uso de marcadores, já empregados comercialmente em análises de pré-explosão, pode oferecer uma alternativa para a Ciência Forense fornecer mais evidências em cenários de pós explosão.

Como exemplo de marcação pós-explosão, na década de 80, a empresa $3 M$ company $^{\circledR}$ desenvolveu um marcador de pós-explosão denominado Microtaggant ${ }^{\oplus}$. Esse material consiste em uma partícula de $800 \mu \mathrm{m}$ de diâmetro 
com multicamadas coloridas de resina de melamina. As diferentes combinações de cores nas camadas criam um código capaz de identificar o explosivo. Uma camada de material magnético é adicionada para facilita a coleta dos marcadores utilizando um imã, por exemplo. ${ }^{38}$ Entretanto, como reportado pelo Office of technology assessment Washington D.C. ${ }^{39}$, esses marcadores dependem de condições muito específicas para a sua identificação e não respondem satisfatoriamente quando o explosivo se encontra confinado. Outras tecnologias de marcação de explosivos serão abordadas na Revisão da Literatura.

\subsection{LUMINESCÊNCIA E PROCESSOS DE EXCITAÇÃO/EMISSÃO}

Segundo Bettencourt-Dias, ${ }^{40}$ considera-se a luminescência como o efeito inverso da absorção. Analisando um átomo de apenas dois níveis de energia, o elétron no estado fundamental é excitado após a absorção de um fóton com comprimento de onda característico. Em seguida, o elétron no estado excitado pode decair para um estados de menor energia, emitindo ou não um fóton: relaxamentos radiativos ou não radiativos, respectivamente. Os processos radiativos são definidos pela emissão de um fóton em um comprimento de onda específico, caracterizando a luminescência. Porém, este relaxamento compete diretamente com o decaimento não-radiativo, no qual elétron perde energia por processos que não envolvem a emissão de fótons, como vibração ou calor. ${ }^{41,42}$

De maneira geral, todos os processos de luminescência apresentam taxas de decaimento não radiativos não desprezíveis. Sendo assim, a energia do fóton emitido não será a mesma do fóton absorvido. Em consequência da perda de energia, o átomo emite um fóton de maior comprimento de onda, ou menor energia, que o fóton absorvido. Esse processo é denominado de Deslocamento Stokes ou downconversion, usualmente empregado em dispositivos de conversão de luz ultravioleta em luz na região do visível. ${ }^{42,} 43$ O diagrama abaixo demonstra um exemplo de processo de emissão a partir dos níveis de energia de um átomo. 


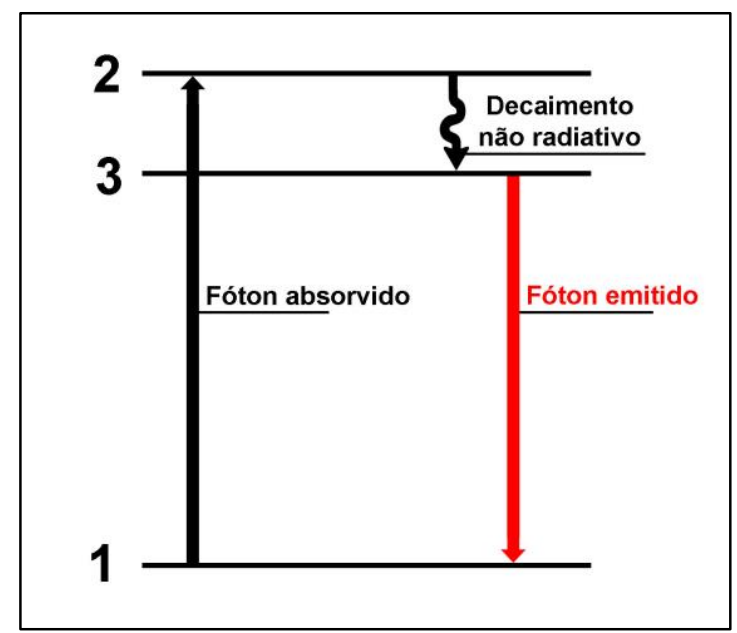

Fonte: adaptado de Solét1

Figura 15. Diagrama de energias para um delocamento Stokes;

A eficiência quântica pode ser definida pela razão entre a taxa de fótons emitida pela taxa de fótons absorvida (equação 1). Consequentemente, materiais com excesso de relaxamento não radiativo, apresentam uma diminuição na eficiência quântica. ${ }^{42,4}$

$$
\eta=\frac{\text { número de fótons emitidos }}{\text { número de fótons absorvidos }}
$$

Os fenômenos de luminescência e suas propriedades dependem intrinsecamente das características do material. Dito isso, os íons terras raras apresentam diversas peculiaridades que os tornam bons candidatos a centros de emissão ou materiais luminescentes.

\subsubsection{Terras Raras}

O estudo dos elementos chamados de "terras raras" teve início no ano de 1787 com a descoberta do Ítrio pelo pesquisador Carl Axel Arrhenius. Atualmente, são classificados como terras raras os elementos do grupo dos Lantanídeos em conjunto com os elementos Ítrio e Escândio. ${ }^{45}$ Devido a sua presença predominante na forma de óxidos minerais e a dificuldade na sua separação, esses elementos receberam a denominação de Terras Raras (TR). Entretanto, a abundância desses elementos muitas vezes não corresponde ao termo "raro" uma 
vez que alguns elementos, como por exemplo o Ítrio, apresentam maior abundância na crosta terrestre que o cadmio ou o mercúrio. 45,46

Os TR possuem orbitais $f$ semipreenchidos 0 que thes confere propriedades ópticas bastante peculiares. Esses elementos sofrem uma diminuição do raio atómico devido ao menor fator de blindagem dos orbitais $f$, fenômeno denominado contração lantanídica. ${ }^{47}$ Como a contribuição do campo cristalino é pequena para os orbitais $f$, a quantidade de ligantes suportados pelos lantanóides é determinada por efeito estéril e tamanho do metal, diferente dos elementos do grupo $d$. Consequentemente, é possível encontrar números de coordenação maiores que seis. ${ }^{48}$

O estado de oxidação comumente encontrado para esses elementos é o +3. 46, 47, 49 A configuração eletrônica dos TR leva em consideração a presença de orbitais $f$ disponíveis, entretanto, o La possui um orbital $5 \mathrm{~d}$ com menor energia que o $4 \mathrm{f}$ implicando em uma configuração eletrônica $[\mathrm{Xe}] 6 \mathrm{~s}^{2} 5 \mathrm{~d}^{1}$. Prosseguindo nos elementos do grupo, mais prótons são adicionados aos núcleos e o orbital $4 f$ contrai rapidamente e se torna mais estável que o $5 \mathrm{~d}$. Entre os elementos $\mathrm{Nd}$ e Eu, a configuração eletrônica é representada por [Xe] $6 s^{2} 4 f^{n}(n=4-7)$. Depois do Eu, o orbital $4 \mathrm{f}$ está parcialmente preenchido e o próximo elétron é adicionado no orbital 5d, como no caso do $\mathrm{Gd}[\mathrm{Xe}] 6 \mathrm{~s}^{2} 5 \mathrm{~d}^{1} 4 \mathrm{f}^{7}$. A partir do Tb, entretanto, $\mathrm{O}$ orbital $f$ passa a ser de menor energia novamente e a configuração é definida por $[X e] 6 s^{2} 4 f^{n}(n=10-14) .48,50$

Tabela 3 relaciona os principais elementos TR com suas respectivas configurações eletrônicas em diferentes estados de oxidação.

Tabela 3. Principais elementos Terras raras e suas configurações eletrônicas;

\begin{tabular}{|c|c|c|c|c|}
\hline Elemento & Configuração do átomo & $T R^{3+}$ & $T R^{4+}$ & $T R^{2+}$ \\
\hline La & {$[\mathrm{Xe}] 5 d^{1} 6 s^{2}$} & {$[\mathrm{Xe}]$} & & \\
\hline $\operatorname{Pr}$ & {$[X e] 4 f^{3} 6 s^{2}$} & {$[\mathrm{Xe}] 4 \mathrm{f}^{2}$} & {$[\mathrm{Xe}] 4 \mathrm{f}^{1}$} & \\
\hline$N d$ & {$[X e] 4 f^{4} 6 s^{2}$} & {$[\mathrm{Xe}] 4 \mathrm{f}^{3}$} & {$[\mathrm{Xe}] 4 \mathrm{f}^{2}$} & {$[\mathrm{Xe}] 4 \mathrm{f}^{4}$} \\
\hline$S m$ & {$[X e] 4 f^{6} 6 s^{2}$} & {$[\mathrm{Xe}] 4 \mathrm{f}^{5}$} & & {$[\mathrm{Xe}] 4 \mathrm{f}^{6}$} \\
\hline$E u$ & {$[\mathrm{Xe}] 4 \mathrm{f}^{7} 6 \mathrm{~s}^{2}$} & {$[\mathrm{Xe}] 4 \mathrm{f}^{6}$} & & {$[\mathrm{Xe}] 4 \mathrm{f}^{7}$} \\
\hline$G d$ & {$[X e] 4 f^{7} 5 d^{1} 6 s^{2}$} & {$[\mathrm{Xe}] 4 \mathrm{f}^{7}$} & & \\
\hline
\end{tabular}




\begin{tabular}{l|cccc}
$T b$ & {$[X e] 4 f^{9} 6 s^{2}$} & {$[X e] 4 f^{8}$} & {$[X e] 4 f^{7}$} & \\
$D y$ & {$[X e] 4 f^{10} 6 s^{2}$} & {$[X e] 4 f^{9}$} & {$[X e] 4 f^{8}$} & {$[X e] 4 f^{10}$} \\
$H o$ & {$[X e] 4 f^{11} 6 s^{2}$} & {$[X e] 4 f^{10}$} & & \\
$E r$ & {$[X e] 4 f^{12} 6 s^{2}$} & {$[X e] 4 f^{11}$} & \\
$T m$ & {$[X e] 4 f^{13} 6 s^{2}$} & {$[X e] 4 f^{12}$} & {$[X e] 4 f^{13}$} \\
$Y b$ & {$[X e] 4 f^{14} 6 s^{2}$} & {$[X e] 4 f^{13}$} & {$[X e] 4 f^{14}$}
\end{tabular}

A propriedades acarretadas pela presença dos orbitais $f$ semipreenchidos são de extrema importância nas propriedades ópticas de materiais que contenham íons TR. ${ }^{51}$ Segundo a regra de Laporte, transições de mesma paridade são proibidas, como no casos das transições f-f. ${ }^{22}$ Entretanto, devido a uma pequena contribuição do campo cristalino dos orbitais $5 d$ quando o metal ocupa um sítio cristalográfico sem simetria de inversão, ocorre uma mudança de paridade significativa para haver um relaxamento da regra de Laporte. ${ }^{52,53,54}$

É bem conhecido que os íons $\mathrm{TR}^{3+}$ não apresentam um alto coeficiente de absorção e, consequentemente, é de se esperar que os compostos contendo íons $\mathrm{TR}^{3+}$ apresentem baixa eficiência quântica quando excitados diretamente. ${ }^{55}$ Esta baixa eficiência quântica se traduz em uma baixa intensidade de luminescência e dificuldade de visualização do material a olho nu. ${ }^{41}$ Para intensificar as propriedades luminescentes dos compostos contendo íons TR, é possível coordena-los a ligantes cromóforos ou inseri-los em matrizes com altos coeficientes de absorção. Desta forma, é possível aumentar a eficiência de conversão de luz através da transferência de energia entre o ligante e o centro ativo (íon do metal). Este fenômeno é denominado efeito antena. ${ }^{44,55}$

No efeito antena, quando um ligante (sensibilizador) absorve radiação acontece uma transição eletrônica interna do estado singlete fundamental para o estado singlete excitado do próprio ligante. Após um decaimento não radioativo, a energia é transferida para o centro metálico através de um estado triplete excitado, que culmina em um decaimento radiativo com a emissão de um fóton em um comprimento de onda maior, ou seja, menor energia que o fóton absorvido. ${ }^{56}$ Quanto menor a diferença de energia entre os estados excitados do ligante e do estado tripleto do íon metálico, melhor será a eficiência quântica do 
material. ${ }^{44}$ A Figura 16 apresenta um diagrama esquemático de uma transferência de energia em compostos luminescentes contendo íons lantanídeos, configurando o efeito antena.

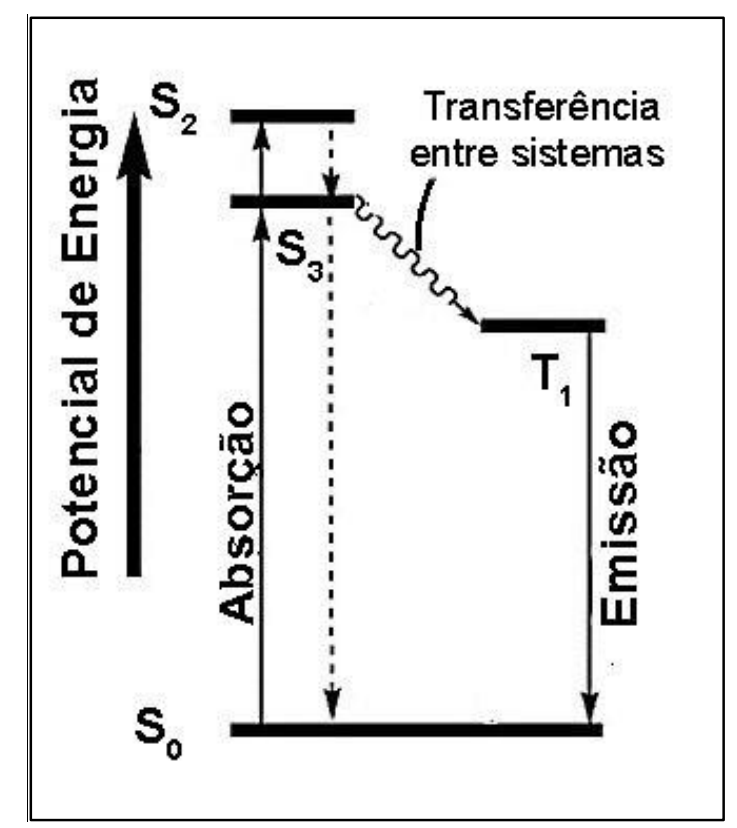

Fonte: Adaptado de Velloso et al..$^{57}$

Figura 16. Diagrama esquemático de um exemplo de efeito antena. Nesse caso, $\mathrm{S}$ representa os estados singlete enquanto $\mathrm{T}$ representa o estado triplete;

Atrelado a esses conceitos, os fósforos podem ser caracterizados como materiais que possuem um centro ativo luminescente em uma matriz inerte, agindo como sensibilizador e amplificando a luminescência do composto. ${ }^{52} \mathrm{~A}$ origem da palavra "fósforo" para designar uma substância que emita luz surgiu no século XVII designada pelo alquimista italiano Vincentinus Casciarolo. ${ }^{58}$ Etimologicamente, a palavra fósforo é oriunda do grego e significa "portador da luz". Atualmente, este termo é empregado a materiais, orgânicos ou inorgânicos, capazes de converter certos tipos de energia em radiação eletromagnética, geralmente dentro da região do visível no espectro. ${ }^{58}$ Os fósforos apresentam uma série de aplicações dentro da indústria moderna. Variando a forma de excitação (como raios catódicos, ultravioleta, raio $X$, corrente elétrica, etc) e dependendo da cor emitida (azul, verde, branco, vermelho, etc) os fósforos estão relacionados com a produção de diodos emissores de luz (LEDs), tubos de televisão, luminárias, telas de radiografia, entre outros. 
Dentro da categoria de fósforos, alguns materiais apresentam destaque por suas características relacionadas a efeitos luminescentes. Entre esses, destacamse os materiais cerâmicos e baseados em Metal Organic-Frameworks (MOFs).

\subsubsection{Cerâmicas e MOFs: candidatos a marcadores luminescentes}

\subsubsection{Cerâmicas}

Cerâmica é classe de matérias cristalinos conhecido por suas características físico-químicas peculiares. Segundo Carter et al.59, esses compostos podem ser definidos como uma mistura de elementos que formam um sólido inorgânico não-metálico, com ligações variando entre covalente, iônica e, algumas vezes, metálica. A maioria dos compostos cerâmicos são constituídos por metais ligados a não-metais, frequentemente associados com óxidos, nitretos e carbonetos. Outra definição sugere que material cerâmico é qualquer composto sólido que não seja um metal, plástico ou derivado de organismos vivos. ${ }^{59}$

As cerâmicas apresentam um amplo espectro de características que são amplamente utilizadas na indústria. Entre algumas características podemos destacar: 60

- Baixa condutividade elétrica;

- Baixa condutividade térmica;

- Baixa densidade;

- Resistência a altas temperaturas e pressão;

- Resistência a corrosão;

- Propriedades físicas específicas (óticas, elétricas, magnéticas).

A dopagem de cerâmicas com íons TR, dependendo da matriz formada, pode agir como fósforo de diversos casos devido a possibilidade de sensibilização, propiciada pelo efeito antena, já discutido anteriormente. Esta dopagem também acarreta um aumento na eficiência quântica na medida em que o tamanho das partículas são reduzidas. Esses fatores são determinados pelo tratamento e rota sintética utilizada para a produção das cerâmicas. 


\subsubsection{Metal Organic-Frameworks}

Na última década, uma nova classe de materiais tem chamado a atenção devido a vasta área de aplicabilidade e possibilidades. Denominadas de Redes de Coordenação, Polímeros de Coordenação ou Metal Organic-Frameworks (MOFs), foram identificadas no início da década de 90 e possuem um número crescente de novos materiais sendo desenvolvidos e publicados anualmente. As MOFs podem ser definidas como sólidos supramoleculares formados por ligantes orgânicos unidos a metais formando estruturas bidimensionais ou tridimensionais, constituindo uma substância de composição altamente cristalina. Desta maneira, as propriedades físico-químicas e estruturais das MOF's são dependentes dos íons metálicos e ligantes utilizados, bem como das condições de sínteses aplicados ao sistema, como pH, temperatura, pressão, concentração, tipos de ligante, entre outros. ${ }^{54,61,62,63}$

Entre as propriedades conhecidas das MOFs, destacam-se a grande área superficial e ajustabilidade nos tamanhos dos poros. Com isso, algumas das principais áreas de atuação das MOFs são as de adsorção de gases e catálise. A Figura 17 demonstra sucintamente a polimerização para formação das redes de coordenação. ${ }^{64}$

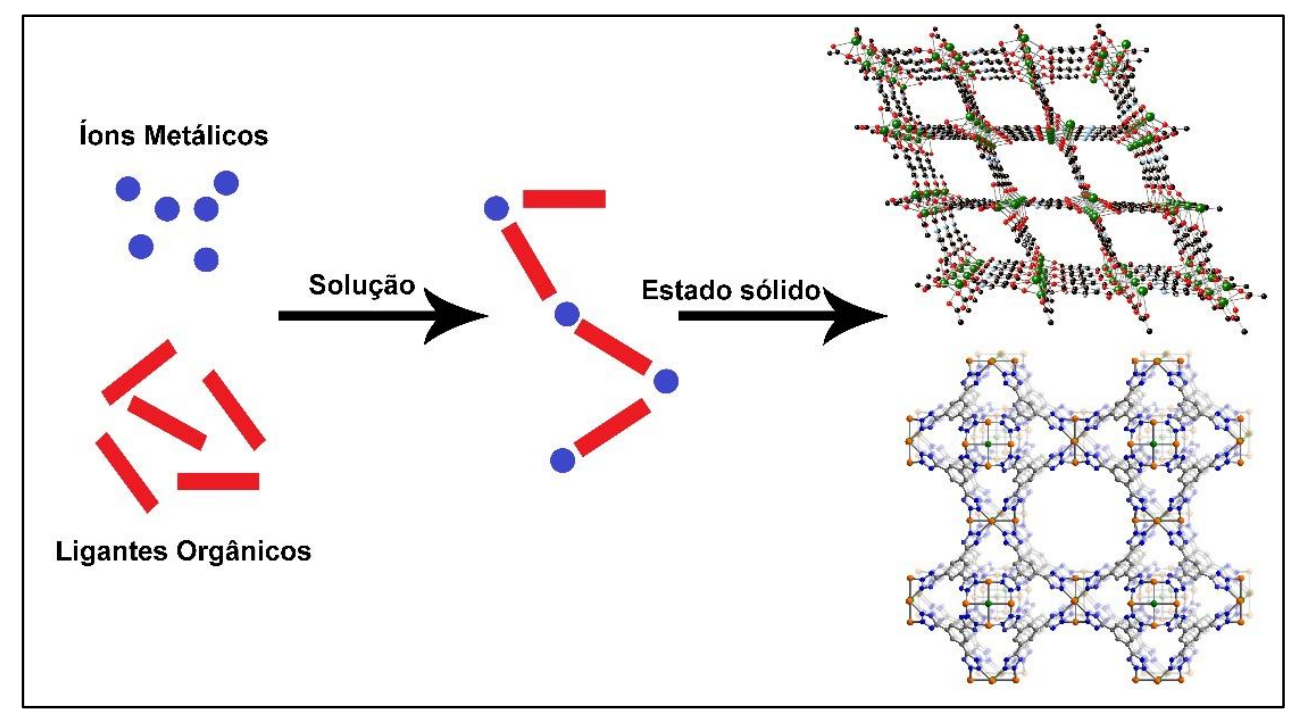

Fonte: Adaptado de Robin et al. ${ }^{64}$

Figura 17. Desenho esquemático de formação das MOFs; 
Entre a gama de aplicações para as MOFs, a capacidade de armazenamento e adsorção de gases é uma das mais importantes para a indústria, empregada no transporte e adsorção de gases como metano, hidrogênio ou nitrogênio. Manipulando o tamanho dos poros é possível tornar o material seletivo para um gás específico. Os principais mecanismos para seletividade em MOFs é o princípio de interação com superfícies e exclusão por tamanho, também conhecido como efeito de peneira molecular (molecular sieving effect). ${ }^{65,66}$

Como a estruturas físico-químicas das MOF's são inevitavelmente dependentes dos parâmetros de síntese, se faz necessário um método capaz de formar cristais homogêneos e, preferencialmente, simples e de baixo custo. Neste contexto, os método mais empregado para a síntese das MOF's é o hidrotermal ou solvotermal. Em ambos, utiliza-se um recipiente fechado hermeticamente (como mostra a Figura 18) colocado em temperaturas acima de $100^{\circ} \mathrm{C}$. Em condições hidrotermais, a solubilidade das partículas é aumentado e a cristalização pode ocorrer a partir de processos simultâneos de redissolução e reprecipitação. ${ }^{67,68}$

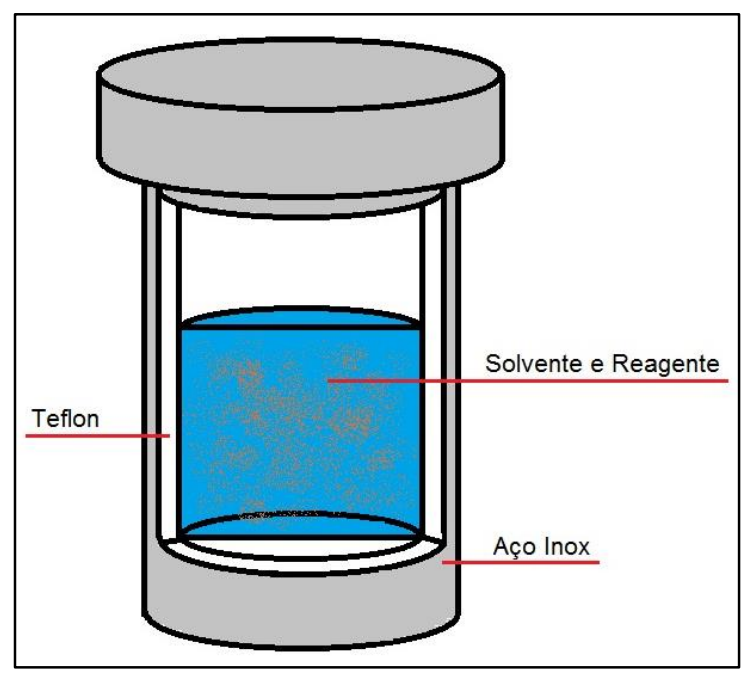

Figura 18. Esquema de reator para sínteses hidrotermais;

Além disso, as propriedades luminescentes das MOFs vem sendo aprimoradas nos últimos anos. O primeiro relato de características luminescentes nestes materiais foi em 2002 e revelou um grande potencial na química de materiais. Dopadas com terras raras, por exemplo, estes compostos podem atuar 
como sensitizadores em processos de absorção/emissão, amplificando os fenômenos de efeito antena e aumentando o rendimento quântico. ${ }^{69}$ 


\section{REVISÃO DA LITERATURA}

No contexto forense, o uso de marcadores luminescentes com forma de se obter informações relativas a um ato criminoso vem ganhando força. Existem exemplos na literatura do uso de marcadores luminescentes tanto na marcação de explosivos quanto na marcação de munições.

\subsection{Marcadores Luminescentes para Munições}

As munições de armas de fogo, convencionalmente, são constituídas de quatro partes: 53,70

- Capsula de espoletamento ou primer. pequeno estojo onde se encontra um explosivo primário responsável pela iniciação da carga de projeção;

- Carga de projeção: constituído de um propelente (classe de explosivos utilizados na propulsão de foguetes, projéteis, entre outros) em geral, constituído de pólvora e responsável pela propulsão do projétil;

- Projétil: componente que é expelido pelo gases provenientes da deflagração da pólvora; e

- Estojo: peça metálica que acomoda constituintes da munição.

Após a deflagração de uma arma de fogo, a carga de projeção e o primer podem deixar traços químicos ou resíduos de seus componentes nos braços, mãos, roupas, cabelos, etc, do usuário da arma. Esses resíduos de tiro são conhecidos como GRS (gunshot residue) e são usados na investigação de crimes cometidos com armas de fogo. A composição do GSR pode variar de acordo com a munição e arma usada, entretanto para fins forenses considera-se como GSR partículas esferoides compostas simultaneamente por $\mathrm{Sb}, \mathrm{Ba}$ e $\mathrm{Pb}$. 53, 71

Entretanto, devido à elevada toxicidade dos metais usados no primer, foram desenvolvidas munições sem metais pesados, chamada de munição limpa ou ambiental. ${ }^{70}$. Como consequência, estas munições produzem resíduos sem composição química definida e portanto torna-se impossível caracterizar o GSR e a identificação de suspeitos de uso de armas de fogo. 
Com o intuito de sanar estes problemas, Weber e colaboradores ${ }^{71}$ vem se dedicando ao desenvolvimento de marcadores luminescentes para munições. Nesse caso, os marcadores são adicionados ao propelente das munições e, após os disparos, os resíduos de tiro contendo os marcadores são depositados no corpo do atirador, na arma, no alvo ou vítima e nos arredores do local do disparo. Devido as propriedades luminescentes dos marcadores dopados com TR, os resíduos podem ser visualizados com o auxílio de lâmpadas UV, fornecendo evidências para os responsáveis, como mostra a Figura $19 .{ }^{71}$ Estes resíduos podem ser facilmente coletados e submetidos a análises complementares para caracterizar de forma inequívoca o GSR (ex. MEV-EDS, VSC, Raman, etc). Assim, o processo de identificação do GSR é simplificado e torna-se compatível com a rotina policial.

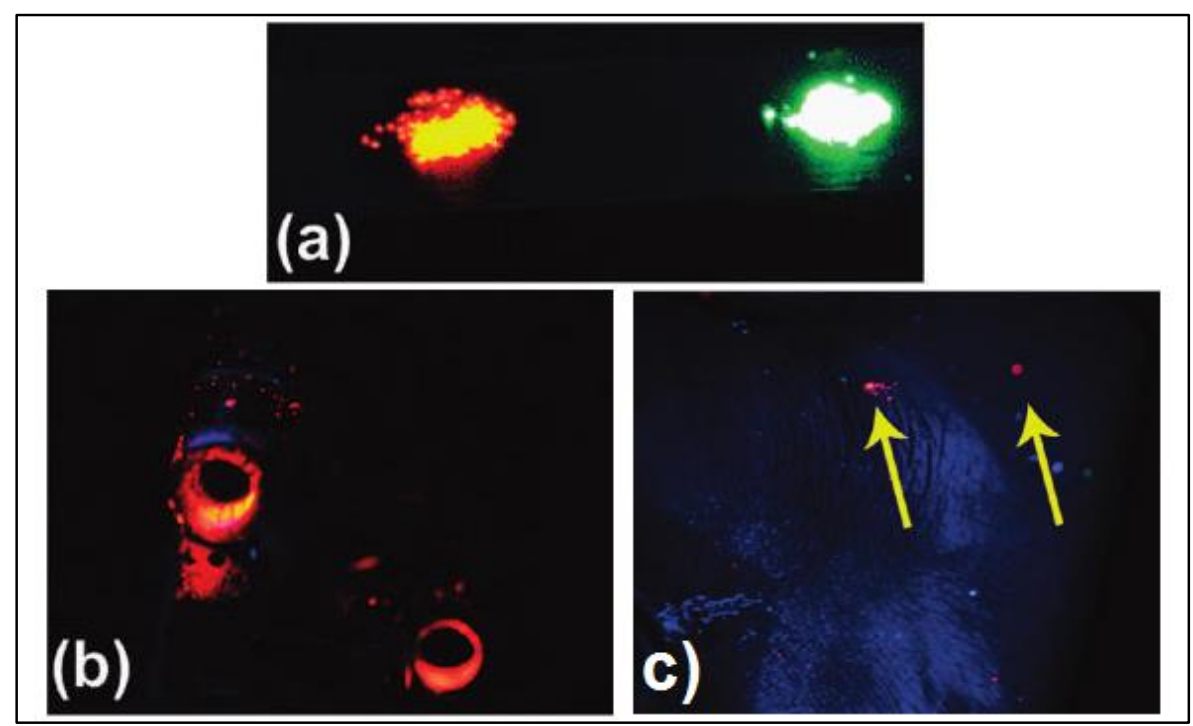

Fonte: Weber et al. ${ }^{71}$

Figura 19. a) Imagem dos marcadores luminescentes sob luz UV; b) Arma após o disparo de munição contendo o marcador; c) resíduos de marcadores na mão do efetuador do disparo;

O trabalho de Weber et al..$^{71}$ obtive sucesso na marcação de munições usando marcadores a base de MOFs. De maneira similar Lucena et al. ${ }^{72}$ desenvolveram marcadores luminescentes para GRS a base de compostos cerâmicos dopados com TR $\left(\mathrm{ZnAl}_{1,95} \mathrm{Ln}_{0,05} \mathrm{O}_{4}, \mathrm{Ln}=\mathrm{Tb}^{3+}\right.$ ou $\left.\mathrm{Eu}^{3+}\right)$. Assim como as MOFs, os materiais cerâmicos apresentam propriedades que se adequam as necessidades da pesquisa, mostrando estabilidade térmica e química suficientes para serem detectados após a deflagração da munição, além de uma alta 
luminescência visível favorecida pelo efeito antena da matriz. Um dos pontos principais para o desenvolvimento de marcadores com composições diferentes, de acordo com o trabalho de Lucena, é o desenvolvimento de um sistema de codificação química para cada tipo de munição, possibilitando obter diferentes informações dos marcadores como tipo de munição, fabricante, lote ou data de uso, etc. ${ }^{72}$

\subsection{Marcadores Luminescentes para Explosivos}

Como anteriormente relatado no item 3.1.7, uma forma eficaz de detecção de voláteis de explosivos é pela diminuição de bandas de emissão em compostos. Nessa perspectiva, Lan e colaboradores ${ }^{73}$ foram os primeiros a desenvolver um método de detecção de voláteis de explosivos (DMNB e Dinitrotolueno - DNT) utilizando MOFs luminescentes. A MOF microporosa [ $\left.\mathrm{Zn}_{2}(\mathrm{bpdc})_{2}(\mathrm{bpee})\right]$ (bpdc=4,4'-biphenyldicarboxylate; bpee=1,2-bipyridylethene), com emissão em $420 \mathrm{~nm}$, foi capaz de detectar seletivamente os vapores de DNT e DMNB. Após a captação dos resíduos pelas estruturas da rede, verifica-se um abafamento (quenching) na intensidade dos picos de emissão acompanhados de um deslocamento batocrômico, indicando a presença de explosivos no local, como mostram os gráficos e os espectros dispostos nas imagens abaixo.

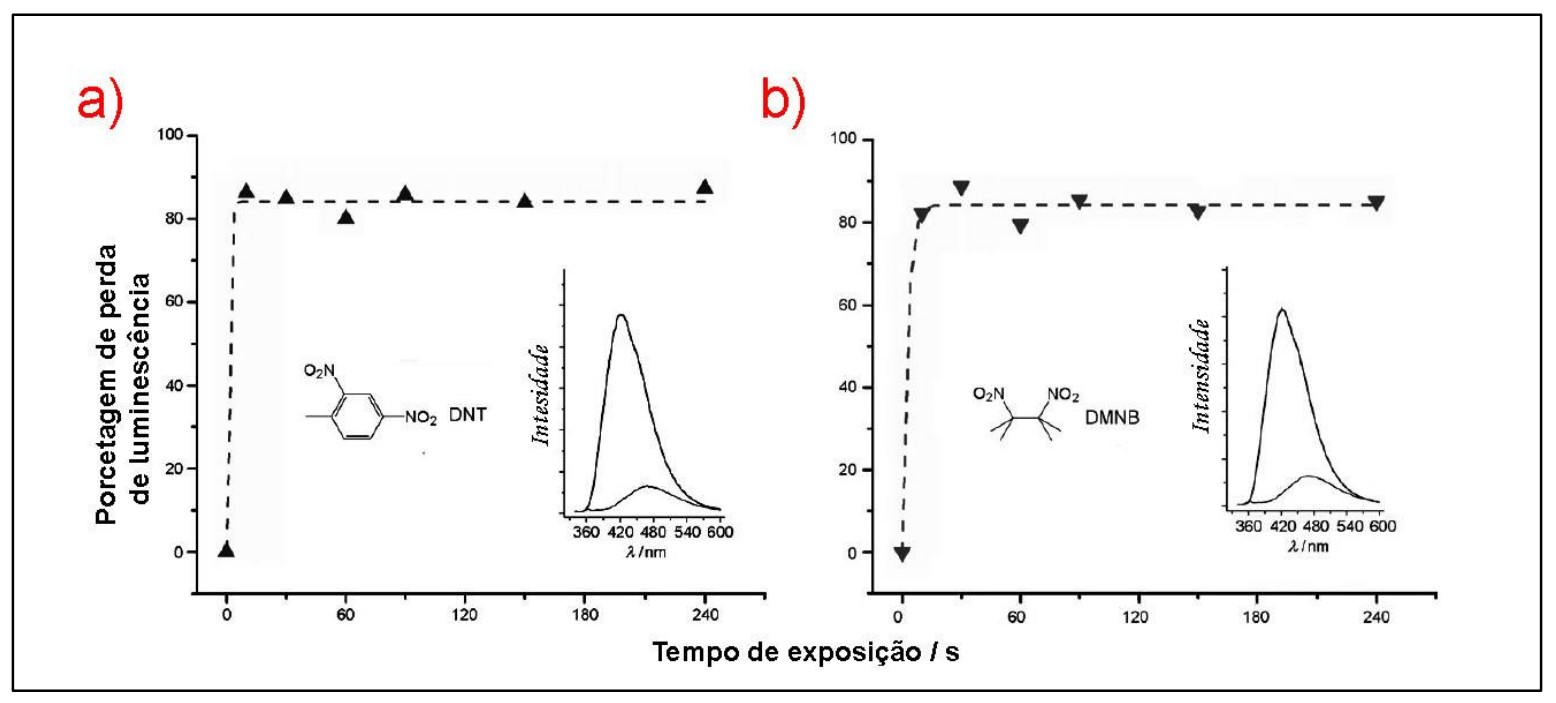

Fonte: Adaptado de Lan et al. ${ }^{73}$ 
Figura 20. Diminuição de luminescência (quenching) do marcador [ $\left.Z \mathrm{n}_{2}(\mathrm{bpdc})_{2}(\mathrm{bpee})\right]$ em contato com a) DNT

(Dinitrotolueno) e b) DMNB (2,3-dimetil-2,3-dinitrobutano) e seus respectivos espectros de fluorescôncia antes e depois;

Em trabalho mais recente, Gole et al. ${ }^{74}$ aprofundou a pesquisa desenvolvendo novos materiais sensores baseados em MOF's para atuar na detecção de explosivos. As principais vantagens na utilização de químiossensores luminescentes elucidadas no trabalho é a alta sensibilidade à presença de traços de explosivos e a capacidade de utilizar dispositivos miniaturizados para a detecção. A partir do método de Gole, o espectro de possibilidade de detecção foi ampliada como mostra o gráfico disposto na Figura 21.

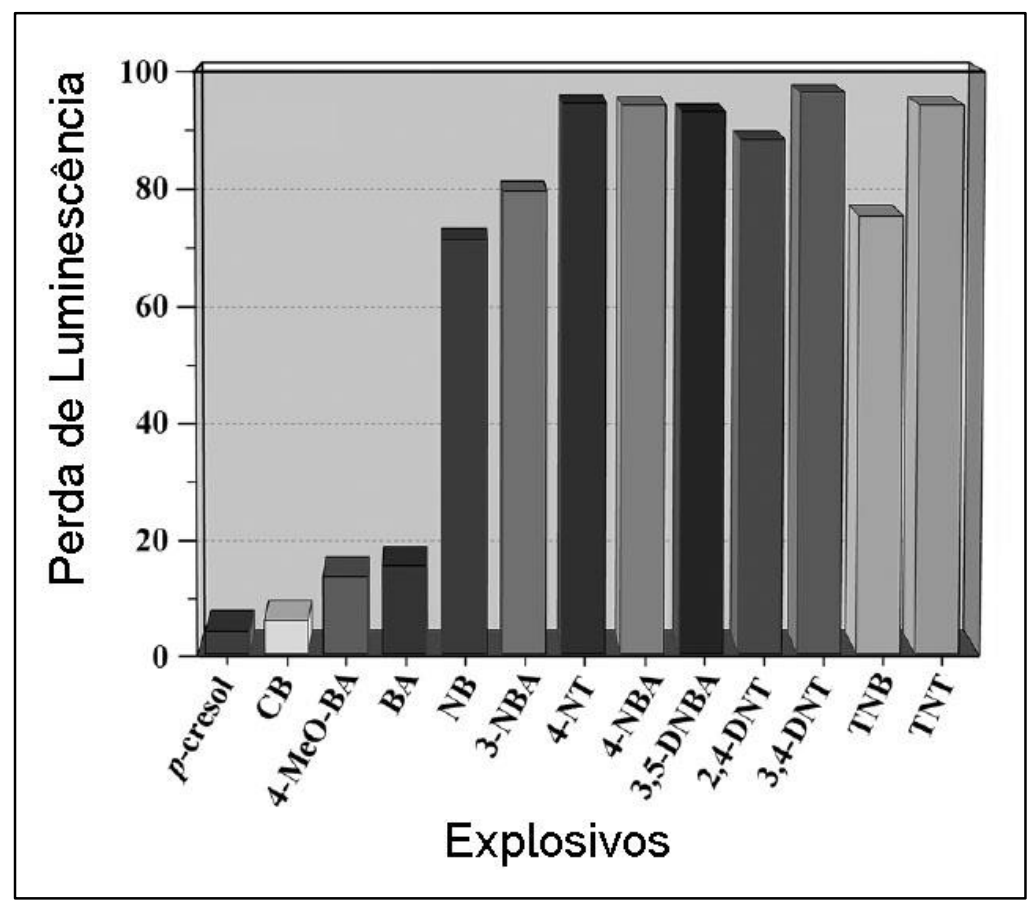

Fonte: Adaptado de Gole et al. ${ }^{74}$

Figura 21. Perda de luminescência em função do tipo de explosivo em contato com um dos sensores químicos baseados em MOF propostos por Gole et al.;

No tocante a identificação de resíduos pós-explosão, uma metodologia foi proposta por Hutchinson et al. ${ }^{75}$ Neste caso é possível obter informações de resíduos inorgânicos de explosivos após uma detonação por condutimetria acoplado com a um detector de capacitância. Separando os ânions e os cátions nos resíduos de explosão a partir de cromatógrafo portátil, a metodologia permite a detecção de traços de metais em resíduos de explosão em aproximadamente 7 
minutos. Esse procedimento pode ser utilizado, principalmente, para a determinação do tipo de explosivo usado em um tempo de uso hábil. Entretanto, percebe-se que a metodologia exige controles rigorosos de parâmetros analíticos (como $\mathrm{pH}$ ou calibragem do equipamento). Essa metodologia também não pode ser considerada determinante ou independente para obter evidências devido à semelhança entre diversos explosivos, dificultando a identificação. Todavia, essa metodologia possui potencial se os explosivos forem marcados com elementos específicos ou se ela for usada de forma combinada a outros métodos de análise.

Entretanto, dentre os trabalhos da literatura relativos a identificação de resíduos pós-explosão, destaca-se o trabalho de Ryan e colaboradores $^{36}$, que data de 1973. Os autores utilizam marcadores baseados em óxidos inorgânicos como forma de codificar e identificar resíduos de pós-explosão. A composição química desses marcadores é constituída de duas partes:

- A primeira é definida como "spotting", componente responsável por emitir luminescência visível sob luz UV. Utilizam-se óxidos de terras raras como emissores, como por exemplo: $\mathrm{Y}_{2} \mathrm{O}_{3}: \mathrm{Gd} ; \mathrm{Y}_{2} \mathrm{O}_{3}: \mathrm{Er}$; $\mathrm{La}_{2} \mathrm{O}_{3}: \mathrm{Pr} ; \mathrm{Y}_{2} \mathrm{O}_{3}: \mathrm{Ho}$, entre outros;

- A segunda parte é denominada de "Coding", e a sua função é criar um código único para o marcador. Esse componente utiliza óxidos de metais de transição, como: $\mathrm{CaWO}_{4} ; \mathrm{Zn}_{2} \mathrm{SiO}_{4}: \mathrm{Mn}$; Halofosfatos, etc;

Com esses dois componentes formando o marcador, eles são misturados em uma solução aquosa de silicato de potássio e deixados em repouso para evaporar. Posteriormente, o produto é aquecido a $80{ }^{\circ} \mathrm{C}$ e 0 resultado são aglomerados de tamanho entre $0,5 \mathrm{~mm}$ e $0,7 \mathrm{~mm}$ de diâmetro. Os metais de cada componente podem ser escolhidos de forma a gerar um código único de identificação do local de manufatura, data de fabricação ou tipo de explosivo. A tabela abaixo mostra alguns exemplos de códigos criados a partir dos íons de metais TR (que determina o tipo de explosivo - Tabela 4) e íons de metais de transição (que determinam o mês de fabricação - Tabela 5). 
Tabela 4. Exemplos de códigos para tipos de explosivos possíveis para os marcadores luminescentes proposto por Ryan et al.;

\begin{tabular}{|c|c|c|c|c|c|c|c|c|c|}
\hline Tipo de explosivo & 1 & 2 & 3 & 4 & 5 & 6 & 7 & 8 & 9 \\
\hline \multirow[b]{2}{*}{ Código usado } & $\mathrm{Pr}^{3+}$ & $\mathrm{Nd}^{3+}$ & $\mathrm{Sm}^{3+}$ & $\mathrm{Eu}^{3+}$ & $\mathrm{Gd}^{3+}$ & $\mathrm{Pr}^{3+}$ & $\mathrm{Pr}^{3+}$ & $\mathrm{Pr}^{3+}$ & $\mathrm{Nd}^{3+}$ \\
\hline & 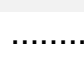 & & & & & $\mathrm{Nd}^{3+}$ & $\mathrm{Sm}^{3+}$ & $\mathrm{Eu}^{3+}$ & $\mathrm{Gd}^{3+}$ \\
\hline
\end{tabular}

Tabela 5. Exemplos de códigos para tipos de explosivos para os marcadores luminescentes propostos por Ryan et al;

\begin{tabular}{l|ccccccc} 
Mês de fabricação & 1 & 2 & 3 & 4 & 5 & 6 \\
\hline \multirow{3}{*}{ Código usado } & $\mathrm{Cr}^{3+}$ & $\mathrm{Mn}^{4+}$ & $\mathrm{UO}_{2}{ }^{2+}$ & $\mathrm{Cr}^{3+}$ & $\mathrm{Cr}^{3+}$ & $\ldots$ \\
& $\ldots \ldots \ldots \ldots \ldots \ldots \ldots \ldots \ldots \ldots \ldots$ & $\mathrm{Mn}^{4+}$ & $\mathrm{UO}_{2}{ }^{+2}$ & $\ldots$ \\
\end{tabular}

Após a detonação, os resíduos contendo os marcadores podem ser visualizados com o auxílio de lâmpadas UV (dependendo do íon presente) e coletados para análises de composição e identificação do código. Um ponto questionável na metodologia proposta é o uso de metais de transição em sua composição. Metais de transição são comumente encontrados nas cenas de crimes e podem ser responsáveis por contaminações ocupacionais nas amostras de resíduos de explosão, comprometendo a inequivocabilidade da metodologia.

Outras questões foram levantadas a respeito do efeito dos marcadores na presença de explosivos. Segundo a patente de Heytmeijer et al. ${ }^{76}$, o acréscimo dos aglomerados de marcadores aos explosivos causa um aumento na sensibilidade a fricção e impacto do mesmo, majorando os riscos de segurança dos usuários do material. Visando diminuir os efeitos deletérios dos marcadores de Ryan et al., o trabalho de Heytmeijer et al. propõe o recobrimento das partículas de marcadores com um revestimento de plásticos orgânicos. Todavia, o autor sugere que essa cobertura ocasiona o acúmulo de cargas eletrostáticas na superfície dos marcadores plastificados, que podem atrair corpos estranhos para o material e/ou causar descargas elétricas. Para contornar essa situação, os marcadores são recobertos com mais uma camada de cera de Carnaúba, que evita a formação de cargas. O tamanho das partículas de marcador também foram otimizados para compreender o diâmetro de 250-400 $\mu \mathrm{m}$.

Outra pesquisa importante para o cenário de marcadores de pós explosão foi publicada por Krystyniak et al. ${ }^{77}$ A temperatura na qual corpos ferromagnéticos 
se tornam não-magnéticos é chamada de temperatura de Curie (Tc). ${ }^{78}$ Baseado nesse princípio, o grupo desenvolveu um marcador utilizando compostos magnéticos de ferrita, óxidos inorgânicos contendo $\left(\mathrm{Fe}_{2} \mathrm{O}_{4}\right)^{2-}$ em sua composição. Ferritas de zinco e cobalto $\left(\mathrm{Co}_{x} \mathrm{Zn}_{1,0-\mathrm{x}} \mathrm{Fe}_{2} \mathrm{O}_{4}\right.$, onde $\left.0<\mathrm{x}<1\right)$, é revestida com uma camada vítrea formando uma partícula com diâmetro entre 100 e $5000 \mu \mathrm{m}$ e posteriormente adicionados aos explosivos. Cada ferrita apresenta diferente Tc que funcionam como uma codificação para os explosivos. Após uma detonação, os marcadores podem ser coletados com o auxílio de um imã. Para determinar a composição do marcador, os resíduos coletados são submetidos a análises de magnetização em função da temperatura. O gráfico abaixo representa a análise de magnetização em função da temperatura de um marcador com pelo menos quatro componentes de ferritas.

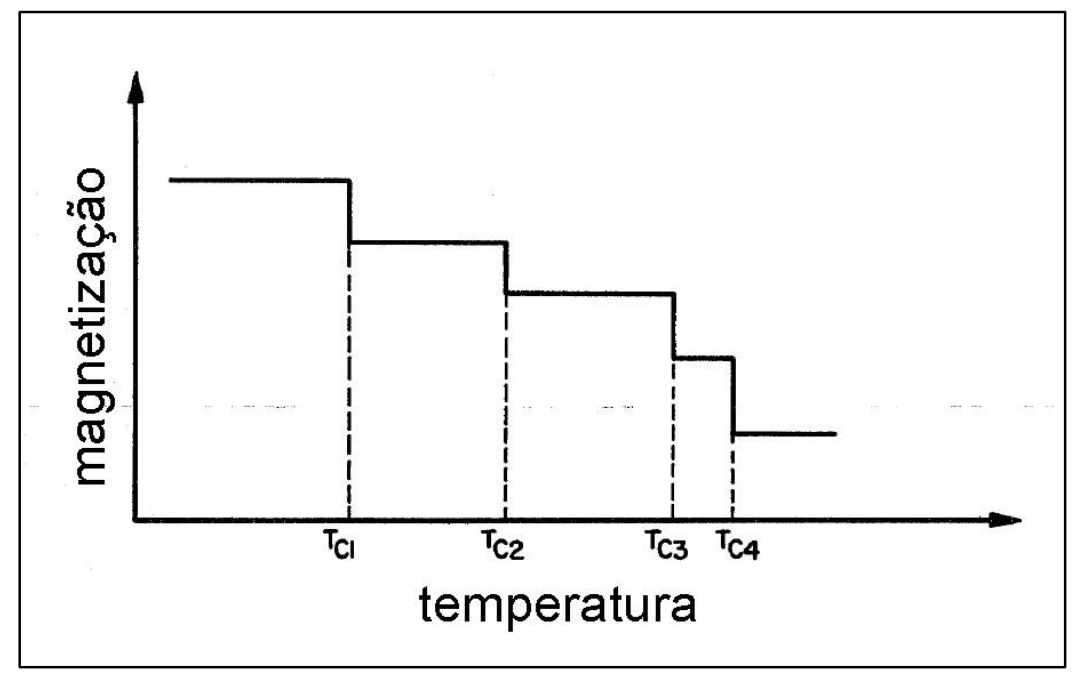

Fonte: Adaptado de Krystyniak et al. ${ }^{77}$

Figura 22. Gráfico de magnetização em função da temperatura de uma amostra de marcador contento pelo menos quatro ferritas ( $\mathrm{Tc}=$ Temperatura de Curie);

Deve-se destacar que não foi encontrado na literatura qualquer tipo de menção a MOFs como marcadores de pós-explosão, inferindo que o presente trabalho é, possivelmente, uma nova tecnologia na área de detecção e identificação de resíduos de explosivos. 


\section{PROCEDIMENTO EXPERIMENTAL}

Optou-se por utilizar dois marcadores baseados em MOFs e um baseado em cerâmica para verificar a adequação dos marcadores para uso em explosivos e fazer uma análise exploratória inicial da possibilidade do uso de marcadores em um sistema de codificação.

\subsection{SÍNTESE DOS MARCADORES BASEADOS EM MOF}

Os dois marcadores baseados em MOFs dopadas com TR foram obtidos utilizando o método de síntese com reatores hidrotermais. Para a síntese do $\left[\left(\mathrm{La}_{0.8} \mathrm{~Tb}_{0.2}\right)_{2}(\mathrm{DPA})_{3}\left(\mathrm{H}_{2} \mathrm{O}\right)_{3}\right]$, foi utilizada a rota proposta por Barreto et al. ${ }^{79}$ e para a síntese do $\left[\left(\mathrm{La}_{0.95} \mathrm{Eu}_{0.3} \mathrm{~Tb}_{0.2}\right)_{2}(\mathrm{DPA})_{3}\left(\mathrm{H}_{2} \mathrm{O}\right)_{3}\right]$ foi utilizada a rota proposta por Rover ${ }^{80}$. Para tal, utilizou-se $\mathrm{La}_{2} \mathrm{O}_{3}\left(\right.$ Aldrich $\left.^{\circledR}, 99,99 \%\right), \mathrm{Tb}\left(\mathrm{NO}_{3}\right)_{3} \cdot 5 \mathrm{H}_{2} \mathrm{O}$ obtido a partir do $\mathrm{Tb}_{4} \mathrm{O}_{7}$ (Aldrich $\left.{ }^{\circledR}, 99,9 \%\right)$; $\mathrm{Eu}_{2} \mathrm{O}_{3}$ (Aldrich ${ }^{\circledR}, 99,99 \%$ ) e 2,6-ácido piridinodicarboxílico ou $\mathrm{H}_{2} \mathrm{DPA}$ (Aldrich ${ }^{\circledR}, 99,98 \%$ ).

A Tabela 6 relaciona a quantidade, em gramas e mols, de cada reagente utilizado nas sínteses de [(La0.8Tb0.2)2(DPA $\left.)_{3}\left(\mathrm{H}_{2} \mathrm{O}\right)_{3}\right]$ e $\left[\left(\mathrm{La}_{0.95} \mathrm{Eu}_{0.3} \mathrm{~Tb}_{0.2}\right)_{2}(\mathrm{DPA})_{3}\left(\mathrm{H}_{2} \mathrm{O}\right)_{3}\right]$, neste trabalho denominados de $\mathbf{A}$ e $\mathbf{B}$, respectivamente.

Tabela 6. Relação de massas utilizadas na síntese dos marcadores baseados em MOFs;

$\begin{array}{cccc}\mathrm{La}_{2} \mathrm{O}_{3}(\mathrm{~g}) & \mathrm{Tb}\left(\mathrm{NO}_{3}\right)_{3} \cdot 5 \mathrm{H}_{2} \mathrm{O}(\mathrm{g}) & \mathrm{Eu}_{2} \mathrm{O}_{3}(\mathrm{~g}) & \mathrm{H}_{2} \mathrm{DPA}(\mathrm{g}) \\ (\mathrm{mmol}) & (\mathrm{mmol}) & (\mathrm{mmol}) & (\mathrm{mmol})\end{array}$
$\boldsymbol{A}$
0,52
0,17
1,33
$(1,62)$
$(0,40)$
0,62
0,03
$(-)$
B
$(1,90)$
$(0,08)$
0,02
1,33
$(0,06)$
$(8,02)$

Os reagentes foram adicionados a $40 \mathrm{~mL}$ de água sob agitação, que foi lentamente aquecida até $100^{\circ} \mathrm{C}$. Ao atingir essa temperatura a solução foi agitada por 15 minutos. Ao final desta etapa obteve-se uma suspensão branca e opaca. Em seguida, a mistura foi transferida para um reator de teflon com capacidade para $200 \mathrm{~mL}$ hermeticamente fechado por uma camisa de aço, o qual foi colocado em uma mufla para aquecimento por 72 horas a $170 \stackrel{\circ}{\circ}$. Após este período, 
verificou-se a formação de um precipitado branco de aspecto cristalino que foi filtrado, lavado e seco a temperatura ambiente. O precipitado foi caracterizado por espectroscopia de absorção na região do IV (FTIR), video spectral comparator (VSC), espectroscopia de fluorescência e microscopia eletrônica de varredura acoplada a espectroscopia por dispersão de energia (MEV/EDS).

Todos os equipamentos utilizados nas análises de caracterização dos marcadores luminescentes e dos resíduos de pós-explosão estão dispostos detalhadamente nos Anexos, Item 10 deste trabalho.

\subsection{SÍNTESE DO MARCADOR BASEADO EM CERÂMICA}

Para a síntese do marcador cerâmico $\mathrm{ZnAl}_{1,95} \mathrm{~Tb}_{0,05} \mathrm{O}_{4}$, utilizou-se a metodologia proposta por Lucena et al..$^{72}$ que utiliza a rota de combustão. Em um cadinho de porcelana, adicionou-se uma pequena quantidade de água seguido dos reagentes:

- $4,7 \mathrm{~g}$ de $\mathrm{Zn}\left(\mathrm{NO}_{3}\right)_{2} \cdot 6 \mathrm{H}_{2} \mathrm{O}(0,01 \mathrm{~mol})\left(\mathrm{VETEC}^{\circledR} 99,99 \%\right)$;

- $11,56 \mathrm{~g}$ de $\mathrm{Al}\left(\mathrm{NO}_{3}\right)_{3} \cdot 9 \mathrm{H}_{2} \mathrm{O}(0,03 \mathrm{~mol})\left(\mathrm{VETEC}{ }^{\circledR} 99,99 \%\right) ;$

- $0,34 \mathrm{~g}$ de $\mathrm{Tb}\left(\mathrm{NO}_{3}\right)_{3} \cdot 5 \mathrm{H}_{2} \mathrm{O}(0,79 \mathrm{mmol})$.

Após a agitação, constatou-se a formação de uma suspensão de coloração branca de aspecto gelatinoso. Posteriormente, acrescentou-se 3,79 g (0,06 mol) de ureia como combustível (VETEC ${ }^{\circledR} 99,99 \%$ ), na proporção de $1: 4 \mathrm{~mol}$ em relação ao $\mathrm{Zn}\left(\mathrm{NO}_{3}\right)_{2} \cdot 6 \mathrm{H}_{2} \mathrm{O}$. Depois da adição do combustível, o cadinho foi levado a mufla em uma temperatura de $400{ }^{\circ} \mathrm{C}$ por uma hora. Durante o aquecimento, constatou-se o aparecimento de chamas acompanhadas de uma fumaça marrom. O pó obtido na reação de combustão foi calcinado a $600{ }^{\circ} \mathrm{C}$, gerando um pó fino de cor branca. O produto final foi caracterizado por espectroscopia de absorção na região do IV (FTIR), video spectral comparator (VSC), espectroscopia de fluorescência, difração de raios-X (DRX) e microscopia eletrônica de varredura acoplado a espectroscopia por dispersão de energia (MEV/EDS). 


\subsection{INCORPORAÇÃO DOS MARCADORES AOS EXPLOSIVOS E COLETA DOS DADOS}

Por medidas de segurança, todo o processo de incorporação dos marcadores aos explosivos foi acompanhado por peritos da divisão antibombas da Polícia Federal no Instituto de Nacional Criminalística (INC). O explosivo utilizado para os testes foi o ANFO (Senatel-Magnafrag ${ }^{\circledR}$ ), fornecido pelo Departamento de Polícia Federal.

Cada amostra de explosivo utilizada corresponde a $10 \mathrm{~g}$ de ANFO, aos quais os marcadores foram adicionados em três proporções: $1 \%, 3 \%$ e $5 \%$ da massa do explosivo. A Tabela 7 resume como os explosivos contendo os marcadores, os quais foram usados nos testes, foram codificados. Os marcadores foram adicionados diretamente aos explosivos, de forma manual, utilizando luvas nitrílicas, indicadas para o manuseio à compostos orgânicos. Todo o processo de adição dos marcadores foi realizado por um responsável da Polícia Federal.

Tabela 7. Codificação dos marcadores luminescentes e suas respectivas proporções;

Proporção de 1\%

Proporção de 3\%

Proporção de 5\%

\begin{tabular}{l|lll}
\hline$\left[\left(\mathrm{La}_{0.8} \mathrm{~Tb}_{0.2}\right)_{2}(\mathrm{DPA})_{3}\left(\mathrm{H}_{2} \mathrm{O}\right)_{3}\right]$ & $\mathrm{A} 1$ & $\mathrm{~A} 3$ & $\mathrm{~A} 5$ \\
{$\left[\left(\mathrm{La}_{0.95} \mathrm{Eu}_{0.3} \mathrm{~Tb}_{0.2}\right)_{2}(\mathrm{DPA})_{3}\left(\mathrm{H}_{2} \mathrm{O}\right)_{3}\right]$} & $\mathrm{B} 1$ & $\mathrm{~B} 3$ & $\mathrm{~B} 5$ \\
$\mathrm{ZnAl} \mathrm{I}_{1,95} \mathrm{~Tb}_{0,05} \mathrm{O}_{4}$ & $\mathrm{C} 1$ & $\mathrm{C} 3$ & $\mathrm{C} 5$
\end{tabular}

Posteriormente, os explosivos marcados foram colocados em pequenos tubos plásticos de $10 \mathrm{~mL}$ e ligados a um cordel de $20 \mathrm{~cm}$ de tetranitrato de pentaeritrina, também conhecido como Nitropenta $\left(\mathrm{C}_{5} \mathrm{H}_{8} \mathrm{~N}_{4} \mathrm{O}_{12}\right)$, um explosivo secundário de maior sensibilidade. As cargas explosivas marcadas ficaram por uma semana em repouso antes da detonação com o intuito de identificar possíveis alterações nos aspectos físico-químicos das cargas, como a inatividade, aumento ou diminuição de sensibilidade, alterações de coloração. A disposição espacial das cargas explosivas são mostradas na Figura 23. 


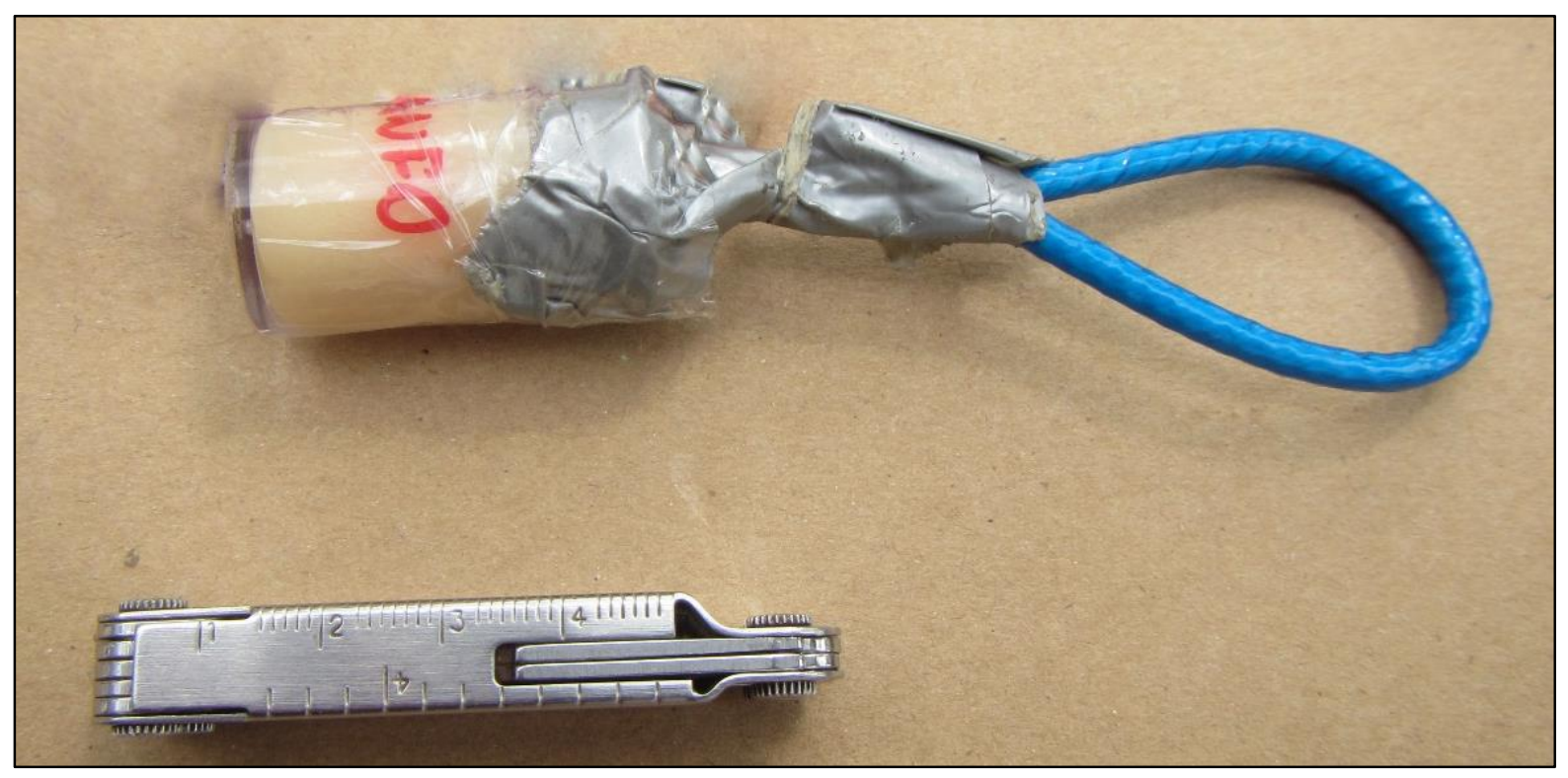

Figura 23. Disposição das cargas explosivas utilizadas nos ensaios;

Os testes de explosão foram realizados em duplicata, totalizando 18 explosões. A estrutura dos caixas eletrônicos foi simulada com gabinetes de computador. As cargas explosivas foram fixadas com fita adesiva a carcaça dos gabinetes e em seguida, os detonadores do tipo não elétrico foram anexados aos explosivos principais (como demonstrado pela Figura 24). A detonações foram realizadas no campo de testes do Instituto de Criminalística Nacional por um perito responsável, utilizando barreiras de concreto e paredes para conter os estilhaços gerados a partir da detonação e ajudar na coleta de dados em lugar arejado o suficiente para não permitir o acúmulo de resíduos no local, evitando possíveis contaminações. Os resultados das explosões foram fotografados e as carcaças dos computadores foram levadas para o laboratório para análises no INC. 


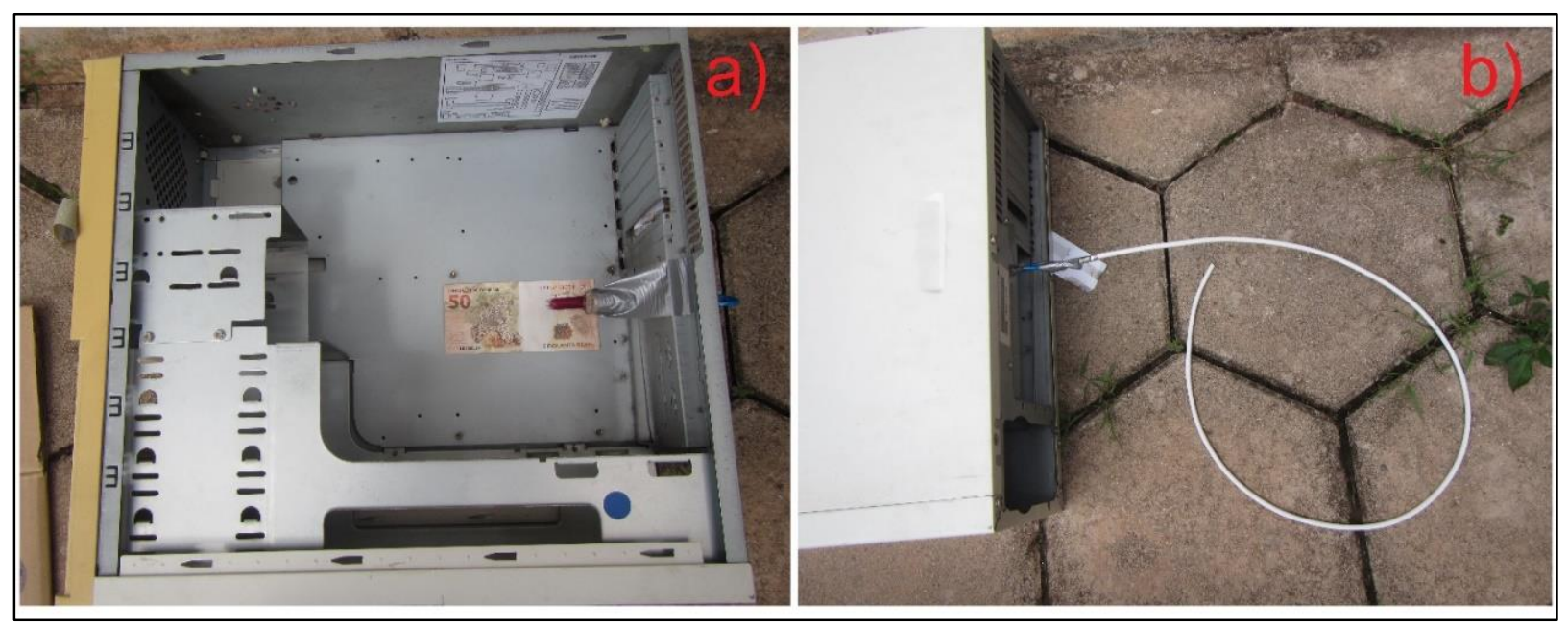

Figura 24. Disposição das cargas explosivas nos gabinetes;

Posteriormente, as amostras foram detonadas e os gabinetes contendo os resíduos de explosão, foram levados a uma sala com pouca iluminação, onde foram inspecionadas sob luz ultravioleta $(254 \mathrm{~nm})$. Utilizou-se Stubs contendo fita adesiva condutora de carbono para a coleta de resíduos de explosão, como mostra a Figura 25.

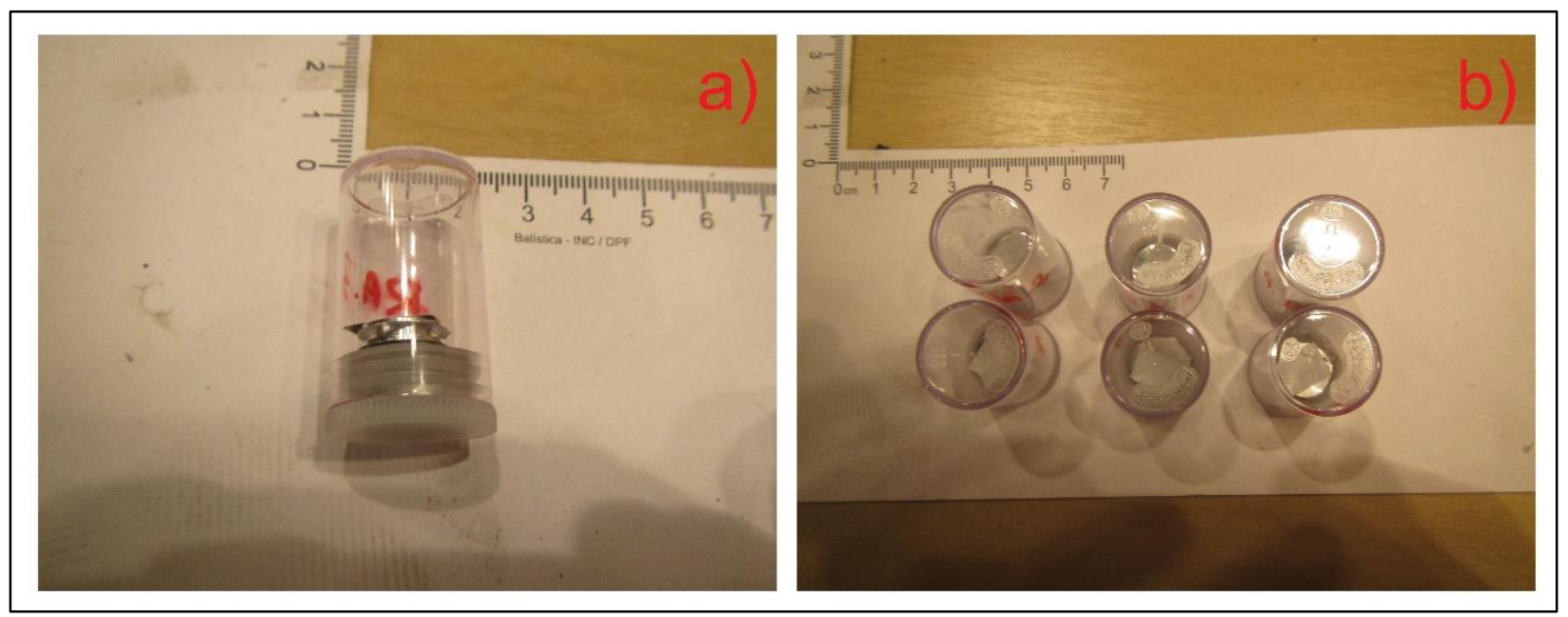

Figura 25. Exemplos de Stubs utilizados na coleta dos resíduos de explosão;

A coleta foi feita pressionando-se os Stubs por 25 vezes em locais onde foram visualizados os resíduos de marcadores com maior luminescência com o auxílio das lâmpadas UV (254 nm), como mostra a Figura 26, para aumentar as chances de coleta efetiva de resíduos de marcadores. As amostras coletadas com Stubs foram analisados por VSC, espectroscopia de fluorescência e microscopia 
eletrônica de varredura acoplado a espectroscopia por dispersão de energia (MEV/EDS).

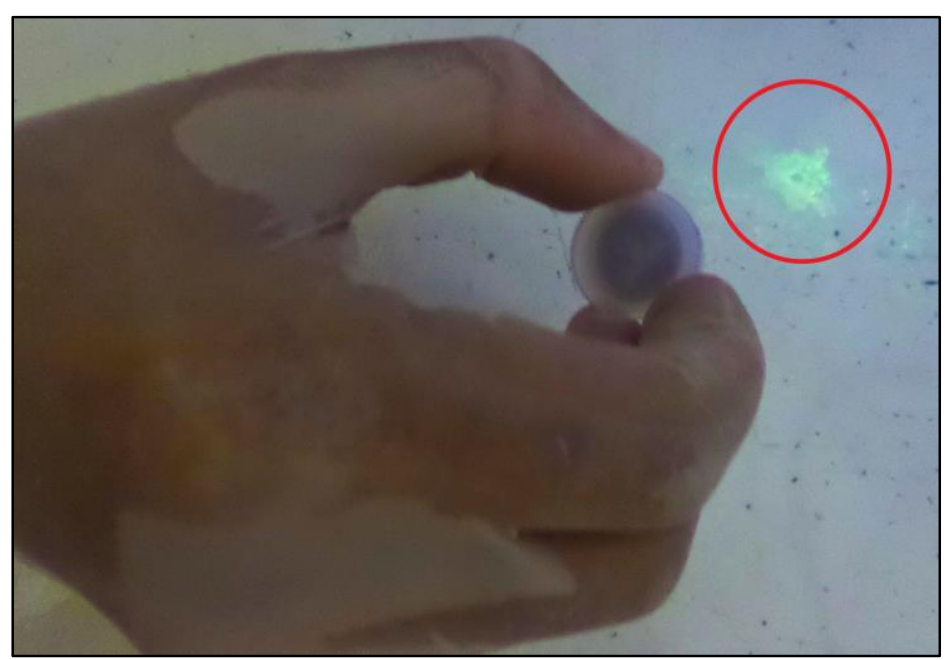

Figura 26. Coleta de resíduos de explosão com o auxílio de Stubs e lâmpadas UV (254 nm); 


\section{RESULTADOS E DISCUSSÃO}

\subsection{CARACTERIZAÇÃO DOS MARCADORES LUMINESCENTES}

Para serem usados como marcadores para resíduos de explosão, os marcadores precisam apresentar alta luminescência, permitindo a sua identificação visual. Buscando avaliar qualitativamente essa luminescência, os produtos das sínteses foram observados no VSC sob a excitação UV ( $254 \mathrm{~nm})$. A Figura 27 mostra a emissão dos marcadores. Observa-se que todos os três compostos apresentam luminescência suficiente para a sua identificação visual. Os compostos $\mathrm{A}$ e $\mathrm{C}$ apresentam uma forte emissão não região verde, típica dos íons $\mathrm{Tb}^{3+}, 54,79$ enquanto o composto $\mathrm{B}$ apresenta uma emissão no laranja, resultante da combinação das emissões dos íons $\mathrm{Tb}^{3+}$ e $\mathrm{Eu}^{3+} .80 \mathrm{~A}$ emissão observada para as três amostras estão de acordo com os dados relatados na literatura.

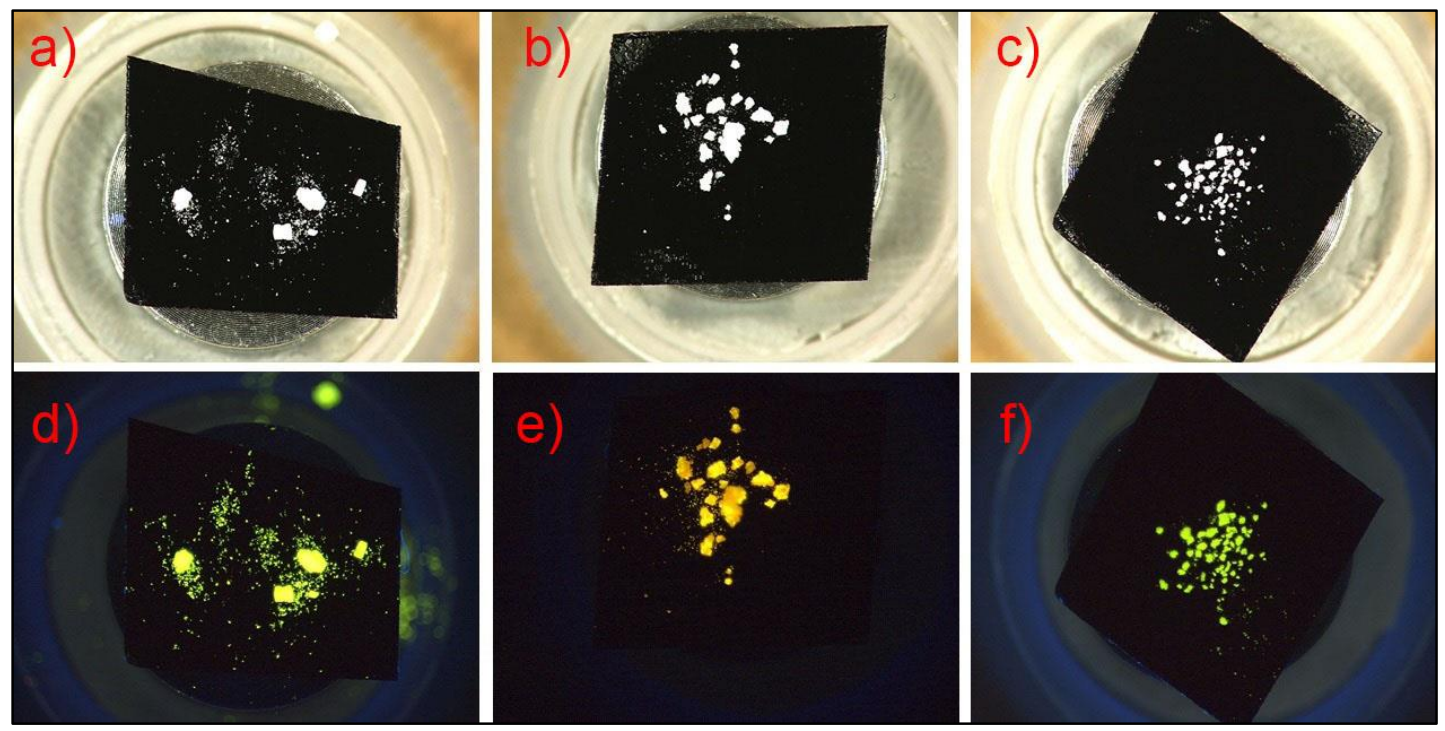

Figura 27. Fotos obtidas por VSC dos marcadores puros A, B e C, respectivamente os itens a), b) e c), sob luz visível e sob luz UV (254nm): itens d), e) e f);

A Figura 28 mostra os espectros vibracionais na região do infravermelho dos compostos A $\left(\left[\left(\mathrm{La}_{0.8} \mathrm{~Tb}_{0.2}\right)_{2}(\mathrm{DPA})_{3}\left(\mathrm{H}_{2} \mathrm{O}\right)_{3}\right]\right)$ e $\mathrm{B}\left(\left[\left(\mathrm{La}_{0.95} \mathrm{Eu}_{0.3} \mathrm{~Tb}_{0.2}\right)_{2}(\mathrm{DPA})_{3}\left(\mathrm{H}_{2} \mathrm{O}\right)_{3}\right]\right)$ e do ligante puro $\left(\mathrm{H}_{2} \mathrm{DPA}\right)$. Observa-se que o ligante puro apresenta uma banda em $1700 \mathrm{~cm}^{-1}$, característica do estiramento C-O, e uma banda em $1573 \mathrm{~cm}^{-1}$ referente ao estiramento $\mathrm{C}=\mathrm{O}$. Entretanto, os produtos da reação com TRs 
apresentam um deslocamento nas bandas de absorção dos estiramento $\mathrm{C}=\mathrm{O}$ e C-O para os números de onda de $1589 \mathrm{~cm}^{-1}$ e $1438 \mathrm{~cm}^{-1}$, respectivamente. Com base nessas informações, infere-se que 0 deslocamento das bandas referentes aos grupos $\mathrm{C}-\mathrm{O}$ e $\mathrm{C}=\mathrm{O}$ do ligante pode ter sido ocasionado por um deslocamento de densidade eletrônica, possivelmente acarretando pela ligação do $\mathrm{H}_{2} \mathrm{DPA}$ a um metal. Constata-se também que os espectros obtidos apresentam bandas coerentes com os resultados obtidos por Barreto et al..$^{79}$ e Rover. ${ }^{80}$

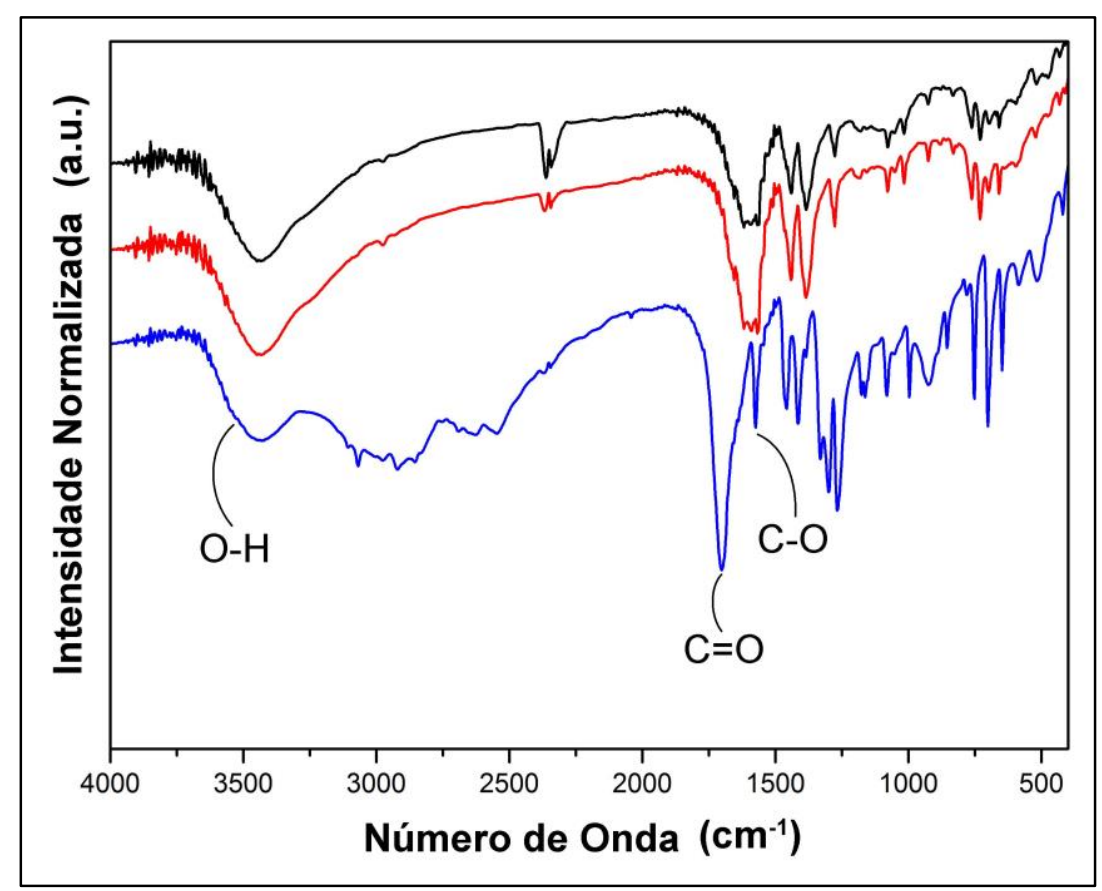

Figura 28. Espectros de IV dos marcadores A e B puros em comparação com o espectro do $\mathrm{H}_{2}$ DPA, e seus respectivos estiramentos;

O marcador cerâmico C $\left(\mathrm{ZnAl}_{1,95} \mathrm{~Tb}_{0,05} \mathrm{O}_{4}\right)$ apresentou picos semelhantes aos encontrados por Lucena et al. ${ }^{72}$, como mostra a Figura 29. Destaca-se a banda ao estiramento Al-OH, encontrado em $1378 \mathrm{~cm}^{-1}$. Também é possível observar a banda encontrada entre $1000 \mathrm{~cm}^{-1}$ e $500 \mathrm{~cm}^{-1}$ associada ao estiramento TR-O (TR = Tb, Y, Yb, Er, ...), mostrando a possível ligação de um íon terra rara no marcador sintetizado. ${ }^{43}$ 


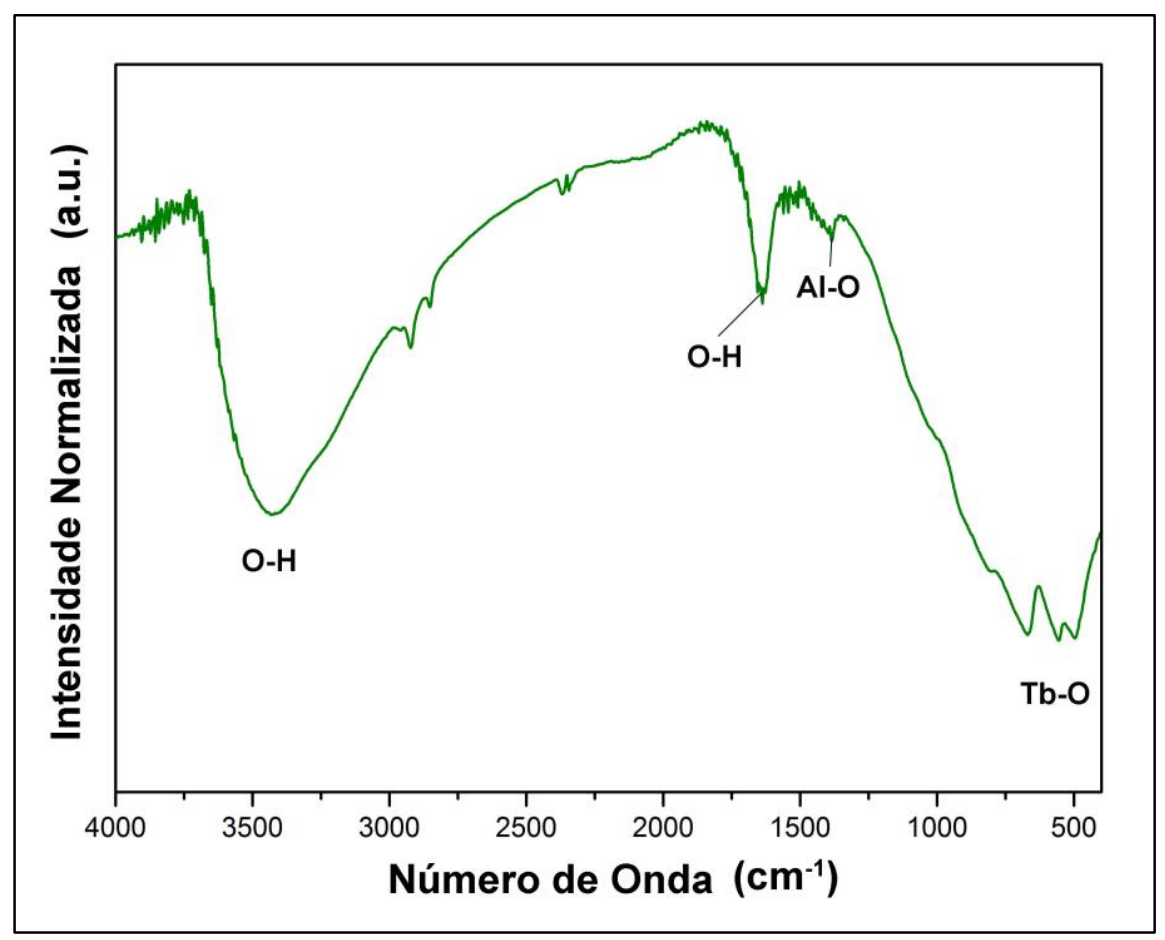

Figura 29. Espectros de IV da amostra C e seus respectivos estiramentos;

Ao analisar compostos baseados em MOFs, deve-se destacar que, dificilmente, celas unitárias de estruturas cristalinas para esses compostos são indexadas por difração de raios $\mathrm{X}$ de pó devido à grande quantidade de picos de difração. Por isto é aconselhável a análise e obtenção de monocristais, ${ }^{81}$ todavia, neste trabalho utilizou-se apenas a difração do pó. Concomitantemente, os compostos de DPA propostos não foram encontrados nos catálogos de bases de dados, como JCPDS, não sendo possível a identificação das fases formadas. ${ }^{54}$ Observa-se nos difratogramas mostrados na Figura 30 , referentes as amostras $\mathrm{A}$ e $B$, uma grande quantidade de picos de difração indicando que a estrutura apresenta características de baixa simetria. $O$ marcador $B$ também apresenta um deslocamento sistemático dos picos em relação ao marcador A. Possivelmente, esse fenômeno foi ocasionado pela adição do átomo de Eu a estrutura cristalina alterando significativamente os ângulos de ligações devido a diferença de tamanho em relação ao $\mathrm{Tb}$ e, consequentemente, deslocando os picos no difratograma. ${ }^{82}$ Esses resultados já eram esperados tendo em vista os difratogramas obtidos nos trabalhos de Wanderley ${ }^{81}$ e Melo ${ }^{53}$. 


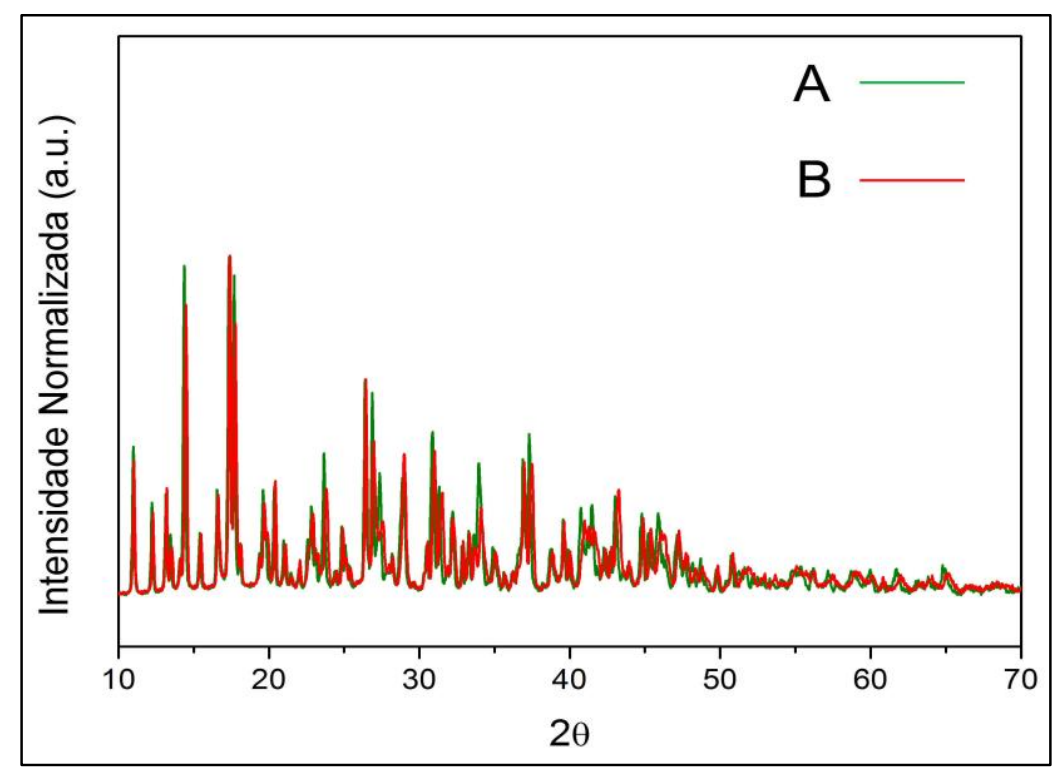

Figura 30. Difratograma dos marcadores baseados em MOFs e I) Contração (esquerda) e expansão (direita) do campo cristalino como resultado da substituição de dopantes de tamanho diferentes na matriz;

A amostra C, apresentou picos definidos e condizentes com a estrutura do tipo espinélio $\mathrm{ZnAl}_{2} \mathrm{O}_{4}$ (JCPDS 82-1043) ${ }^{72}$, proporcionando uma estrutura cristalina definida, como mostra o difratograma na Figura 31. A partir das análises de DRX não é possível determinar a presença do íon TR no retículo cristalino, entretanto, é possível inferir que a matriz $\mathrm{ZnAl}_{2} \mathrm{O}_{4}$ foi obtida com sucesso seguindo o método de combustão. ${ }^{83}$

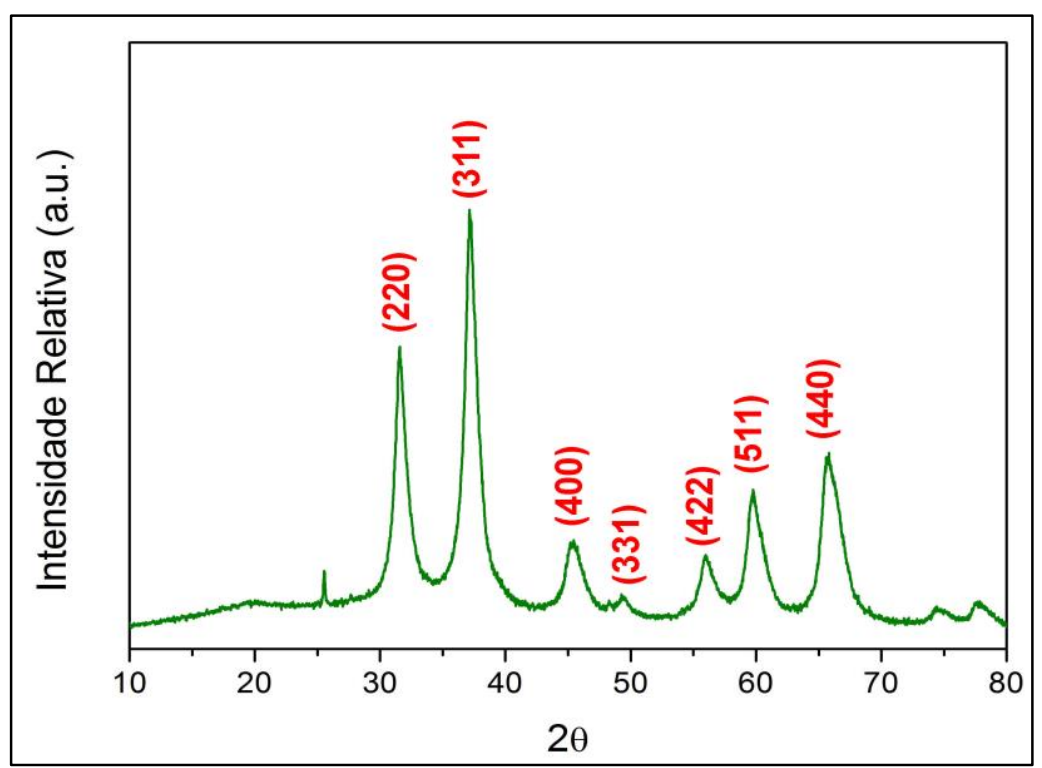

Figura 31. Difratograma da amostra C; 
As micrografias obtidas por Microscopia Eletrônica de Varredura (MEV) dos compostos A, B e C estão dispostas Figura 32. Em todas as imagens, observamse morfologias irregulares, como relatado pela literatura. ${ }^{72,79,80}$

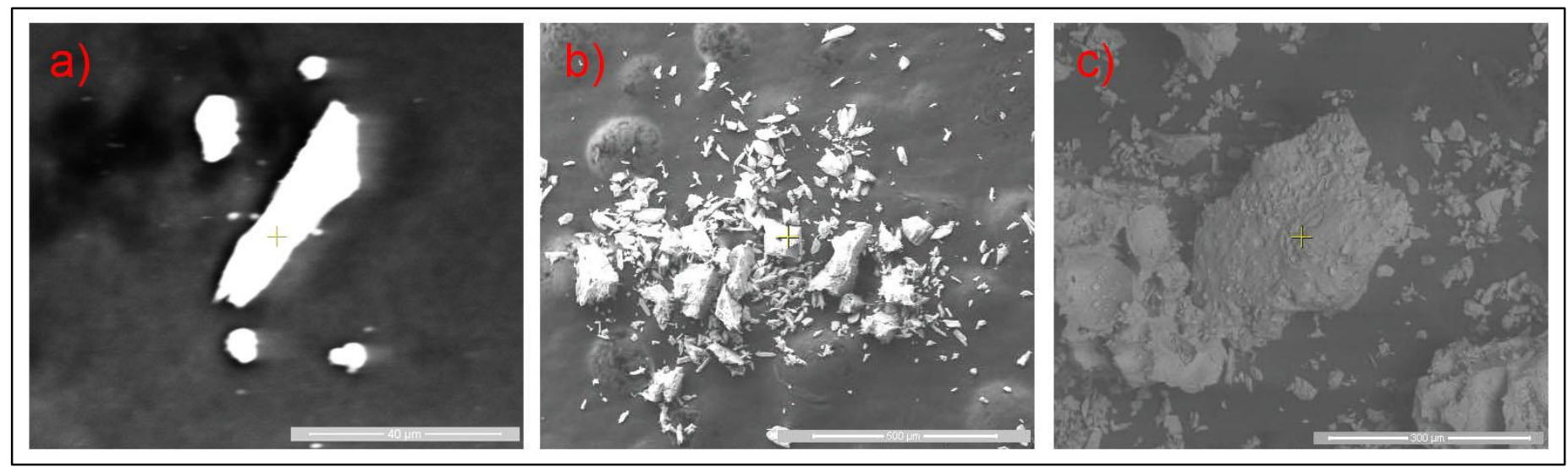

Figura 32. Micrografias referentes ao: a) marcador A, b) marcador B e c) ao marcador C;

Os espectros obtidos por EDS mostrados na Figura 33 ratificam a composição dos marcadores sintetizados. O marcador A e B exibem picos característicos referentes ao elementos $\mathrm{La}$ e $\mathrm{Tb}$, entretanto apenas o marcador $\mathrm{B}$ apresenta picos referentes ao Eu, como esperado. Analogamente, o marcador $\mathrm{C}$ exibe os picos dos elementos $\mathrm{Al}$ e $\mathrm{Zn}$ e Tb. Não foi observada a presença de outros elementos que não encontrados na composição dos marcadores, que poderia significar a presença de impurezas ou contaminação nas amostras. De acordo com a estequiometria, a proporção esperada dos elementos característicos dos marcadores para as análises de EDS devem ser: $20 \%$ de Tb e $80 \%$ de La para o marcador A ([(La0.8Tb0.2 $\left.\left.)_{2}(\mathrm{DPA})_{3}\left(\mathrm{H}_{2} \mathrm{O}\right)_{3}\right]\right) ; 10 \%$ de Tb, $10 \%$ de Eu e $80 \%$ de La para o marcador B ([(La0.95Eu0.3 $\left.\left.\left.\mathrm{Tb}_{0.2}\right)_{2}(\mathrm{DPA})_{3}\left(\mathrm{H}_{2} \mathrm{O}\right)_{3}\right]\right)$; e $2 \%$ de $\mathrm{Tb}, 33 \%$ de $\mathrm{Zn}$ e $65 \%$ de Al para o marcador $\mathrm{C}\left(\mathrm{ZnAl}_{1,95} \mathrm{~Tb}_{0,05} \mathrm{O}_{4}\right)$. O valores de porcentagem obtidos por EDS apresentam valores próximos de proporção referentes a composição nominal dos marcadores, como mostrado no gráficos da Figura 33. 


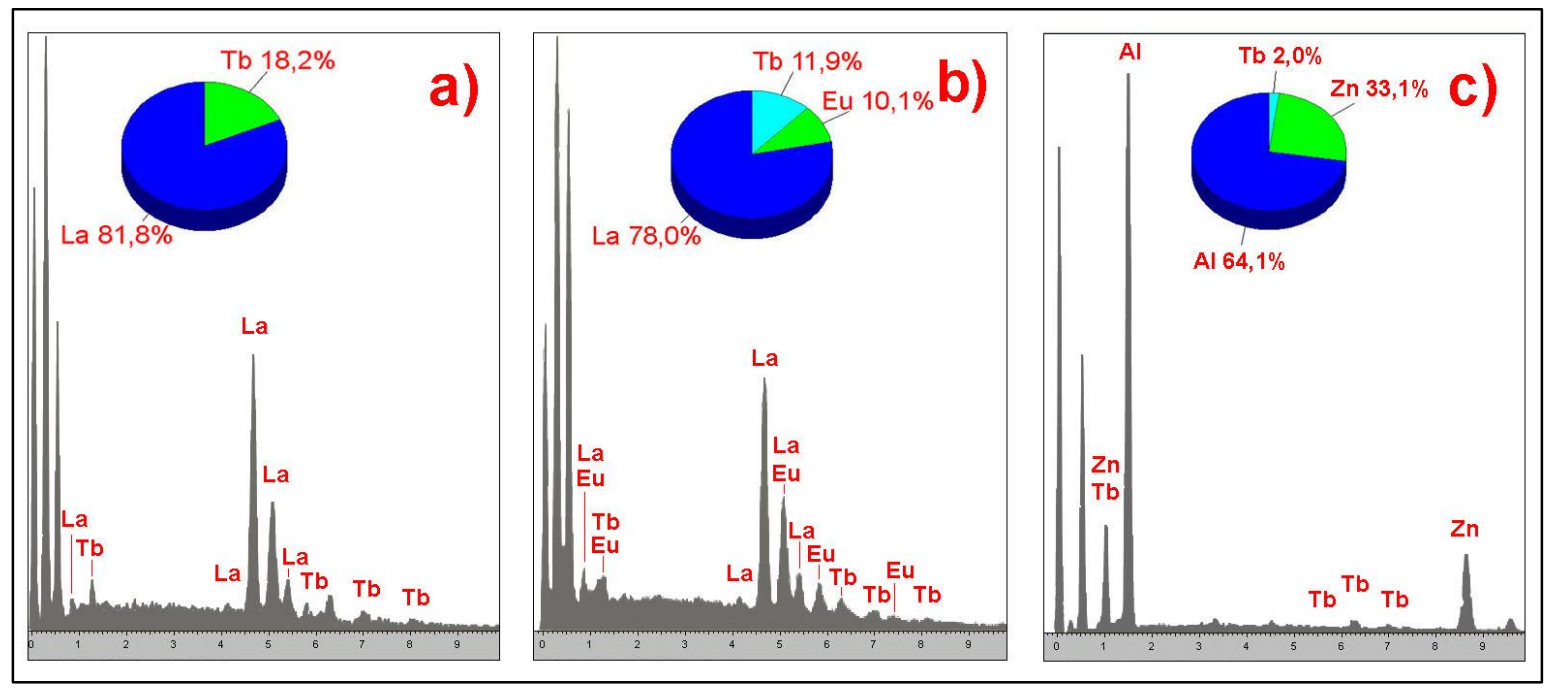

Figura 33. Espectros de EDS das amostras dos marcadores a) A b) B e c) C;

Os espectros de emissão foram medidos mediante excitação em $254 \mathrm{~nm}$. Os espectros de emissão dos marcadores A e C são mostrados na Figura 34. Ambos apresentam picos estreitos nas regiões próximas a 490, 545, 580 e 615 $\mathrm{nm}$, relacionados, respectivamente, com as transições ${ }^{5} \mathrm{D}_{4} \rightarrow{ }^{7} \mathrm{~F}_{6},{ }^{5} \mathrm{D}_{4} \rightarrow{ }^{7} \mathrm{~F}_{5}$, ${ }^{5} \mathrm{D}_{4} \rightarrow{ }^{7} \mathrm{~F}_{4}$ e ${ }^{5} \mathrm{D}_{4} \rightarrow{ }^{7} \mathrm{~F}_{3}$ do íon $\mathrm{Tb}^{3+} .{ }^{72},{ }^{79}$ Observa-se que a transição ${ }^{5} \mathrm{D}_{4} \rightarrow{ }^{7} \mathrm{~F}_{5}$ apresenta a maior intensidade e é responsável pela emissão de cor verde característica dos composto contendo $\mathrm{Tb}^{3+} \cdot{ }^{84}$

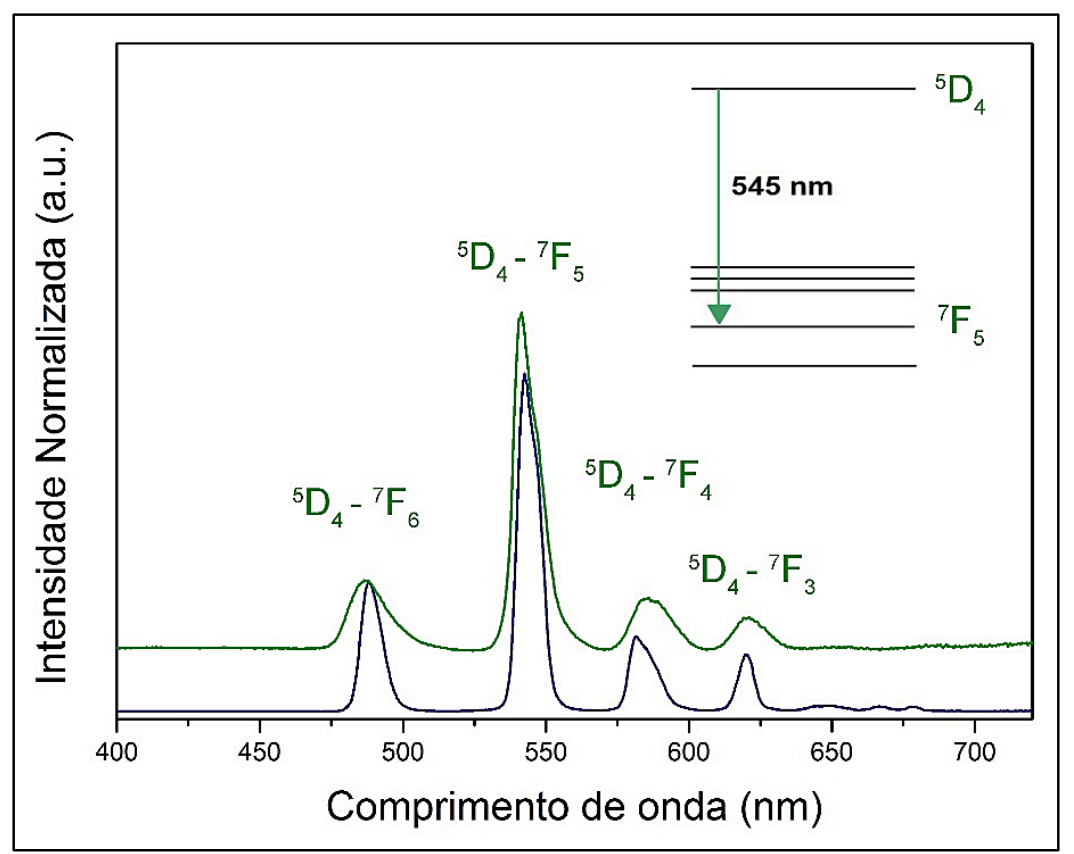

Figura 34. Espectros de emissão dos marcadores A (azul) e C (verde); e o diagrama de energias do íon Tb3+ indicando a transição mais intensa; 
De maneira análoga, o espectro do marcador B (Figura 35) apresenta picos centrados em 476, 543, 581, 591, 614, 650 e $587 \mathrm{~nm}$, respectivamente. Estes picos são atribuídos às transições ${ }^{5} \mathrm{D}_{4} \rightarrow{ }^{7} \mathrm{~F}_{6},{ }^{5} \mathrm{D}_{4} \rightarrow{ }^{7} \mathrm{~F}_{5}$ e ${ }^{5} \mathrm{D}_{4} \rightarrow{ }^{7} \mathrm{~F}_{4}$, do íon $\mathrm{Tb}^{3+}$, além das transições ${ }^{5} \mathrm{D}_{0} \rightarrow{ }^{7} \mathrm{~F}_{1},{ }^{5} \mathrm{D}_{0} \rightarrow{ }^{7} \mathrm{~F}_{2},{ }^{5} \mathrm{D}_{0} \rightarrow{ }^{7} \mathrm{~F}_{3}$ e ${ }^{5} \mathrm{D}_{0} \rightarrow{ }^{7} \mathrm{~F}_{4}$ do íon $\mathrm{Eu}^{3+} .80 \mathrm{O}$ marcador também possui dois picos de grande intensidade: ${ }^{5} \mathrm{D}_{4} \rightarrow{ }^{7} \mathrm{~F}_{4}$ e ${ }^{5} \mathrm{D}_{0} \rightarrow{ }^{7} \mathrm{~F}_{2}$. A primeira transição encontrada na região de $543 \mathrm{~nm}$, como anteriormente citado, é referente ao íon $\mathrm{Tb}^{3+}$ e se apresenta na região do verde. A segunda transição está relacionada com o íon $\mathrm{Eu}^{3+}$, e encontra-se na região $614 \mathrm{~nm}$ oferecendo uma emissão no vermelho. A combinação destas transições conferem ao composto a coloração laranja. ${ }^{80}$

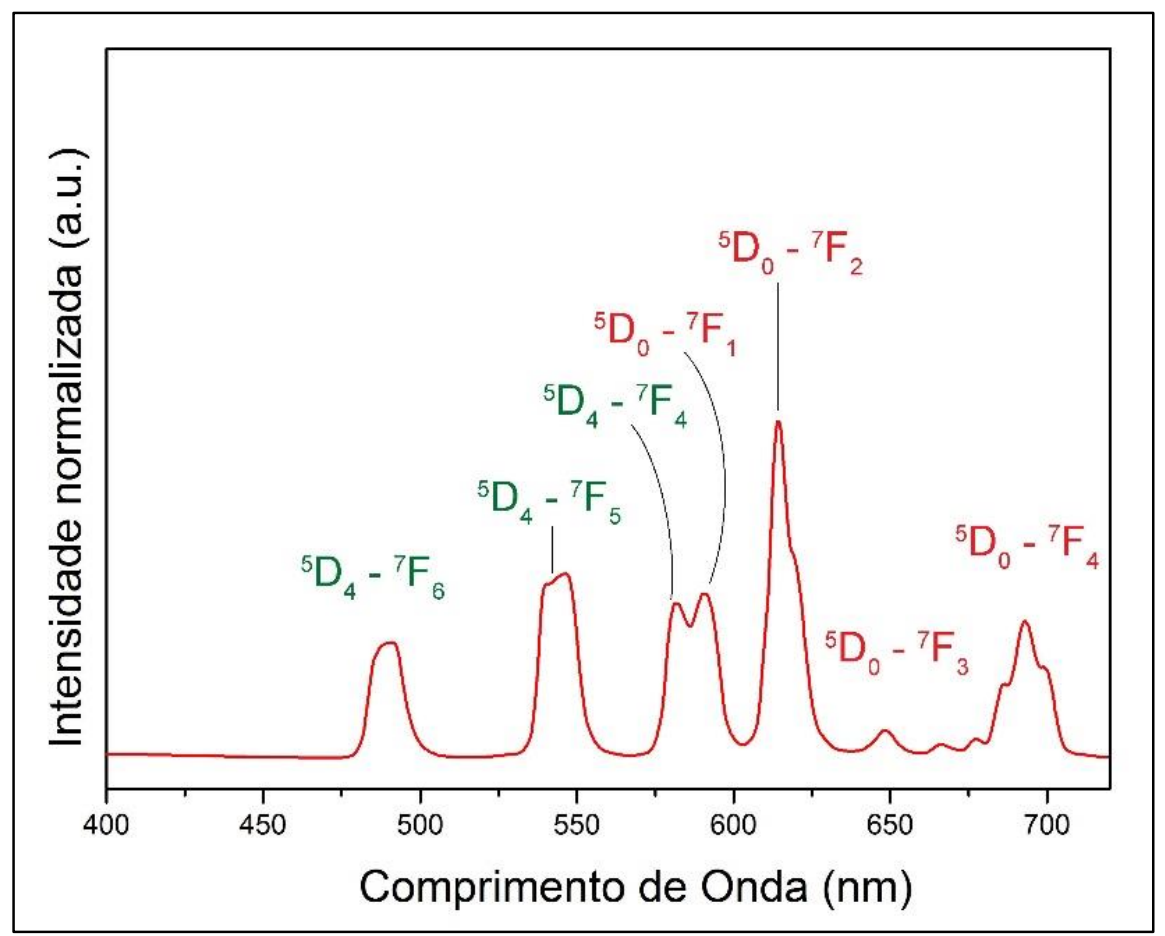

Figura 35. Espectro de emissão do marcador B e suas respectivas transições; em verde, as transições ao íon $\mathrm{Tb}^{3+}$; em vermelho, as transições referentes ao íon $\mathrm{Eu}^{3+}$;

Os espectros de emissão dos marcadores $A, B$ e $C$ também foram adquiridos também no microespectrômetro do VSC. Este espectrômetro não possui alta sensibilidade, pois é um equipamento que se destina prioritariamente a análises documentoscópicas (e não a medidas espectroscópicas). Entretanto o VSC é um equipamento com maior disponibilidade nas unidades de perícia do DPF e com isto seu uso para a identificação de resíduos de explosivos pode ser 
de grande valia para fins periciais. Sendo assim, foi avaliado se, apesar das limitações do equipamento, seria possível fazer uso deste recurso tendo em vista a aplicação final dos marcadores.

A imagem abaixo demonstra uma comparação dos espectros de emissão obtidos pelo espectrofluorímetro de modelo K2 (Multifrequency Cross-Correlation Phase and Modulation Fluorometer) e pelo microespectrômetro do VSC 6000/HS em relação as amostras dos marcadores $A\left(\left[\left(\operatorname{La}_{0.8} \mathrm{~Tb}_{0.2}\right)_{2}(\mathrm{DPA})_{3}\left(\mathrm{H}_{2} \mathrm{O}\right)_{3}\right]\right)$ e $\quad \mathrm{C}$ $\left(\mathrm{ZnAl}_{1,95} \mathrm{~Tb}_{0,05} \mathrm{O}_{4}\right)$. Observa-se que não há alterações significativas nas posições dos picos e transições. Entretanto, a amostra C analisada por VSC apresentou maiores índices de ruídos que as demais mas sem dificultar a identificação de sus respectivas transições.

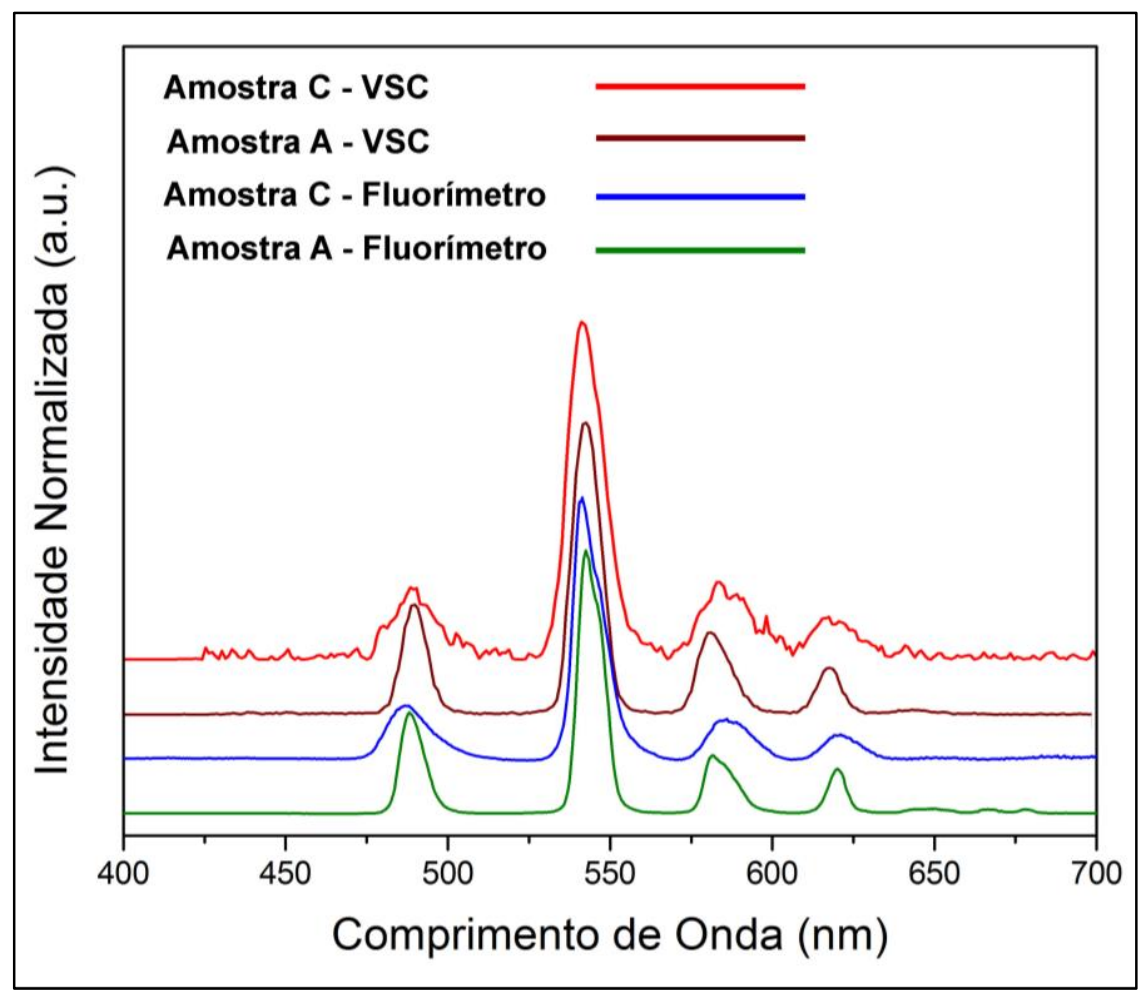

Figura 36. Comparação entre os espectros de emissão dos marcadores A e C utilizando o espectrofluorímetro de modelo K2 e o microespectrômetro do VSC;

Os espectros de emissão obtidos a partir do VSC do marcador B são mostrados na Figura 37. Foram observadas as principais transições tanto do íon $\mathrm{Tb}^{3+}$ quanto o íon $\mathrm{Eu}^{3+}$. Nenhuma mudança significativa na posição ou forma dos picos foi observada. Todavia, a transição ${ }^{5} \mathrm{D}_{0} \rightarrow{ }^{7} \mathrm{~F}_{4}$, referente ao íon $\mathrm{Eu}^{3+}$, não é visível. 


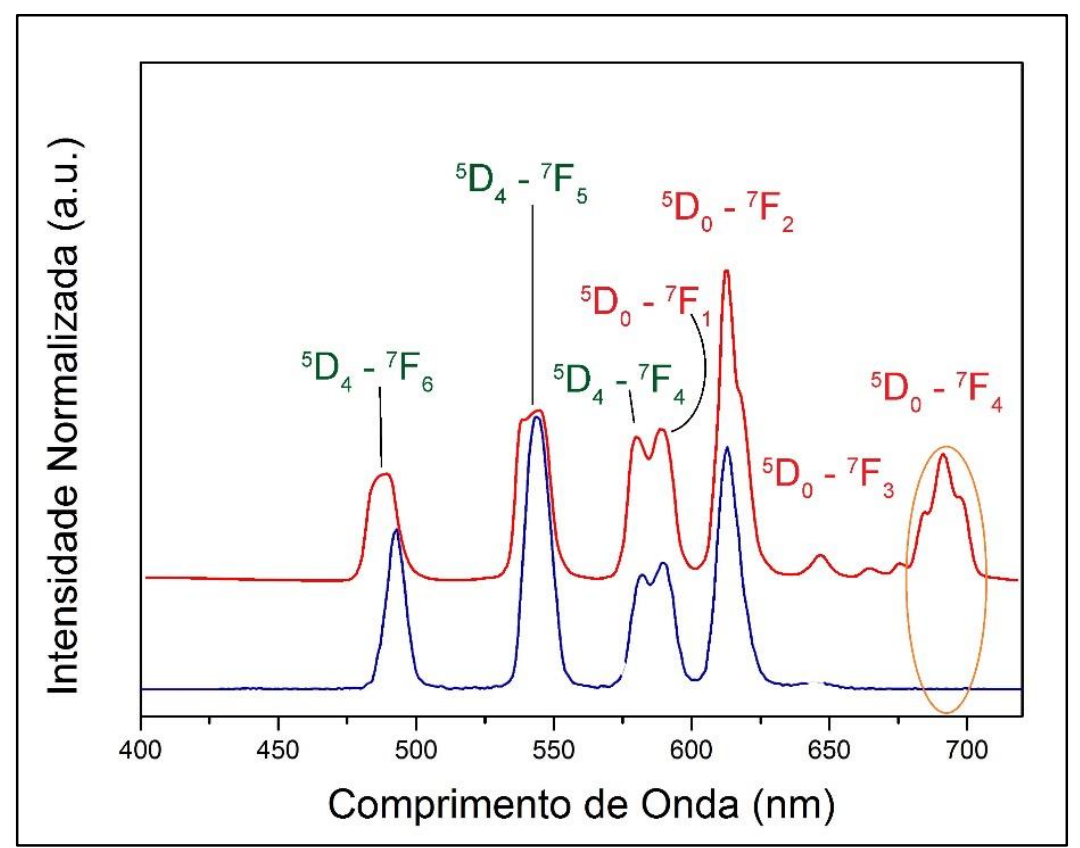

Figura 37. Espectros de fluorescência do marcador B aferido por VSC (azul) e por Espectrômetro de Fluorescência (vermelho), destacando a ausência da transição ${ }^{5} \mathrm{D}_{0} \rightarrow{ }^{7} \mathrm{~F}_{4}$;

Os resultados indicam que, apesar das limitações do equipamento, é possível utilizar as ferramentas espectroscópicas do VSC para avaliação de marcadores luminescente. Dada a disponibilidade de VSC em unidades de perícia, esta possibilidade abre uma porta para o uso dos marcadores luminescentes para explosivos. Entretanto, se faz necessário a otimização do tipo e da quantidade de marcador utilizada o aprimoramento e adequação dos marcadores para que os problemas na sensibilidade do microespectrômetro não sejam significativas na determinação dos resíduos de explosão. Como pontos importantes para a inclusão do VSC nas rotinas periciais, pode-se destacar o curto tempo de resposta nas análises e a diminuição dos custos operacionais, além da disponibilidade deste equipamento.

\subsection{TESTE COMO MARCADORES PARA RESÍDUOS DE EXPLOSÃO}

As cargas explosivas, submetidas ao repouso de uma semana após a adição dos marcadores, não apresentaram mudanças de coloração que indicassem uma possível reação. As 18 cargas preparadas para os testes foram detonadas com sucesso, sem exibir indícios de alterações no comportamento dos explosivos. A imagem abaixo mostra alguns exemplos das carcaças utilizadas 
pouco antes da detonação (Figura 38.a) e após (Figura 38.b e 38.c). Posteriormente a explosão, os gabinetes exibiram várias deformidades e danos na estrutura devido ao impacto, além da presença de resíduos de coloração amarela clara (Figura 38.e), semelhante a coloração dos explosivo antes da detonação. Esses resíduos foram encontrados em um raio de até 3 metros da origem da explosão. É possível relacionar esses resíduos encontrados com pequenas quantidades da carga principal de ANFO que não foram detonados completamente. Este fato é relatado na literatura para explosivos secundários devido a sua baixa sensibilidade. ${ }^{8}$ As marcas de detonação também apresentam um padrão, mostrado na Figura 38.f, aonde os resíduos de explosão possuem linhas no sentido oposto ao local em que o explosivo foi anexado, mostrando a direção da onda de choque proveniente da detonação.

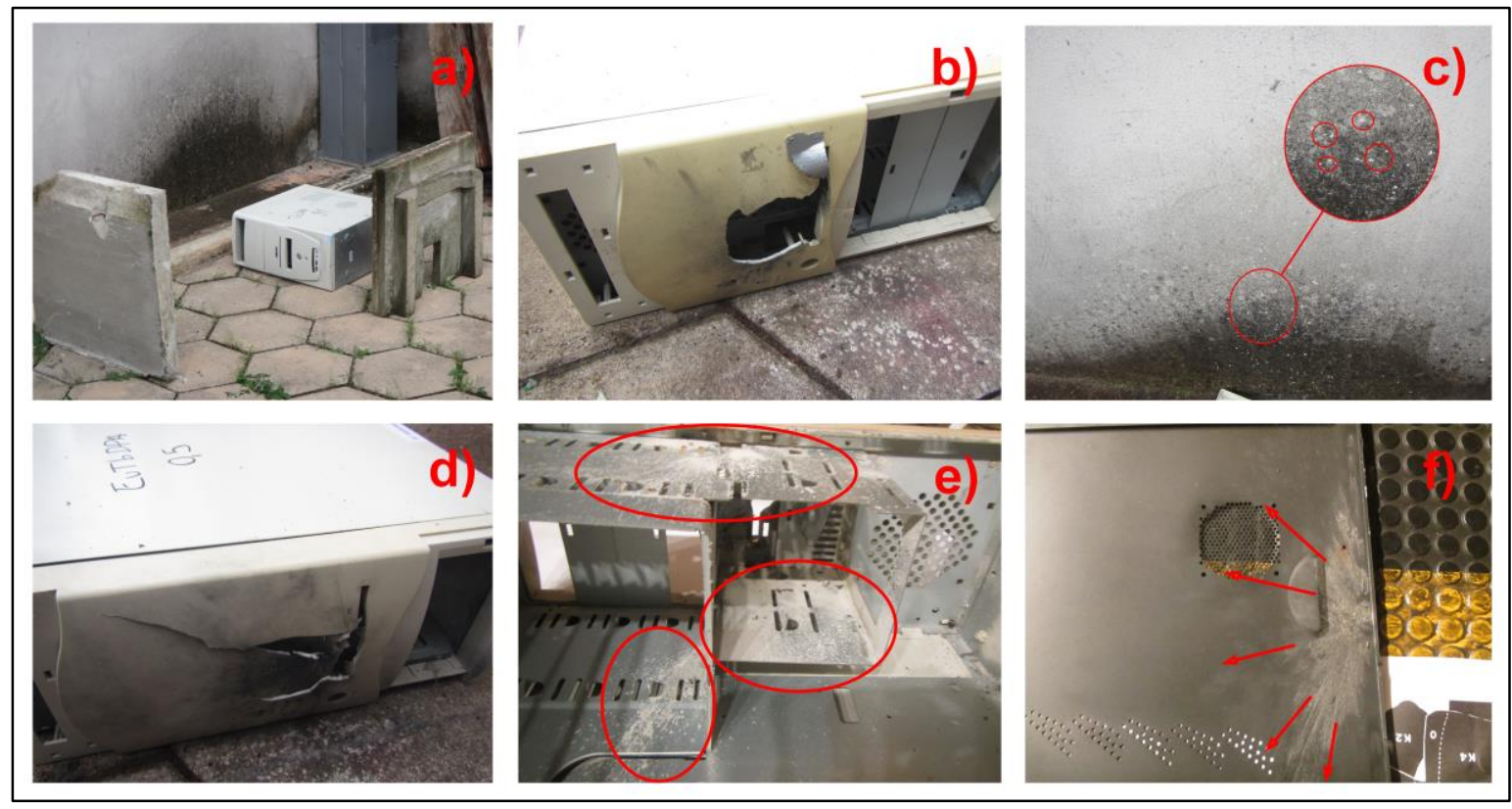

Figura 38. a) gabinete de computador antes da detonação b) Gabinete após a detonação; c) em destaque, resíduo de explosivo encontrando na parede próxima ao local de detonação; d) Gabinete após a detonação e) resíduos de explosivos encontrados no interior da carcaça após a detonação e f) resíduo de explosão e sentido da onda de impacto proveniente do explosivo;

A presença de resíduos de explosivos não detonados de ANFO pode ser um ponto relevante na detecção dos marcadores luminescentes em cenários de crime. Isso porque os marcadores podem ser mais facilmente encontrados nessas manchas devido a maior concentração e traços inalterados da carga explosiva, favorecendo a identificação e coleta dos resíduos. 
Após a detonação, os gabinetes foram levados para um local de pouca iluminação para a análise visual dos marcadores luminescentes. Os gabinetes foram expostos a radiação UV (254 nm) para uma avalição visual da presença dos resíduos marcados. A Tabela 8 resume os resultados da inspeção visual. Observou-se que os marcadores, A $\quad\left(\left[\left(\mathrm{La}_{0.8} \mathrm{~T} \mathrm{~Tb}_{0.2}\right)_{2}(\mathrm{DPA})_{3}\left(\mathrm{H}_{2} \mathrm{O}\right)_{3}\right]\right)$ e $\quad$ B ([(Lao.95 $\left.\left.\left.\mathrm{Eu}_{0.3} \mathrm{~Tb}_{0.2}\right)_{2}(\mathrm{DPA})_{3}\left(\mathrm{H}_{2} \mathrm{O}\right)_{3}\right]\right)$, ambos compostos por MOFs, apresentaram luminescência perceptível a olho nu quando excitados no UV, mesmo nas proporções de marcadores mais baixos empregados (1\% de massa). Como esperado, houve um aumento na intensidade de luminescência proporcional à concentração de marcadores na carga explosiva (Figura 39). Por outro lado, não foi possível visualizar os resíduos do marcador $\mathrm{C}\left(\mathrm{ZnAl} \mathrm{l}_{1,95} \mathrm{~Tb}_{0,05} \mathrm{O}_{4}\right)$, mesmo quando a maior proporção ( $5 \%$ de massa) foi utilizada (figura 40 ).

Tabela 8. Relação entre os resíduos de explosão e sua visualização a olho nu sob luz UV;

\begin{tabular}{|c|c|c|c|c|c|}
\hline $\begin{array}{c}\text { Marcadores } \\
\text { presentes nos } \\
\text { resíduos }\end{array}$ & $\begin{array}{c}\text { Verificação } \\
\text { visual }\end{array}$ & $\begin{array}{c}\text { Marcadores } \\
\text { presentes nos } \\
\text { resíduos }\end{array}$ & $\begin{array}{c}\text { Verificação } \\
\text { visual }\end{array}$ & $\begin{array}{c}\text { Marcadores } \\
\text { presentes nos } \\
\text { resíduos }\end{array}$ & $\begin{array}{c}\text { Verificação } \\
\text { visual }\end{array}$ \\
\hline$A 1$ & Sim & B1 & Sim & C1 & Não \\
$A 3$ & Sim & B3 & Sim & C3 & Não \\
A5 & Sim & B5 & Sim & C5 & Não \\
\hline
\end{tabular}

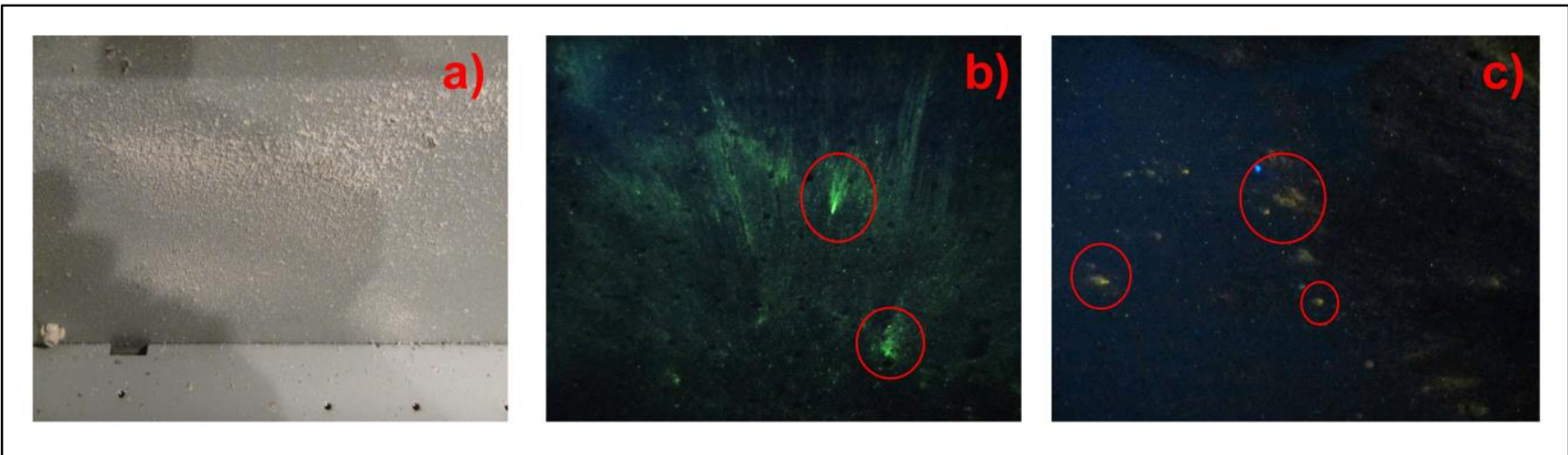

Figura 39. Imagens dos gabinetes após as detonações dos a) resíduos de pós explosão na parte interna superior da carcaça sob luz visível; b) resíduos de explosão das cargas A5 sob luz UV na parte interna lateral e c) resíduos de explosão das cargas B5 sob luz UV; 


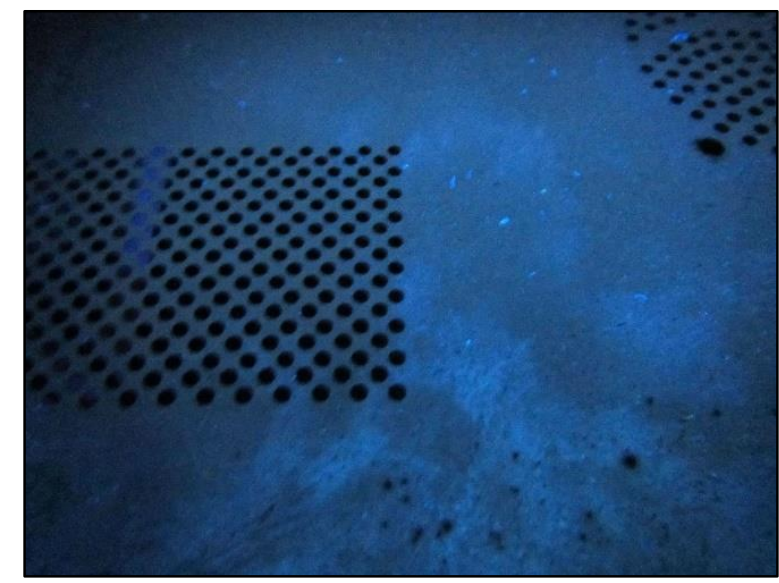

Figura 40. Gabinete contendo resíduos do marcador C5 sob luz UV;

É importante destacar que compostos cerâmicos possuem uma alta estabilidade térmica e química devido a sua composição baseada em óxidos, inferindo que o marcador $C$ provavelmente não reagiu quimicamente com os componentes do explosivo. Somado a isso, Nenhuma das análises de caracterização dos marcadores (por fluorímetro e VSC) não apresentaram indícios de diminuição da luminescência.

Após as explosões, resíduos luminescentes foram coletados com stubs e levados para análises complementares. Os resíduos foram fotografados no VSC (Figura 41), tanto com o uso de luz visível quanto de luz UV (254 nm). As amostras contendo os marcadores A e B, assim como observado in loco, apresentaram-se com alta luminescentes e os resíduos foram facilmente observados em todas as proporções testadas.

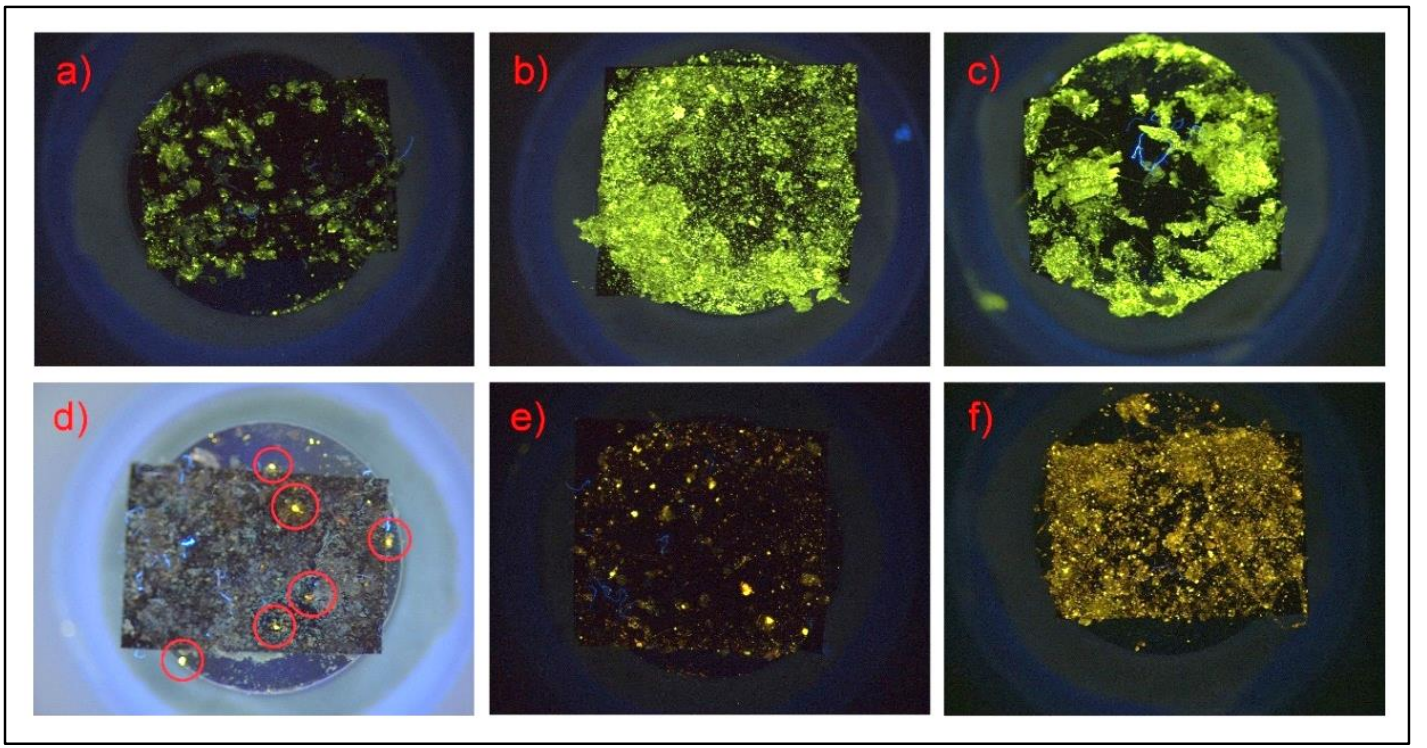

Figura 41.Amostras de resíduo de explosão fotografadas por VSC referentes aos marcadores a) A1, b) A3 e c) A5; e os marcadores d) B1, e) B3 e f) B5; 
Todavia, apesar do procedimento de coleta aumentar a quantidade de amostra no stub, não foi possível visualizar a luminescência nas amostras contendo o marcador C pelo método de VSC, ratificando os dados obtidos dos ensaios in loco. As fotografias das amostras contendo o marcador $\mathrm{C}$ estão dispostas na Figura 42.

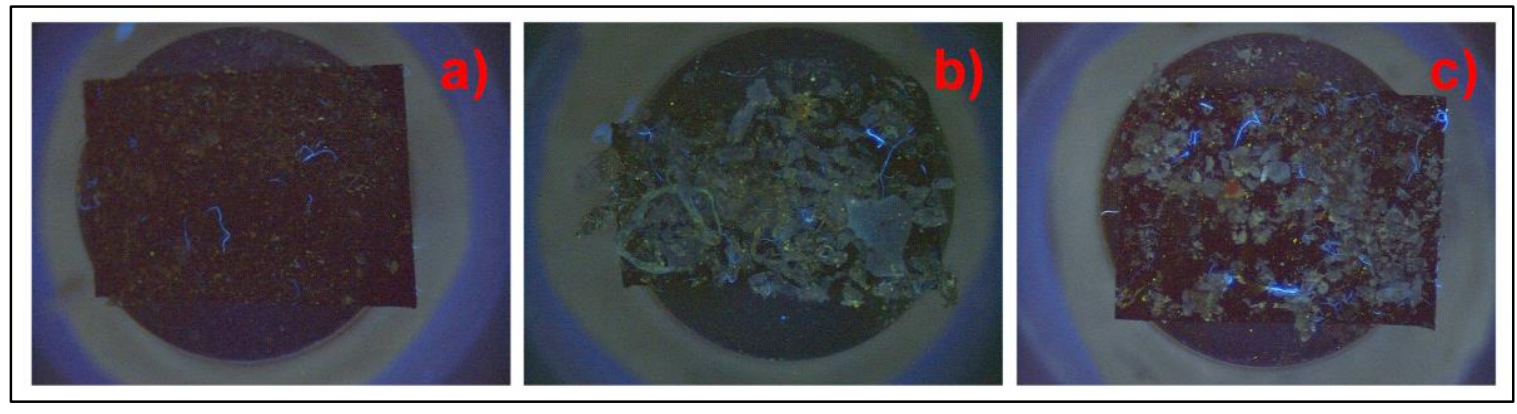

Figura 42. Amostras de resíduos de explosão analisadas por VSC sob luz UV (254 nm) das cargas a) C1, b) C3 e c) C5;

Os espectros de EDS, mostrados na Figura 43, confirmaram a presença dos elementos característicos dos marcadores nas amostras analisadas. É interessante notar que apesar de não ter sido possível visualizar in locu os resíduos luminescentes contendo o marcador $\mathrm{C}$, foi possível identifica-los por meio de EDS nas amostras C1, C3 e C5. Para caracterizar o inequivocamente o resíduo de explosão, os constituintes do marcador não podem ser facilmente confundidos com elementos de origem ambiental. Sendo assim, os elementos $\mathrm{O}$, $\mathrm{C}$, N, entre outros constituintes do marcador/explosivo, não podem ser considerados para fins de marcação química. Por outro lado, os TR não são facilmente encontrados em partículas de origem ambiental e ocupacional. Desta forma, a presença conjunta de Zn, Al e Tb (Figura 43.g, h e i) caracteriza, com alto grau de confiabilidade, o marcador de explosivos $C$. No caso dos marcadores A (Figura 43.a, b, c) e B (Figura 43.d, e, f), que são MOFs, a marcação química se dá pela presença e pela razão dos íons $L a, T b$ e Eu.

Para a obtenção das proporções de EDS foi aferido pelo menos três posições diferentes de partículas encontradas nas micrografias. Observa-se que as amostras A1, A3 e A5 apresentam valores que variam de 15 a $23 \%$ de $\mathrm{Tb}$ e 77 a $85 \%$ de La. Estes valores correspondem a uma variação de $8 \%$ em relação a composição nominal da amostra que é $20 \%$ Tb e $80 \%$ La, com um desvio padrão 
de 2,91 para ambos. As amostras B apresentam resultados com menor flutuação, mantendo tem suas proporções próximas a $12 \%$ para o Tb, 10\% de Eu e $78 \%$ de La. Os valores teóricos de B são 10\% de Tb, 10\% de Eu e $80 \%$ de La, ou seja observa-se uma variação de $2 \%$ e um desvio padrão de 0,22 para o Tb, 0,49 para o Eu e 0,71 para o La. Já o marcador C, apresenta valores que variam de 2 a $3 \%$ de Tb, 22 a 33\% de Zn e 68 a 75\% de Al. Nominalmente esta amostra apresenta $2 \%$ de $\mathrm{Tb}, 33 \%$ de $\mathrm{Zn}$ e $65 \%$ de $\mathrm{Al}$, apresentando a maior taxa de variação, 10\% e 7\%, para os elementos $\mathrm{Zn}$ e $\mathrm{Al}$, respectivamente. Os desvios padrões encontrados para os elementos $\mathrm{Tb}, \mathrm{Zn}$ e Al para a amostra $\mathrm{C}$ são, respectivamente, 0,$41 ; 3,97$ e 4,30. Todas as proporções condizem com os valores de composição nominal dos compostos sintetizados encontrados na literatura. ${ }^{72,79,80}$

Tabela 9. Variação de proporção nominal entre os valores teóricos e os valores encontrados por EDS das amostras de resíduos de explosão, e seus respectivos desvio padrão;

Variação máxima de Proporção Desvio Padrão em relação ao valor teórico

\begin{tabular}{l|ccc}
\hline \multirow{3}{*}{ Marcador $A$} & Tb & $8 \%$ & 2,92 \\
& La & $8 \%$ & 2,92 \\
\hline \multirow{3}{*}{ Marcador B } & Tb & $2 \%$ & 0,22 \\
& Eu & $2 \%$ & 0,49 \\
& La & $2 \%$ & 0,71 \\
\hline \multirow{3}{*}{ Marcador C } & Tb & $1 \%$ & 0,41 \\
& Zn & $11 \%$ & 3,97 \\
& $\mathrm{Al}$ & $10 \%$ & 4,30 \\
\hline
\end{tabular}




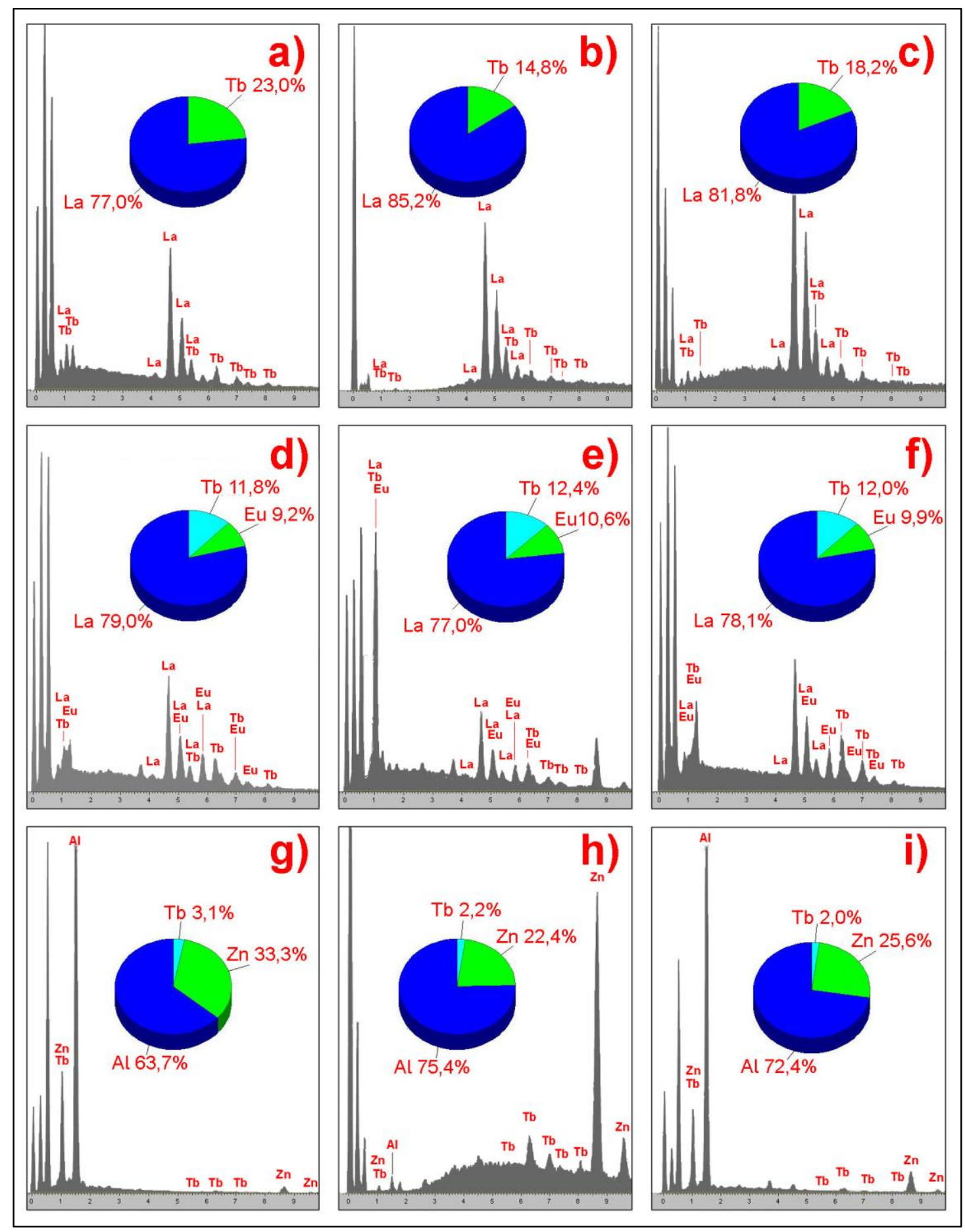

Figura 43. Espectros de EDS e suas respectivas razões de massas dos elementos constituintes dos marcadores: A1, A3, A5 (a, b e c), B1, B3, B5 (e, f e g), C1, C3 e C5 (g, h e i);

A partir dos percentuais obtidos com o EDS, é possível criar um sistema de codificação baseada na proporção de metais específicos. Por exemplo, um certo marcador de explosivo pode ser conter 30\% Tb e 70\% de La enquanto outro contém 10\% Tb e $90 \%$ La. 
Por fim, foram obtidos os espectros de fluorescência das amostras dos resíduos de explosão contendo os marcadores (Figura 44). Nas amostras contendo os marcadores A (Figura 44.a) e B (Figura 44.b), foi possível identificar todos os picos característicos do $\mathrm{Tb}^{3+}$ e Eu${ }^{3+}$. Todavia, a amostra contendo o marcador B1 apresenta grandes quantidades de ruídos nos espectro, oriundo provavelmente da pequena quantidade de amostra coletada ou alinhamento errado da fonte de excitação. Esse resultado sugere que a utilização dos marcadores em quantidades maiores que $1 \%$ favorecem a eficácia da marcação.

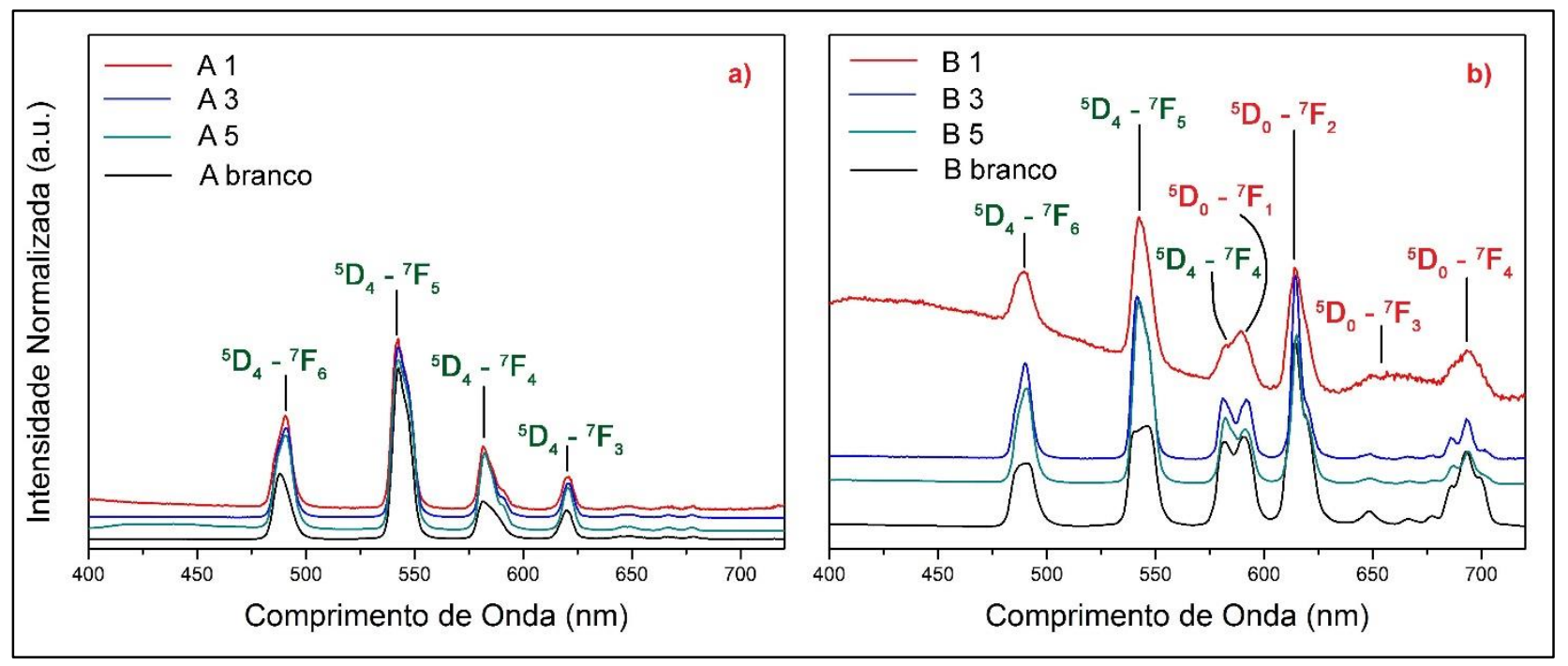

Figura 44. Espectros de fluorescência dos resíduos de explosão contendo os marcadores a) A e b) B;

Os espectro das amostras contendo o marcador C (Figura 45) apresentam uma diminuição drástica nas intensidade das amostras $C_{1}$ e C3, além do alargamento e deslocamento das bandas à medida em que se aumenta a proporção dos marcadores. 


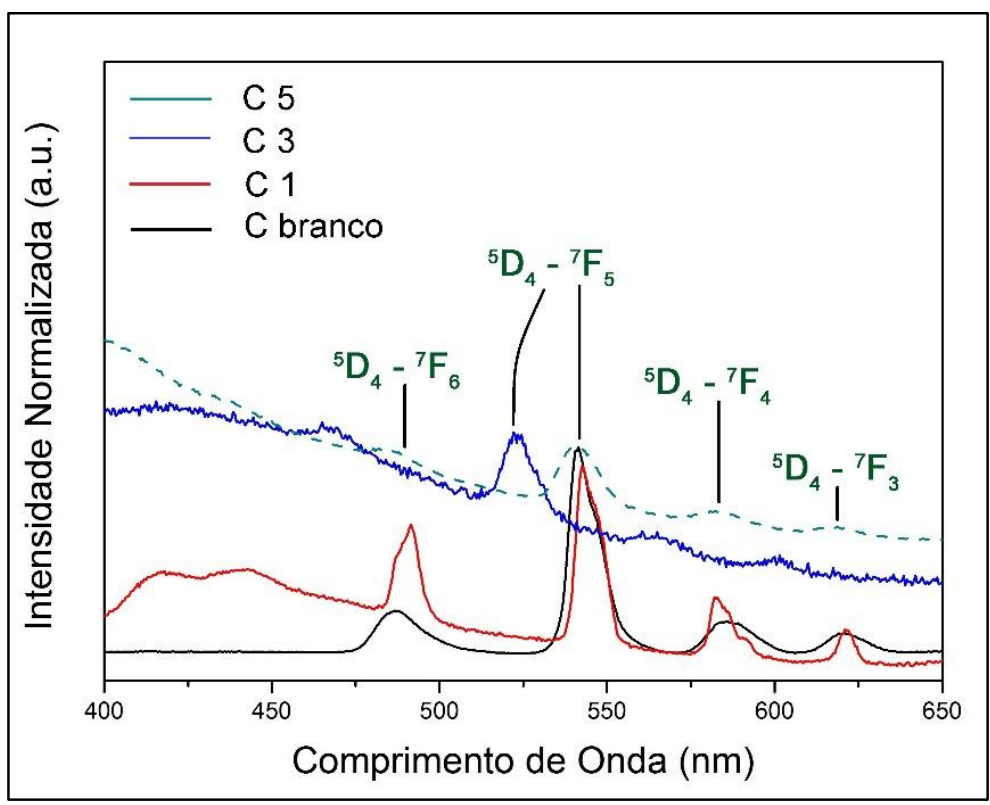

Figura 45. Espectro de fluorescência dos resíduos de explosivos contendo o marcador C;

Além das análises tradicionais de fotoluminescência, os espectros de emissão também foram adquiridos no VSC. Como já mencionado, o VSC é um equipamento muito disponível nas unidades de perícia do DPF e portanto é interessante avaliar a sua potencialidade de uso para identificação de resíduos de explosão. Os espectros mostraram que para concentrações de marcador igual ou superior a $3 \%$ foi possível identificar todos os picos característicos das transições dos íons $\mathrm{Tb}^{3+}$ e $\mathrm{Eu}^{3+}$. Para a concentração de $1 \%$ a relação sinal-ruído torna-se muito baixa e compromete a identificação dos marcadores, como demonstrado pelos espectros mostrados abaixo.

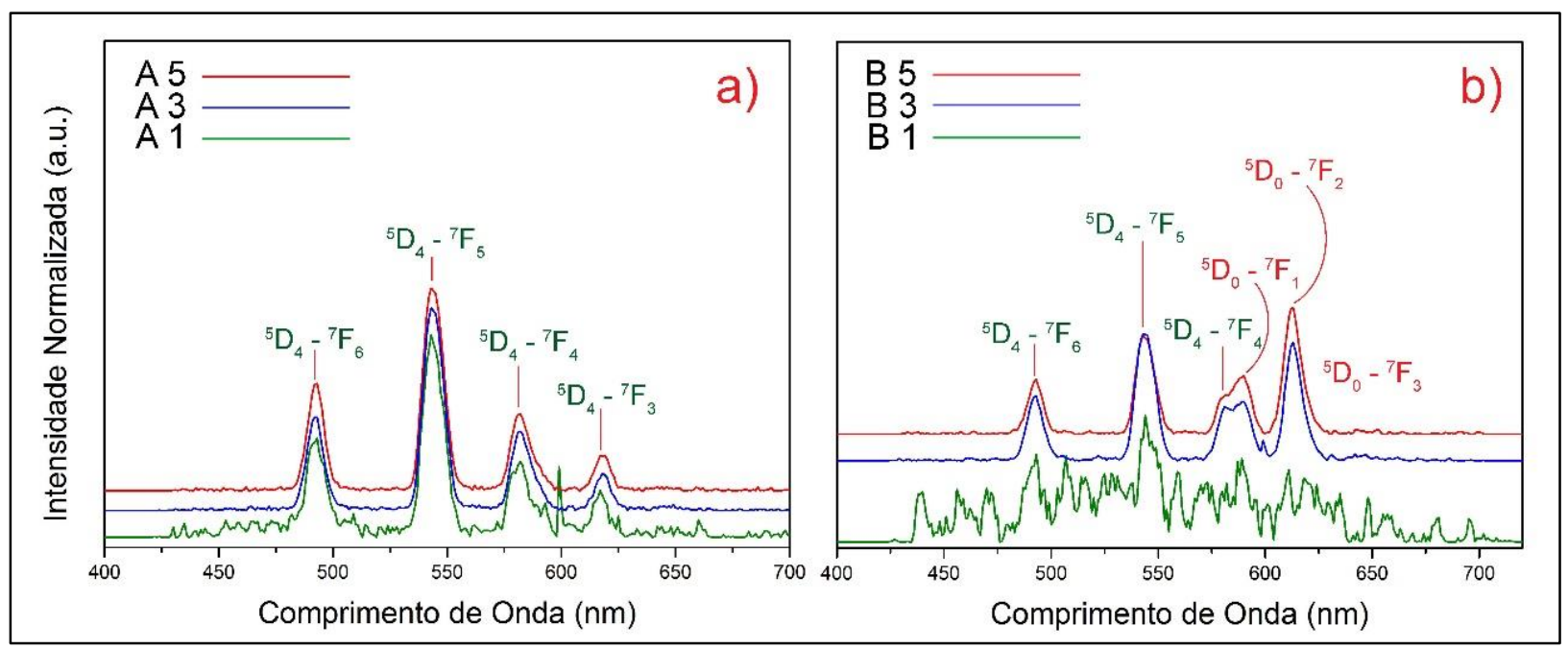

Figura 46. Espectros de Fluorescência obtidos por VSC das amostras A (a) e B (b); 
O marcador $\mathrm{C}\left(\mathrm{ZnAl}_{1,95} \mathrm{~Tb}_{0,05} \mathrm{O}_{4}\right)$ baseado em cerâmica, apesar de exibir alta estabilidade físico-química e teoricamente não ser susceptível a reações com os componentes do explosivo ${ }^{58}$, não foi detectado a olho nu nos ensaios in loco, não se mostrando apto para candidato a marcador de explosivos. Entretanto, um comportamento similar já havia sido reportado por Melo. ${ }^{53}$ Sua pesquisa também observou uma forte diminuição de luminescência em função do envelhecimento de marcadores $\left.\mathrm{ZnAl}\right|_{1,95} \mathrm{Eu}_{0,05} \mathrm{O}_{4}$ quando adicionados a carga iniciadora ou pólvora de munições. Nesse contexto, faz-se necessário a continuidade de estudos para determinar a causa da perda de luminescência desses materiais quando misturados a explosivos.

Por outro lado, os marcadores baseados em MOFs, A $\left(\left[\left(\mathrm{La}_{0.8} \mathrm{~Tb}_{0.2}\right)_{2}(\mathrm{DPA})_{3}\left(\mathrm{H}_{2} \mathrm{O}\right)_{3}\right]\right) \quad$ e $\quad$ B $\quad\left(\left[\left(\mathrm{La}_{0.95} \mathrm{Eu}_{0.3} \mathrm{~Tb}_{0.2}\right)_{2}(\mathrm{DPA})_{3}\left(\mathrm{H}_{2} \mathrm{O}\right)_{3}\right]\right), \quad$ apresentaram luminescência visível quando irradiadas depois de adicionados aos explosivos e foram identificadas nos resíduos de detonação com relativa facilidade. Esta alta luminescência pode ser o diferencial para a visualização in loco e coleta do marcador.

Ao comparar os resultados obtidos com tecnologias já existentes, observase que o presente trabalho se diferencia do trabalho de Ryan et al. ${ }^{36}$ por utilizar um sistema mais simples de marcação, não necessitando de um segundo componente de marcação (Coding). A luminescência dos marcadores pode fornecer as primeiras informações a respeito do explosivo (ex. Cada tipo de explosivo conter um marcador com cor de emissão diferente) e medidas muito simples de EDS podem fornecer a composição química, o que poderia, por exemplo, caracterizar o fabricante. Ambas as medidas citadas são rápidas, dispensam preparo de amostra e confiáveis. Além disso, empregam instrumentação relativamente disponível em unidades de perícia e centros de pesquisa.

Além disto, a forma de adição do marcador é mais simples. Segundo Ryan et al. ${ }^{36}$, é necessário criar um particulado de aproximadamente 0,5-0,7 mm com a mistura de fósforos para adiciona-las as cargas. Trabalhos subsequentes ${ }^{76,85}$ apontam a necessidade de recobrimento dos marcadores com filmes plásticos e cera de carnaúba. A metodologia proposta neste trabalho, consegue resultados satisfatórios com a adição direta dos marcadores (baseados MOFs) aos 
explosivos para proporções acima de $1 \%$ de massa utilizando a espectroscopia de fluorescência, e acima 3\% de massa para o uso do VSC6000/HS.

Trabalhos subsequentes ao de Ryan et al. foram desenvolvidos baseados nas implicações do acréscimo dos marcadores aos explosivos. De acordo com Heytmeijer et al., o acréscimos de marcadores está relacionado com um aumento na sensibilidade dos explosivos a fricção. Entretanto, essas patentes não trazem nenhum dado ou informação que mostre o comportamento descrito, nem mesmo os métodos de aferição da sensibilidade.

Não foi possível realizar as análises de sensibilidade necessários para os marcadores propostos para o presente, sendo necessários trabalhos futuros para a total avalição do material. Todavia, não foram observados indícios de alterações no comportamento dos explosivos quando misturados aos marcadores.

Outro ponto destacável são as metodologias de identificação dos marcadores. Utilizando metais de transição na composição dos marcadores, torna-os susceptíveis a contaminações dependentes do ambiente aonde foi coletado os resíduos. Elementos como Mg, $\mathrm{Fe}, \mathrm{Cu}, \mathrm{Ag}, \mathrm{Zn}$, entre outros, podem ser encontrados na maioria dos locais e, possivelmente, oferecem falsas informações para os investigadores. Já a metodologia aqui proposta permite identificar os marcadores baseados em MOFs utilizando outros ensaios analíticos, como MEV, EDS e VSC, que podem ser combinados para obter um resultado inequívoco além de um uma codificação, proporcionada pela alteração do ligante ou TR dopante na matriz e a composição nominal dos elementos nos espectros de EDS. Os marcadores também apresentam e sua composição apenas íons TR, ao invés de metais de transição. Isso significa que existe menos possibilidade de contaminação oriundo do ambiente e/ou ocupacional do que marcadores que dependem de metais de transição. 


\section{CONCLUSÕES}

Todos os marcadores luminescentes foram facilmente sintetizados e caracterizados, e os resultados obtidos são coerentes com o descrito na literatura. Foi possível adicionar os marcadores aos explosivos diretamente. Não houve nenhum indício de reação entre os marcadores e o explosivo. Isto ocorreu provavelmente devido à baixa sensibilidade de explosivos secundários como o ANFO, e é um indicativo de que o uso dos marcadores pode ser seguro. A etapa de detonação dos explosivos ocorreu como esperado. Ou seja, não houve falhas de detonação (mostrando a preservação do explosivo). Foram observadas marcas da onda de choque também como previsto. Apesar de não ter sido possível mensurar a energia liberada na detonação, aparentemente também não houve aumento na energia liberada pela detonação.

Após a detonação, ambos os marcadores baseados em MOFs foram identificados visualmente no local de explosão com a lâmpadas UV, em todas as concentrações testadas. A coleta dos marcadores A $\left(\left[\left(\mathrm{La}_{0.8} \mathrm{~Tb}_{0.2}\right)_{2}(\mathrm{DPA})_{3}\left(\mathrm{H}_{2} \mathrm{O}\right)_{3}\right]\right)$ e B ([(Lao.95Euo.3Tbo.2) $\left.\left.)_{2}(\mathrm{DPA})_{3}\left(\mathrm{H}_{2} \mathrm{O}\right)_{3}\right]\right)$ foi favorecida pela emissão dos compostos, que permitiu o uso prático e rápido de stubs contendo adesivos. O marcador cerâmico C ( $\left.\mathrm{ZnAl}_{1,95} \mathrm{~Tb}_{0,05} \mathrm{O}_{4}\right)$ não foi identificado visualmente em nenhuma das cargas testadas, independente das concentrações empregadas.

$\mathrm{Na}$ etapa de caracterização dos resíduos coletados, apenas os marcadores A e B foram identificados nas fotos tiradas pelo VSC, ratificando os resultados encontrados in loco. Também foi possível caracterizar os marcadores contidos nos resíduos de explosão por meio do microespectrômetro do equipamento VSC6000/HS no caso dos marcadores baseados em MOFs (A e B). O marcador $A$ ofereceu os melhores resultados em comparação com os espectros obtidos pelo espectrômetro de fluorescência. As análises do marcador $B$, apresentaram ausências de transições se comparados com os espectros do fluorímetro. Entretanto, foi possível identificar as demais transições facilmente indicando que o equipamento tem potencial para ser implementado já que está de acordo com a rotina pericial.

Entretanto todas as amostras de resíduos contendo marcadores, inclusive aquelas contendo o marcador $\mathrm{C}$, apresentaram resultados satisfatórios quando 
analisadas por EDS e espectroscopia de fluorescência. Considerando a relação sinal-ruído dos espectros de emissão, considerou-se como resultados satisfatórios aqueles obtidos com proporção de marcador igual ou maior que $3 \%$ em massa.

As proporções entre metais obtidas a partir de análises semiquatitativas de EDS mostraram que é possível diferenciar os marcadores não só pela cor da emissão e metais presentes, como também pela proporção entre eles. Foi possível identificar a proporção entre os metais com uma margem de 3,0\%, para mais ou para menos da concentração nominal. Dessa forma, podemos inferir que utilizando concentrações em marcadores acima da margem, podemos obter um método inequívoco de identificação e codificação dos marcadores, que pode ser otimizado em trabalhos futuros.

Desta forma, hoje é possível propor um sistema marcação com três níveis: cor de emissão, tipo de metal presente e proporção entre metais. Neste caso, seria possível por exemplo, utilizar a cor de emissão para indicar o tipo do explosivo ou sua destinação (comercial ou militar), os metais presentes para indicar o fabricante e a proporção entre os metais para indicar o ano de fabricação ou destinatário (comprador).

Apesar dos resultados promissores obtidos neste trabalho, para propor a utilização em larga escala dos marcadores é necessário realizar uma avaliação da sensibilidade e da estabilidade em longo prazo dos explosivos marcados - e assim estabelecer o grau de segurança de uso dos marcadores em explosivos. Estes testes não foram realizados devido à falta de acesso a instrumentação específica. 


\section{PERPERCTIVAS}

Tendo em vista os resultados apresentado neste trabalho, algumas perspectivas para continuação do trabalho estão descritas nos tópicos abaixo.

- Realizar testes de sensibilidade (aquecimento, fricção, impacto, faísca, etc.) nas cargas explosivas marcadas com LnMOFs para determinação da viabilidade da tecnologia;

- Melhorar os métodos de inserção dos marcadores nos explosivos, priorizando a redução do custo e segurança;

- Otimizar a concentração utilizada de marcadores luminescentes nos explosivos;

- Diversificar a quantidade de matrizes/ligantes utilizados como marcadores para a criação de um sistema de codificação e rotulação química de explosivos;

- Estudar a possibilidade de aplicação da tecnologia em larga escala;

- Regulamentar a marcação de explosivos no Brasil através de lei federal. 


\section{REFERÊNCIAS}

1. Stochero, T. Em um ano, roubo de explosivos no Brasil cresce $170 \%$, diz Exército. http://g1.globo.com/brasil/noticia/2011/04/em-um-ano-roubo-deexplosivos-no-brasil-cresce-170-diz-exercito.html (acessado 02 de dezembro).

2. DIPOL Roubo de explosivos em SP aumenta em 63\%, indica DIPOL. http://jovempan.uol.com.br/noticias/brasil/policia/roubo-de-explosivos-em-spaumenta-em-63-indica-dipol.html (acessado 04 de dezembro).

3. $\quad 5^{\circ}$ pesquisa nacional de ataques a Bancos, Vol. V. CONTRAF: 2013;.

4. Matias, O. Bandidos explodem caixas eletrônicos na região de Londrina http://www.odairmatias.com.br/blog/item/2115-alerta-bandidos-explodem-caixaseletr\%C3\%B4nicos-na-regi\%C3\%A3o-de-londrina.html (acessado 02 de dezembro).

5. LaFree, G.; Dugan, L.; Miller, E., Putting Terrorism in Context: Lessons from the Global Terrorism Database. Taylor \& Francis: 2014.

6. Global Terrorism Index: Measuring and understanding the impact of terrorism. Instute for Economics and Peace: 2014.

7. LaFree, G., The Global Terrorism Database: Accomplishments and Challenges. Terrorism Research Initiative: 2010.

8. Akhavan, J., Chemistry of Explosives, 3rd Edition. Royal Society of Chemistry: 2004.

9. Zukas, J. A.; Walters, W.; Walters, W. P., Explosive Effects and Applications. Springer New York: 2002.

10. Ledgard, J., The Preparatory Manual of Explosives. Jared Ledgard: 2007.

11. Urbanski, T., Chemistry and Technology of Explosives. Panstwowe Wydawnictwo Naujawe Pwn: 1967.

12. Persson, P. A.; Holmberg, R.; Lee, J., Rock Blasting and Explosives Engineering. Taylor \& Francis: 1993.

13. Richmond, K. Initiation Systems http://tracefireandsafety.com/VFRE99/Recognition/Initiation/initiation.htm (acessado 05 de dezembro).

14. Sickler, R. A., Explosive Principles: An Essential Guide to Understanding Explosives and Detonations. Paladin Press: 1992.

15. Thurman, J. T., Practical Bomb Scene Investigation, Second Edition. CRC Press: 2011.

16. Agrawal, J. P., High Energy Materials: Propellants, Explosives and Pyrotechnics. Wiley: 2010.

17. Suceska, M., Test Methods for Explosives. Springer New York: 1995.

18. Bruckman Jr, H. J.; Guillet, J. E., Theoretical calculations of hot-spot initiation in explosives. Canadian Journal of Chemistry 1968. 
19. Copp, J.; Napier, S.; Nash, T.; Powell, W.; Skelly, H.; Ubbelohde, A.; Woodward, P., The sensitiveness of explosives. Philosophical transactions of the royal society of london series a-mathematical and physical sciences: 1948.

20. Schubert, H.; Kuznetsov, A., Detection of Liquid Explosives and Flammable Agents in Connection with Terrorism. Springer: 2008.

21. Barkakati, N., Technology Assessment: Explosives Detection Technologies to Protect Passenger Rail. DIANE Publishing Company: 2010.

22. Bernier, E. T.; Island, U. o. R., Explosive Signatures: Pre \& Post Blast. University of Rhode Island: 2008.

23. Johns, C.; Shellie, R. A.; Potter, O. G.; O’Reilly, J. W.; Hutchinson, J. P.; Guijt, R. M.; Breadmore, M. C.; Hilder, E. F.; Dicinoski, G. W.; Haddad, P. R., Identification of homemade inorganic explosives by ion chromatographic analysis of post-blast residues. Journal of Chromatography A: 2008.

24. Marshall, M.; Oxley, J. C., Aspects of Explosives Detection. Elsevier Science: 2011.

25. Schubert, H.; Kuznetsov, A., Detection of Bulk Explosives Advanced Techniques Against Terrorism. Springer: 2004.

26. Peveler, W. J.; Binions, R.; Hailes, S. M. V.; Parkin, I. P., Detection of explosive markers using zeolite modified gas sensors. Journal of Materials Chemistry A: 2013.

27. Lawrence, A. H.; Neudorfl, P., Detection of ethylene glycol dinitrate vapors by ion mobility spectrometry using chloride reagent ions. Analytical Chemistry: 1988.

28. Marcação de Explosivos plásticos e de Explosivos laminados para fins de detecção. Em, Portaria 017 - Diretoria de fiscalizaçção de produtos controlaldos, Brasil, 2002.

29. Roscioli, K. M.; Davis, E.; Siems, W. F.; Mariano, A.; Su, W.; Guharay, S. K.; Hill, H. H., Modular Ion Mobility Spectrometer for Explosives Detection Using Corona lonization. Analytical Chemistry: 2011.

30. Eiceman, G. A.; Karpas, Z.; Hill, H. H., Ion Mobility Spectrometry, Third Edition. Taylor \& Francis: 2013.

31. Sun, Y., Field Detection Technologies for Explosives. ILM Publications: 2009.

32. Shaw, P. E.; Chen, S. S. Y.; Wang, X.; Burn, P. L.; Meredith, P., HighGeneration Dendrimers with Excimer-like Photoluminescence for the Detection of Explosives. The Journal of Physical Chemistry C: 2013.

33. Beveridge, A., Forensic Investigation of Explosions, Second Edition. Taylor \& Francis: 2011.

34. Yinon, J.; Zitrin, S., Modern Methods and Applications in Analysis of Explosives. Wiley: 1996.

35. Martinez, H. P.; Grant, C. D.; Reynolds, J. G.; Trogler, W. C., Silica anchored fluorescent organosilicon polymers for explosives separation and detection. Journal of Materials Chemistry: 2012. 
36. Ryan, F.; Miller, R., Phosphor combination and method, particularly adapted for use with explosives, for providing a distinctive information label. Google Patents: 1973.

37. Mozayani, A.; Noziglia, C., The Forensic Laboratory Handbook Procedures and Practice. Humana Press: 2010.

38. Yinon, J., Forensic and Environmental Detection of Explosives. Wiley: 1999.

39. Assessment, U. S. C. O. o. T.; Affairs, U. S. C. S. C. o. G., Taggants in explosives. Congress of the United States, Office of Technology Assessment : for sale by the Supt. of Docs., U.S. Govt. Print. Off.: 1980.

40. de Bettencourt-Dias, A., Luminescence of Lanthanide lons in Coordination Compounds and Nanomaterials. Wiley: 2014.

41. Solé, J.; Bausa, L.; Jaque, D., An Introduction to the Optical Spectroscopy of Inorganic Solids. Wiley: 2005.

42. Kitai, A., Luminescent Materials and Applications. Wiley: 2008.

43. Câmara, S. S. Propriedades luminescentes upconversion do YVO4:Er, Yb aplicads ao estudo forense de resíduos de tiro. Dissertação de Mestrado, Universidade de Brasília: 2014.

44. Guilbault, G. G., Practical Fluorescence, Second Edition. Taylor \& Francis: 1990.

45. Szabadvary, F., Karl A. Gschneidner, Jr.; LeRoy, E., Eds. Chapter 73 The history of the discovery and separation of the rare earths. Em, Handbook on the Physics and Chemistry of Rare Earths, Vol. 11. Elsevier: 1988;

46. Cotton, S., Introduction to the Lanthanides. In Lanthanide and Actinide Chemistry, John Wiley \& Sons, Ltd: 2006.

47. Lawrance, G. A., Introduction to Coordination Chemistry. Wiley: 2013.

48. Cotton, S., Lanthanide and Actinide Chemistry. Wiley: 2007.

49. Barrett, S. D., Dhesi, S. S., Introduction to the Rare Earths. In The Structure of Rare-Earth Metal Surfaces. World Scientific: 2001.

50. Huang, C. H., Rare Earth Coordination Chemistry: Fundamentals and Applications. Wiley: 2011.

51. Hatanaka, M.; Yabushita, S., Theoretical Study on the $f-f$ Transition Intensities of Lanthanide Trihalide Systems. The Journal of Physical Chemistry A: 2009.

52. Blasse, G.; Grabmaier, B. C., Luminescent Materials. Springer Berlin Heidelberg: 1994.

53. Melo, A. J. G. d. Desenvolvimento de marcadores Luminescentes para detecção de resíduos de tiros. Dissertação de Mestrado, Universidade Federal de Pernambuco, 2009.

54. Lucena, M. A. Desenvolvimento de marcadoes Nanoestruturados luminescentes para resíduos de tiro. Universidade Federal de Pernambuco, 2010.

55. Hänninen, P.; Härmä, H., Lanthanide Luminescence: Photophysical, Analytical and Biological Aspects. Springer: 2011. 
56. Barbosa Neto, N. M.; Oliveira, S. L.; Guedes, I.; Dinelli, L. R.; Misoguti, L.; Mendonça, C. R.; Batista, A. A.; Zílio, S. C., Reverse saturable absorption in 5, 10,15,20-Tetra(4-pyridyl)-21H,23H-porphyrin with ruthenium outlying complexes. Journal of the Brazilian Chemical Society: 2006.

57. Nathália Vieira Velloso, L. A. M., João Paulo Figueiró Longo, Jaqueline Rodrigues da Silva, Daniela Cervelle Zancanela, Antônio Cláudio Tedesco and Ricardo Bentes de Azevedo, Aluminum-Phthalocyanine Chloride-Based Photodynamic Therapy Inhibits PI3K/Akt/Mtor pathway in Oral Squamous Cell Carcinoma Cells In VitroAluminum-Phthalocyanine Chloride-Based Photodynamic Therapy Inhibits PI3K/Akt/Mtor pathway in Oral Squamous Cell Carcinoma Cells In Vitro. OMICS Publishing Group: 2012.

58. Shionoya, S.; Yen, W. M.; Yamamoto, H., Phosphor Handbook. Taylor \& Francis: 2006.

59. Carter, C. B.; Norton, G., Ceramic Materials: Science and Engineering. Springer: 2007.

60. Munz, D.; Fett, T., Ceramics: Mechanical Properties, Failure Behaviour, Materials Selection. Springer: 1999.

61. Dang, S.; Zhang, J.-H.; Sun, Z.-M.; Zhang, H., Luminescent lanthanide metal-organic frameworks with a large SHG response. Chemical Communications: 2012.

62. Omar M. Yaghi, H. L., Charles Davis, David Richardson, and Thomas L. Groy, Synthetic Strategies, Structure Patterns, and Emerging Properties in the Chemistry of Modular Porous Solids. Accounts of Chemical Research: 1998.

63. Zhou, H.-C.; Long, J. R.; Yaghi, O. M., Introduction to Metal-Organic Frameworks. Chemical Reviews: 2012.

64. Robin, A. Y.; Fromm, K. M., Coordination polymer networks with $\mathrm{O}$ - and $\mathrm{N}$ donors: What they are, why and how they are made. Coordination Chemistry Reviews 2006.

65. Li, J.-R.; Kuppler, R. J.; Zhou, H.-C., Selective gas adsorption and separation in metal-organic frameworks. Chemical Society Reviews 2009.

66. Yang, R. T., Introductory Remarks. In Adsorbents: Fundamentals and Applications, John Wiley \& Sons, Inc.: 2003.

67. Mourão, H. A. J. L.; Mendonça, V. R. d.; Malagutti, A. R.; Ribeiro, C., Nanoestruturas em fotocatálise: uma revisão sobre estratégias de síntese de fotocatalisadores em escala nanométrica. Química Nova 2009.

68. Tanabe, K. K.; Wang, Z.; Cohen, S. M., Systematic Functionalization of a Metal-Organic Framework via a Postsynthetic Modification Approach. Journal of the American Chemical Society 2008.

69. Allendorf, M. D.; Bauer, C. A.; Bhakta, R. K.; Houk, R. J. T., Luminescent metal-organic frameworks. Chemical Society Reviews: 2009.

70. Tochetto, D., Resumo do I seminário de Balística Forense Avançada: 2004. 
71. Weber, I. T. v.; de Melo, A. J. G.; Lucena, M. A. d. M.; Rodrigues, M. O.; Alves Junior, S., High Photoluminescent Metal-Organic Frameworks as Optical Markers for the Identification of Gunshot Residues. Analytical Chemistry: 2011.

72. Lucena, M. A. M.; de Sa, G. F.; Rodrigues, M. O.; Alves, S.; Talhavini, M.; Weber, I. T., ZnAl2O4-based luminescent marker for gunshot residue identification and ammunition traceability. Analytical Methods: 2013.

73. Lan, A.; Li, K.; Wu, H.; Olson, D. H.; Emge, T. J.; Ki, W.; Hong, M.; Li, J., A Luminescent Microporous Metal-Organic Framework for the Fast and Reversible Detection of High Explosives. Angewandte Chemie International Edition: 2009.

74. Gole, B.; Bar, A. K.; Mukherjee, P. S., Modification of Extended Open Frameworks with Fluorescent Tags for Sensing Explosives: Competition between Size Selectivity and Electron Deficiency. Chemistry - A European Journal: 2014.

75. Hutchinson, J. P.; Johns, C.; Breadmore, M. C.; Hilder, E. F.; Guijt, R. M.; Lennard, C.; Dicinoski, G.; Haddad, P. R., Identification of inorganic ions in postblast explosive residues using portable CE instrumentation and capacitively coupled contactless conductivity detection. Electrophoresis: 2008.

76. Heytmeijer, H. R.; Panaccione, E. S., Method for applying wax or plastic coatings to granular materials. Google Patents: 1976.

77. Krystyniak, C. W.; Borom, M. P., Magnetic tag process. Google Patents: 1980.

78. Rudnev, V.; Loveless, D.; Cook, R. L.; Black, M., Handbook of Induction Heating. Taylor \& Francis: 2002.

79. Barreto, A. S.; da Silva, R. L.; Dos Santos Silva, S. C.; Rodrigues, M. O.; de Simone, C. A.; de Sa, G. F.; Junior, S. A.; Navickiene, S.; de Mesquita, M. E., Potential of a metal-organic framework as a new material for solid-phase extraction of pesticides from lettuce (Lactuca sativa), with analysis by gas chromatography-mass spectrometry. Journal of separation science 2010.

80. Rover, K. Produção de nanofibras luminescentes e sistemas emissores de branco baseados em Lanthanide Metal Organic Framework. Dissertação de Mestrado, Universidade de Brasília: 2013.

81. Wanderley, K. A. Espectroscopia de Fotoluminescência e Reações de Acoplamento Usando Redes de Coordenação. Tese de Doutorado, Universidade Federal de Pernambuco: 2013.

82. Han, S.; Deng, R.; Xie, X.; Liu, X., Enhancing Luminescence in LanthanideDoped Upconversion Nanoparticles. Angewandte Chemie International Edition 2014.

83. Barros, B. S. Sintese por reação de combustão, caracterização e propriedades luminescentes do Aluminato de Zinco dopado com íons terras raras Eu3+ eTb3+. Dissertação de Mestrado, UFCG: 2005.

84. Yersin, H.; Bray, K. L., Transition Metal and Rare Earth Compounds III: Excited States, Transitions, Interactions. Springer: 2004.

85. Ryan, F. M.; Handke, P. C., Tagging particles which are easily detected by luminescent response, or magnetic pickup, or both. Google Patents: 1978. 
86. The Foster \& Freeman VSC6000 Video Spectral Comparator. http://www.greenefoundation.ca/expertizing_and_fees.html (acessado 24 de novembro de 2014).

87. Aambø, M., Use of the "Video Spectral Comparator 6000" as a nondestructive method for pigment identification : - an experiment. Institutionen för kulturvård, Göteborgs universitet: Göteborg: 2011. 


\section{ANEXOS}

\subsection{EQUIPAMENTOS UTILIZADOS NA CARACTERIZAÇÃO DOS MARCADORES LUMINESCENTES E DOS RESÍDUOS DE EXPLOSÃO}

10.1.1. VSC

O equipamento utilizado para as análises foi o VSC6000/HS (Video Spectral Comparator), produzido pela Foster\&Freeman ${ }^{\circledR}$, disposto na figura abaixo. ${ }^{86} \mathrm{O}$ VSC é um equipamento empregado principalmente na área de documentoscopia e possui uma série de ferramentas acopladas com o intuito de facilitar a identificação de documentos falsificados, alterados ou irregulares. Como principais ferramentas acopladas, o VSC possui: ${ }^{87}$

- Uma câmera científica digital de alta resolução, com zoom de aproximação com alcance entre 1.5X e 170X;

- Forte iluminação visível direta (vertical) e indireta (horizontal);

- Iluminação UV nas regiões de ondas longas, medias e curtas;

- Microespectrômetro com resolução de $9 \mathrm{~nm}$, com alcance de $400 \mathrm{~nm}$ a $1000 \mathrm{~nm}$;

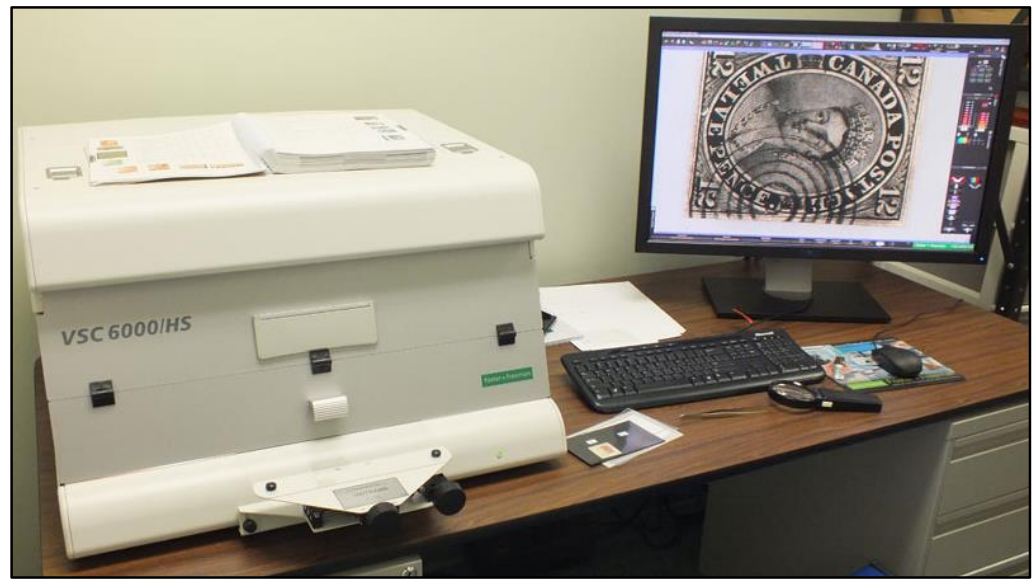

Figura 47. Exemplo de video spectral comparator (VSC6000/HS da Foster\&Freeman ${ }^{\circledR}$ );

Para as análises de VSC, foram utilizadas as lâmpadas UV de 254 nm, tanto para a visualização da luminescência quanto para obtenção dos espectros de fotoluminescência obtidos pelas análises com o microespectrômetro. 


\subsubsection{Infravermelho}

Os amostras foram analisadas utilizando um espectrômetro de infravermelho com transformada de Fourier (FTIR) de modelo VARIAN-640 IR, presente na central analítica do $\mathrm{IQ} / \mathrm{UnB}$, utilizando pastilha de $\mathrm{KBr}$. A região de alcance do equipamento é de $400 \mathrm{~cm}^{-1}$ até $4000 \mathrm{~cm}^{-1}$, com resolução de espectral de $4 \mathrm{~cm}^{-1}$.

\subsubsection{DRX de pó}

As análises de difração de raios $X$ de pó foram realizadas na Universidade de Brasília, sede Ceilândia, utilizado um difratômetro Miniflex600 de marca Rigaku®. $\mathrm{O}$ equipamento foi operado com tubo de voltagem em $40 \mathrm{kV}$, corrente de $15 \mathrm{~mA}$ e equipado com uma fonte de radiação Cu-Ka $(\lambda=1,540598 \AA \check{A})$. As amostras utilizaram como parâmetros intervalo de $2 \theta$ entre $10^{\circ}$ e $80^{\circ}$, incremento de $0,02^{\circ} \mathrm{e}$ velocidade de $5 \% / \mathrm{min}$.

\subsubsection{MEV/EDS}

O equipamento utilizado para as análises foi um microscópio eletrônico de varredura (MEV) modelo FEI Quanta 200 3D, operando em alto vácuo e $20 \mathrm{keV}$. Este equipamento foi acoplado a um espectrômetro de energia dispersiva (EDS) da marca INCA X-Sight, pertencentes ao Instituto de Criminalística Nacional (INC) com sede na Polícia Federal do DF, no intuito de analisar morfologicamente e quimicamente os marcadores luminescentes e resíduos de explosão.

\subsubsection{Espectros de Fluorescência}

Os espectros de fotoluminescência foram realizados a partir de um espectrofluorímetro de modelo K2 (Multifrequency Cross-Correlation Phase and Modulation Fluorometer), pertencente a marca ISS, com excitação a partir de uma lâmpada de Xenônio de 300W. 